\title{
Art and the Inaka: \\ Yamamoto Kanae and New Conceptions of Modernity in Rural Japan
}

\author{
by \\ Margaret Bryan
}

\begin{abstract}
A thesis submitted to the Faculty of Graduate and Postdoctoral Affairs in partial fulfillment of requirements

for the degree of

Master of Arts

in
\end{abstract}

Art History

Carleton University

Ottawa, Ontario

(C) 2020

Margaret Bryan 


\begin{abstract}
Yamamoto Kanae (山本鼎, 1882-1946) is credited as the founder of sōsaku hanga (The Creative Prints Movement) in Japan as well as the developer of nomin bijutsu (The Farmers’ Art Movement) and jidō jiȳūga no shōrei (The Children's Free Drawing Movement), all of which have retained lasting social and cultural legacies up to the present day. However, while some scholarship exists on his work with these individual projects, there is a paucity of research connecting these seemingly disparate, yet deeply thematically entangled, movements. This thesis divides Yamamoto's career into three periods - his time in Paris, Moscow, and Ueda-looking at how his experience in Moscow particularly informed his complex ideological approach to art. The discussion of his engagement with Russian folk arts and thinkers acts as a stepping stone to construct a broader understanding of moments of transcultural exchange between Japan and Russia at the turn of the twentieth century. By examining Yamamoto's life and work within the context of his contemporaries and concurrent political and cultural events, this thesis seeks not only to provide a comprehensive English-language monograph of the artist's activities, but also to use this analysis as a case study to discuss broader issues concerning local-translocal relationships in rural art and negotiating urban-rural binary frameworks that persist in contemporary arts discourse. The examination of these kinds of bifurcated structures through the lens of Yamamoto Kanae explores means of dismantling them as the field continues to work towards more nuanced ways of framing global art history.
\end{abstract}




\section{Acknowledgements}

First and foremost, the completion of this thesis would not have been possible without the support of my advisor, Ming Tiampo, who provided excellent feedback and exercised enormous patience with some of my more fantastical ramblings throughout the course of this project. I am also immensely grateful to the members of my defense committee-Mitchell Frank, Birgit Hopfener, and Monica Patterson-for taking the time to review my work even in the midst of a global pandemic, and for the academic support that they have provided throughout my time at Carleton.

In addition, I would like to thank Reiko Tomii for putting me in touch with Hideki Tachikawa at the Tobunken in Tokyo, as well as Mr. Tachikawa for welcoming me there and providing invaluable assistance in finding material last November. I would also like to acknowledge the generous accommodation of the employees at the Ueda City Museum of Art (particularly the security guard who lent me a pencil so that I could take notes!). I would also like to give a huge shout out to some of the loveliest friends in the worldMichelle Daher, Megan Dung, Aoi Hirota, Kacey Whittaker, and Koki Agata—for providing me with food, lodging, and emotional support for the duration of my research trip to Japan (Archival research is far more productive when it is bookended by laughter, okonomiyaki, and the occasional language clarification). This project would also not have been possible without the daily encouragement and wisdom of my roommate, Kelsey Perreault, a handy and supportive source of experience who had already been through the Masters thesis process.

Finally, I want to thank my sister, Anna, and my parents for their unwavering patience with my flair for melodrama, as well as their well-feigned expression of interest 
in intersections between Japanese and Russian folk arts. I could not have done it without you. 


\section{Table of Contents}

Abstract $\quad$ ii

Acknowledgements $\quad$ iii

Table of Contents $\quad$ V

List of Illustrations

Introduction $\quad 1$

Chapter One: Sōsaku hanga and a Sojourn in Paris 12

Chapter Two: The Voyage Home: Finding Purpose in Moscow 31

Chapter Three: Folk Art and New Modernities in Yamamoto's Inaka 60

$\begin{array}{ll}\text { Conclusion } & 82\end{array}$

$\begin{array}{ll}\text { Appendix 1: Illustrations } & 87\end{array}$

$\begin{array}{ll}\text { Bibliography } & 101\end{array}$ 


\section{List of Illustrations}

Fig. 1 Yamamoto Kanae, Gyofu (Fisherman), 1904, woodcut

Fig. 2 Yamamoto, Kaya (The Mosquito Net), 1906, oil on canvas

Fig. 3 Yamamoto, Hagaki (Postcard), 1917, woodcut

Fig. 4 Yamamoto, Dekki no ichigû (A Corner of the Deck), 1912, woodcut

Fig. 5 Yamamoto, Shina Fujin (Chinese Woman), 1917, woodcut

Fig. 6 Yamamoto, Burutaanyo Irie (Bay in Breton), 1913, woodcut

Fig. 7 Yamamoto, Buratonnu no suiyoku (Bathing in Brittany), 1913, woodcut

Fig. 8 Yamamoto, Burutonnu (Breton Woman), 1920, woodcut

Fig. 8a Yamamoto, Burutonnu (Breton Woman-Study), 1913, watercolor on paper 95

Fig. 8b Yamamoto, Burutonnu (Breton Woman-Study), 1913, watercolor on paper 96

Fig. 9 Yamamoto, Mosukuwo (Moscow), 1916, woodcut

Fig. 10 Yokokawa Yoshimasa, Akebi, relief carving, date unknown

Fig. 11 Artist unknown, Hōzuki, n.d., wood sculpture 


\section{Introduction}

This past fall, while traveling to Japan to conduct research for this project in Tokyo and Ueda City in Nagano, I stopped by the village where I used to teach English to have dinner with my former coworkers, one of whom lived in Tokyo for many years, and has for decades harbored a strong interest in the Japanese and international art scene. In passing, I asked them whether or not they were aware of the sōsaku hanga artist Yamamoto Kanae. Sōsaku hanga, or the Creative Prints Movement, was first pioneered by Yamamoto in 1904, and continued to evolve and garner recognition on a global scale until well after the Second World War. Aside from his international success, Yamamoto had returned to Ueda in the second half of his career to work on more local projects, only a few short hours from the foot of the Minami Alps, where I was dining. To this day, Yamamoto's work is the defining feature of the Ueda City Museum of Art's collection, and he is regarded as one of the municipality's most distinguished former residents.

To my surprise, while both of my coworkers were well aware of sōsaku hanga, neither of them strongly associated Yamamoto with this movement, and told me that, within Japan, Yamamoto's greatest legacy is that of an educator and as the developer of two movements: the Children's Free Drawing Movement (jidō jiȳūga no shōrei) and the Farmer's Art Movement (nōmin bijutsu).

This discrepancy is also reflected in existing scholarship on the artist. Englishlanguage material focuses primarily on his early career, and refers to the time he spent as a printmaker and oil painter in Europe from 1912 - 1917 as the "height of his career." In contrast, within Japan, this apex is regarded to have occurred several years later, when he had returned to Japan and settled down in Ueda to spearhead local artistic projects and 
curricula that would have widespread legacies across Japan that pervade to the present day. ${ }^{1}$

The different ways in which so-called 'Western' and Japanese scholars frame Yamamoto's career, and what aspects of it they choose to highlight, are instructive as the field continues to work towards "decentering" traditional center-peripheral constructs of art history, while simultaneously acknowledging Japan's own role as an imperial power during this time period. ${ }^{2}$ While traditional canonical approaches have been reevaluated in recent years to reflect these efforts, as Reiko Tomii notes, "Eurocentrism is far from a thing of the past."3 Tomii, who studies the art of 1960s Japan, acknowledges that the field has identified decentering as an objective, and contends that the next step is to implement

\footnotetext{
${ }^{1}$ Stephanie Su, "Classicizing the Creative Print: Yamamoto Kanae in France," Awash in Color: French and Japanese Prints, eds. Chelsea Foxwell et al. (Chicago: University of Chicago Press, 2012), 161.

In Japan, study of Yamamoto's life and work is largely focused on his career as an educator and pioneer of the Farmers' art movement, as evidenced by numerous texts and ongoing exhibitions at the Ueda City Museum of Art, the most recent of which includes "Farmer's Art and the Children's Free Drawing Movement: 100 Years," primarily revolving around Yamamoto's life and legacy.

${ }^{2}$ Partha Mitter and Ming Tiampo both use the term "decentering" to describe an effort towards a new framing of art history that dissolves the geographical center-periphery model characteristic of the Western canonical approach. Mitter writes, “...The Western avant-garde failed to take into account either the progressive heterogenization of art or the richness and creativity of art practices in the peripheries. Its limitations stem from the monolithic, linear narrative of an art history that does not allow for difference, in part a reflection of the unequal power relations between center and periphery. My argument contributes to the recent debates on the need to shift the center of gravity from the originary discourse to a more heterogeneous definition of global modernism, incorporating the changes that have taken place in the twentieth century. It responds to the challenge of transnational art, calling into question the 'purity' of the modernist canon and the consequent imputation of the derivative character of the periphery."

Partha Mitter, "Decentering Modernism: Art History and Avant-Garde Art from the Periphery," The Art Bulletin 90, no. 8 (December 2008): 544. Ming Tiampo, Gutai: Decentering Modernism (Chicago: University of Chicago Press, 2011).

${ }^{3}$ Reiko Tomii, Radicalism in the Wilderness: International Contemporaneity and $1960 \mathrm{~s}$ Art in Japan (Cambridge, MA: MIT Press, 2016), 9.
} 
it into our discourse. She writes, "We have begun to deconstruct and decenter art history but barely know how to regroup and narrate in a decentered manner," and uses her own work with the concept "international contemporaneity" in Japanese art of the 1960s as a means to "devise an expansive historical framework to construct a multicentered world art history.",

Japanese art produced during the early decades of the twentieth century is equally instructive to these efforts. Sōsaku hanga is a richly complex movement that spanned the course of half a century during a pivotal time in Japan's development as an international power, both culturally and politically. However, like other Japanese movements of the epoch, it has also been framed in Western discourse as a kind of "Western-infused" offshoot of ukiyo-e that did not fully "rise" until the mid-1940s. ${ }^{5}$ In reality, it was a far more nuanced product of a decades-long internal struggle between individual and national cultural values waged through the vehicle of art, a battle already evident in more prominent movements like $y \overline{o g} a$ and nihonga. ${ }^{6}$ The political elements that permeated the ideological basis for sōsaku hanga fluctuated depending on the aims of the individual

${ }^{4}$ Tomii, Radicalism in the Wilderness, 9-10.

${ }^{5}$ Alison Miller, "Exhibition Essay: Sōsaku Hanga: Twentieth-Century Japanese Creative Prints," The Bowdoin College Museum of Art, https://courses.bowdoin.edu/sosakuhanga-2016/exhibition-essay/ (accessed January 20, 2020). Su, "Classicizing the Creative Print," 170-173.

Alicia Volk, Made in Japan: The Postwar Creative Print Movement (Seattle: University of Washington Press, 2005).

${ }^{6} Y \bar{g} g a$ (directly translated as "Western painting") and nihonga ("Japanese painting") were two competing movements that arose during the Meiji period and served to distinguish artists influenced by European painting from those seeking to perpetuate "indigenous" Japanese sensibilities. In reality, both schools drew upon a transnational amalgamation of influences, and the relationship between the two movements was not as simple as a distillation of East and West. In the end, the primary difference boiled down to medium, yōga painters worked primarily in oil on canvas, while nihonga painters used water-soluble pigments. Bert Winther-Tamaki, Maximum Embodiment: Yōga, the Western Painting of Japan, 1912 - 1955 (Honolulu: University of Hawaii Press, 2012), 79. 
artists. This flexible structure permitted the genre to change considerably over the course of the ensuing decades, and even contemporaries interpreted the tenets of sosaku hanga in very different ways, as exemplary in the work and ideology of Yamamoto and his arguably more famous counterpart, Onchi Koshiro. ${ }^{7}$

Yamamoto's role in the development of sōsaku hanga, and his later role as pioneer of both the Children's Free Drawing Movement and the Farmers' Art Movement, while occurring at different points in his career, are far from incongruous with one another. The latter two initiatives represented a further refined development of his tendency to focus on creativity and personal expression within art, simply applying and adapting these ideas to an institutional context. While there is a bastion of rich material to explore in just this small window in the rich and enduring life of sōsaku hanga, this investigation focuses more heavily on the second half of Yamamoto's career. This decision is simultaneously due to 1) an effort to fill a significant gap in the literature in English examining the artist's work as an educator and cultural activist; 2) the observed potential to delve more deeply into the sociopolitical undercurrents that propelled his transformative experience with socialist thought in Russia; and 3) perhaps most crucially, the necessity of further examining the significant impact of these movements in contemporary Japanese art and its institutions today, particularly in the context of negotiating the false binary of the so-called 'global' and the 'local' in rural art.

The latter theme has, from the beginning, been the defining impetus for this project, which has been percolating and evolving considerably over the course of the past year and a half. The decision to focus specifically on Yamamoto came while I was

\footnotetext{
7 Chiaki Ajioka, "Introduction: Hanga: Japanese Creative Prints," in Hanga: Creative
} Japanese Prints, ed. Chiaki Ajioka (Sydney: Art Gallery NSW, 2000), 9. 
conducting research this past summer on Asian artists who came to Paris to study and practice art in the mid-twentieth century. As I was working on this project, it occurred to me that the bulk of current discourse surrounding terms like 'global' and 'transcultural' focus on urban spaces as hubs for creative development and artistic collaboration. Conversely, rural spaces have historically been characterized as quieter destinations for artists to retreat for solitary contemplation, often carrying with them connotations of the simplistic, or even primitive.

I became interested in looking at artists who traveled to the city and did not find the creative fulfillment they were searching for there, but still yearned for a creative social network and a push for artistic innovation. For this, Yamamoto was a perfect case study. Having traveled to Paris in his early career, in opposition to the prevailing romanticization of the city as a creative nexus, it seemed that he quickly became disenchanted by the community he found there. As a result, after several years he made his way back to Japan with a more clearly articulated vision of what he wanted the - or more specifically his—art world to look like. Upon his move to Ueda, his own artistic production halted to a near standstill for nearly twenty years to make way for his efforts to enact change in Japanese art education and create a prominent rural arts scene. Despite his professed focus on the interests of the individual, however, he remained in many respects shackled to a pervasive narrative of Japanese imperialist national identity, traveling to Taiwan and Korea and enforcing a similarly conflicting narrative on the arts education system there as well. In this vein, my thesis uses the case study of Yamamoto as a springboard to assess more broadly the ways in which individual 'local' art spheres 
can act simultaneously as liberated, yet also peculiarly contrived, microcosms of global modernity. $^{8}$

\section{A Brief Review of the Literature}

While a fair number of Japanese-language retrospectives of Yamamoto's work exist, the bulk of these publications were produced by either the Ueda City Museum of Art or the recently dissolved Kanae Yamamoto Memorial Museum, also in Ueda. This select sampling suggests a limited breadth of perspectives on the artist within the field of art history; in fact, the majority of texts that mention Yamamoto reference him in relation to the Free Drawing Movement that he pioneered in the 1920s, whose legacy continues to play a significant part in Japanese art education today. As such, the literature that does discuss Yamamoto's life as an artist seems to be largely biographical and logistical rather than critical.

The paucity of critical research on Yamamoto in languages other than Japanese is even more glaring, with the majority of literature on the artist taking the form of a single chapter or small excerpt in a larger text on modern Japanese prints, or occasionally sōsaku hanga specifically, that provides a general overview of his life and work. While

\footnotetext{
${ }^{8}$ Although she is focusing on a slightly different time period than I am here, Reiko Tomii explores similar aspects of liberation in Radicalism and the Wilderness, not only working to link facets of the local and the global in the context of "international contemporaneity," but also arguing that the displacement of many avant-garde movements of the 1960s from the city centre allowed artists to develop independent oeuvres located "outside the seat of power." She writes: "Their choice to be in the wilderness, as much as their innovative practices, positions them among the most radical examples of 1960s art in Japan. Even though Japan is a small country, its condensed yet dispersed urban populations and geographical complexities give it many distinct locales. In this regard, it is imperative to counterbalance the frequent metropolitan and cosmopolitan focus in the study of postwar and contemporary practices of Japan." Tomii, "Prologue," Radicalism in the Wilderness, 8-10.
} 
there exists some literature that addresses his work as an artist or his role in the Free Drawing movement independently, it is rare to come across a text that engages critically with both of these topics and attempts to delineate their relationship with one another. Yamamoto's philosophy on art education and community engagement as an individual pursuit was deeply entangled with his own artistic processes; as such, similarly to the theoretical frameworks discussed above, it would be beneficial for future research to draw connections between these two previously compartmentalized topics.

Yamamoto is mentioned in passing in a number of texts on broader artistic and political movements in Japan, credited for his indirect impact on mingei by Yuko Kikuchi, as well as his lasting legacy on Japanese education by various scholars. ${ }^{9}$ However, there appears to be little to no scholarship that focuses chiefly on his political and philosophical ideologies, and how these manners in which he conceived the world informed the development of his subsequent artistic movements, as well as his own oeuvre.

These issues lie at the heart of my own research, and the efforts to uncover them thus require a bit of creativity. Most of Yamamoto's correspondence has been previously compiled in a collection of his letters put out by the Yamamoto Kanae Memorial Museum, Yamamoto Kanae no tegami, which has allowed me to draw out some more

\footnotetext{
${ }^{9}$ Yamamoto's legacy is often cited in histories of Japanese art education, including in the work of Takuya Kaneda, Kayoko Komatsu, and Yoko Yamasaki.

Takuya Kaneda, "The Concept of Freedom in Art Education in Japan," The Journal of Aesthetic Education 37, no. 4 (Winter 2003): 12-19.

Kayoko Komatsu, "Genealogy of Self-Expression: A Reappraisal of the History of Art Education in England and Japan," Paedagogica Historica, vol. 53, no. 3 (2017): 214-227. Yoko Yamasaki, "New Education and Taisho Democracy 1900 to 1930s," in The History of Education in Japan (1600 - 2000), ed. Masashi Tsujimoto and Yoko Yamasaki (London: Routledge, 2017), 61-85.
} 
details about his life and views through his correspondence with his colleagues and parents (primarily his parents). ${ }^{10}$

Yamamoto drew a variety of inspiration from both Japanese and European thinkers, the latter particularly in regards to education. Leo Tolstoy's notebooks outlining his own theories on education have been particularly helpful in this regard, as has literature on Marx's philosophy on education and Noam Chomsky's compilation of essays and interviews, On Anarchism, to situate both Tolstoy and Yamamoto's thought processes within their ideological contexts. ${ }^{11}$ In addition, as there is more critical literature that exists on Japanese anarcho-utopianism and anarcho-syndicalism within scholarship on Japan's literary humanists than the visual arts, I have turned to several of these sources for further context, in particular Miyazawa Kenji. ${ }^{12}$ Yamamoto's friendships and professional dealings with several participants of these movements, in particular Katagami Noboru, connect him tangentially, if not directly, with these philosophies, and have helped to paint a more comprehensive picture of the socio-cultural landscape in agrarian communities in Japan at the time. ${ }^{13}$

My final chapter examines Yamamoto's legacy on rural art and Japanese education and bridges that with contemporary art movements. There, I have considered

${ }^{10}$ Kanae Yamamoto and Shuzo Yamagoshi, Yamamoto no tegami, ed. Yamagoshi Shuzo (Ueda: Yamamoto Kanae Memorial Museum of Art, 1971).

${ }^{11}$ Leo Tolstoy, On Education, trans. Leo Weiner (Chicago: University of Chicago Press, 1967).

Robin Small, Marx and Education (Hampshire, UK: Ashgate, 2005).

Noam Chomsky and Peter Jay, "The Relevance of Anarcho-Syndicalism," in Chomsky on Anarchism, ed. Barry Pateman (Edinburgh, Oakland and West Virginia: AK Press, 2005). ${ }^{12}$ Hoyt Long, On Uneven Ground: Miyazawa Kenji and the Making of Place in Modern Japan (Stanford: Stanford University Press, 2011).

${ }^{13}$ Margaret Mehl, "N.F.S. Grundtvig, Niels Bukh and Other 'Japanese' Heroes: The Educators Obara Kuniyoshi and Matsumae Shigeyoshi and Their Lessons from the Past of a Foreign Country," European Journal of East Asian Studies 6, no. 2 (Leiden: Brill, 2007): 165 . 
existing literature on arts education in Japan and beyond, including work by Takuya Kaneda, Kayoko Komatsu, and Yoko Yamasaki. A holistic understanding of his legacy has been supplemented by aforementioned recent exhibition catalogues and other materials produced by the art museums in Ueda City. In my subsequent case studies of many contemporary rural arts movements and institutions within Japan, substantial research exists regarding both local contemporary folk arts and large international projects like the Echigo Tsumari Triennial/Art Field and Naoshima, also known as "Art Island." These studies are widely varied and interdisciplinary, and include contributions to the fields of anthropology, geography, and sociology, as well as art history. Sociological explorations that examine how the local communities are affected by and work within these institutions have been formative to my understanding of these localtranslocal rapports, and I have found the critical analysis of scholars like Thekla Boven, Eike Grossman, and Ian Rapley to be particularly integral to my background research. ${ }^{14}$

\section{Chapter Breakdown}

This thesis is divided into three chapters. The first chapter provides an overview of Yamamoto's early life and the development of sōsaku hanga in 1904. It contextualizes Yamamoto's role as the first pioneer of the movement within the broader narrative of hanga, and provides a few possible explanations for why he had largely separated himself from the movement by the 1920s. This chapter also details Yamamoto's artistic

\footnotetext{
${ }^{14}$ Thekla Boven, “Assessment of Echigo-Tsumari Art Triennial's Repurposing of Schools: For a Locally Designed Culture-Led Revitalization of Assets in Declining Rural Areas," Journal of Architecture Planning AIJ 81, no. 730 (December 2016): 2693-2700. Eike Grossman, Kurokawa Nō: Shaping the Image and Perception of Japan's Folk Traditions, Performing Arts and Rural Tourism (Leiden: Brill, 2013). Ian Rapley, "When Global and Local Culture Meet: Esperanto in 1920s Rural Japan," Language Problems and Language Planning 37, no. 2 (2013): 179-196.
} 
educational background and the time he spent in Europe, primarily in Paris, from 1912 to 1917, and analyzes how his oeuvre and approach to art developed and changed during those years as a result of his travels.

The second chapter begins with Yamamoto's return trip to Japan from Paris as the latter was on the cusp of the First World War. It traces his activities in and around Moscow during the summer of 1916, on the eve of the Russian Revolution, and unpacks how his experiences there and exposure to the late Leo Tolstoy's education and folk arts movement were so formative to his subsequent approaches to art, education, and politics following his return to Japan. In this chapter, I also deconstruct Tolstoy’s politics and views on education, particularly in regards to art education, and challenge historical claims that Yamamoto's political ideologies were informed primarily by Socialist thought, unpacking the complicated relationship between the artist's more anarchist tendencies and his role in the Japanese empire. I continue to examine how Yamamoto's own oeuvre was evolving throughout this time of flux, and how it served as a mirror of his perceptions of the world around him as detailed in his writing during this time.

Towards the conclusion of Chapter Two, I look at Yamamoto's correspondence regarding his own budding Farmers' Art Movement and Free Drawing Movement and how they came into development, arguing that, rather than being two distinct phenomena, they actually are simply two components of the same ideological initiative.

The third and final chapter explores Yamamoto's legacy as an artist and educator from the mid-twentieth century to the present day, in both Japan and elsewhere, and how this legacy has been characterized in different parts of the world and different fields. This analysis includes an examination of the impact that the Children's Free Drawing 
movement and the Farmer's Art Movement have had on conceptions of local and rural art movements within and beyond Japan, detailing how these structures persist in contemporary farmer and folk art movements, and have even permeated international events. I argue that the Echigo Tsumari Triennial for example, and other institutions of its type, with their focus on directly linking art to local culture and landscape, as well as their particular brands of community engagement, find their historical foundation in many of the same ideas promulgated by Yamamoto and his colleagues in the first half of the twentieth century. ${ }^{15}$ Contemporary institutions of this kind, adapted over the decades to fit within the framework of the contemporary art world, on the one hand improve upon the relatively contained transculturally local space that Yamamoto had constructed; however, on the other hand, they continue to face many of the same challenges in reconciling the urban-rural center-periphery model that existed in the same region a century prior. In the case of Echigo Tsumari and Kurokawa nō, I examine how these two case studies respectively negotiate the stakes of the local and the translocal, and often transnational, within a contemporary context. I argue that the contemporary rural arts and folk arts can lend to a new understanding of modernity that allows for contemporaneity without a necessary link to urbanity, but that this reconciliation is challenged by many preexisting social, economic, and cultural frameworks that have included bifurcated conflation of the rural with archaism and the urban with modernity.

\footnotetext{
${ }^{15}$ Echigo Tsumari Art Field, “About,” Echigo Tsumari Art Field, http://www.echigotsumari.jp/eng/about/ (accessed January 18, 2020).
} 


\section{Chapter One:}

\section{Sōsaku hanga and a Sojourn in Paris}

"The major issue in my life at the moment is my continued experimentation with many artistic faiths." 16

Yamamoto penned these words to his parents in 1914, two years into his extended stay in Paris. Much as in his approach to art, Yamamoto spent the first part of his career exploring the world, traveling from Japan to France, and then later taking brief sojourns in England, Italy, Sweden, and Russia. His liberal views on art and education, intricately entangled with his sometimes contradictory connections to the Japanese imperial government, muddle his place in history. In Japan, he retains his legacy as the pioneer of the Free Drawing and Farmer's Art movements in his adopted hometown of Ueda, where his ideas continue to live on in contemporary exhibitions at the Ueda City Museum and in the arts curricula of primary schools in Nagano Prefecture and beyond. ${ }^{17}$ Outside of Japan, his story remains fairly obscure, a surprising fact considering his instrumental role in the development of sōsaku hanga, as well as his extensive travels and prolific artistic production throughout Europe, Russia, Taiwan, and beyond.

My research explores the life and career of a creative thinker who, above all else, was seeking to seamlessly distort and fuse established global perspectives on the concepts of tradition and contemporaneity through a very particular framing of connection to place and materiality within art. Yamamoto's efforts and articulation of his philosophies, often

\footnotetext{
${ }^{16}$ Yamamoto Kanae Memorial Museum, Yamamoto no furansu (Yamamoto's France) (Ueda: Yamamoto Kanae Memorial Museum, 2007), 39. Translated by author. ${ }^{17}$ In November 2019, the Ueda City Museum of Art put on an exhibition titled, "Farmer's Art and the Children's Free Drawing Movement: 100 Years," that featured a retrospective on Yamamoto's work as well as contemporary "Farmers' Art." In elementary and junior high schools across Nagano Prefecture, many schools take their students out into nature for a designated day of the school year to paint the landscape.
} 
contradictory and a bit disjointed, nevertheless spawned the three major significant movements previously mentioned during the course of his lifetime: Sōsaku hanga (the Creative Prints Movement), jiy $\bar{u}$-do (or the Children's Free Drawing Movement and Nōmin bijustu (The Farmer's Art Movement). Throughout Yamamoto's travels, culminating in his final years when he settled in Ueda City, the artist cherry-picked various elements of different Western and Japanese ideologies to fit within his own framework of promoting 'local' art. As a result, it is impossible to succinctly distill the Free Drawing Movement and the Farmer's Art Movement (as well as arguably significant aspects of the Creative Prints Movement) down to derivations of one or a combination of these ideologies. In general, he abhorred the city and more urban spaces because he found them detached from the realities of everyday life, as his ultimate professed objective was to capture the reality of the world through art.

This definition of 'reality' changed frequently depending on the context. In the context of the children's art, it was about unfettered, free, immediate expression. In the case of his admiration for the work of Pierre Puvis de Chavannes, it spoke to some ineffable understanding of the hidden reality of the human spirit. And in the case of the Farmer's Art movement, Yamamoto's 'reality' sought to escape the elitism of the institution and formal instruction (and in the process inadvertently created parallel versions of both). Through all of this, despite spending extensive time in Paris, Tokyo, London, and other major cities throughout his career, Yamamoto directed his focus and passion towards cultivating artistic communities in rural rather than urban spaces. ${ }^{18}$ In

\footnotetext{
${ }^{18}$ Many Japanese artists that came after Yamamoto would place a similar emphasis on the rural as the locus for contemporary art production, though admittedly with far different manifestations. Tomii specifically highlights Matsuzawa Yutaka, The Play, and GUN.
} 
addition to the subjects discussed previously, this thesis explores how, and to what extent these efforts can help to reevaluate how rural art is often framed in art historical discourse.

\section{Humble Beginnings: Yamamoto's Education and the Birth of sōsaku hanga}

Yamamoto was born in 1882 in the small city of Okazaki in Aichi Prefecture, but spent most of his childhood in Tokyo, where his father was studying Western medicine. Yamamoto had a modest upbringing, and became interested in art from an early age, in

part due to his mother's part time work as a model for the painter Harada Naojiro. ${ }^{19}$

Yamamoto's comprehensive, albeit tumultuous, education as an artist began in 1893, when the eleven-year old began an apprenticeship for a local wood engraver, which continued until he turned eighteen. At this time, his family relocated to Ueda, where his father opened a medical practice. Yamamoto wished to study painting at this time, but knew that his parents' income would not permit them to fund his education. As such, in 1902, he discreetly enrolled at the Tokyo School of Fine Arts where he studied yog $a$ for several years. ${ }^{20}$

The opportunity to merge his dual artistic backgrounds in wood carving and oil painting came in 1904, while Yamamoto was on a trip with friends to a rural part of Chiba Prefecture. There, he created what is now one of his best-known works, a

Tomii, "Prologue," Radicalism in the Wilderness, 1-5.

${ }^{19}$ Aiko Kanda, Yamamoto Kanae Monogatari (The Story of Kanae Yamamoto) (Ueda: Kanae Yamamoto Memorial Museum, 2009), 9-15.

${ }^{20}$ Gunji Kosaki, Yamamoto Kanae hyōden: Yume ōki senkaku no gaka (Kanae Yamamoto critical biography: Pioneer artist of many dreams) (Tokyo: Shinanoji, 1979), 17. 
woodblock print of a local fisherman (fig. 1). ${ }^{21}$ Monochromatic and rustically carved, Fisherman features a massively scaled depiction of the subject in profile. Stephanie Su's analysis of this work has characterized this rendering of the fisherman as a majestic romanticization of the profession, which is certainly indicated by the scale of the figure, though I would dispute the assertion that this romanticized narrative is further emphasized by a "magnificent sunset." 22 The background of the image, with its monochromatic, vaguely distinguished details, is in fact far more modest. While the figure's billowing and intricately chiseled robes blend into the landscape of wispy gray clouds and minute thatched dwellings behind him, his black boots and the prominence of his profile against the pale gray sky render him simultaneously separate from it. Unlike woodblock prints of Yamamoto's ukiyo-e predecessors that feature both landscapes and figures, here the human figure is not rendered small and insignificant compared to the majesty of the natural landscape, as in ukiyo-e. In this way, the composition of the work more likely reflects the influence of Yamamoto's yogga training despite the medium used, with emphasis on the individual human figure as opposed to backdrop of lake and hills and homes that he all but consumes. That said, as previously alluded, the similarity between the carving marks on his garments and the scenery behind him, as well as the monochromatic color scheme, simultaneously tether him to the land and place.

Instead of superimposing a drawn image as a guide upon the woodblock, and carving out the line of the design in relief, Yamamoto opted to blacken the entire surface of the block, and then etch his design from there, a practice more compatible with the technique of his European printmaking counterparts. Having been present when

${ }^{21}$ Yuko Kikuchi, Japanese Modernisation and Cultural Theory: Cultural Nationalism and Oriental Orientalism (London: Routledge, 2004), 32.

${ }^{22}$ Stephanie Su, "Classicizing the Creative Print," 166. 
Yamamoto created Fisherman, the artist's friend and colleague Ishii Tsuruzo remarked on Yamamoto's dexterity in the woodblock medium, noting that he had only used a gouge in carving the wood - a larger, more unwieldy tool than the traditional burin. When the print was published in the literary magazine Hosun, fellow artist Ishii Hakutei observed that Yamamoto had used his gouge "like the painter would use his brush.",2324 The creation of Fisherman would come to mark the beginning of the somewhat obliquely named Creative Prints movement in Japan. As the movement developed, the name would come to mean different things for different artists, but the motives behind it were consistent in that it reflected a complex negotiation between rejection and embrace of its precursor, ukiyo-e. Perhaps more importantly, it sought to establish the Japanese print within Japan as a work of fine art in its own right, a status that became formally cemented in the 1930s with the inclusion of hanga in the Teiten, or government-sponsored exhibitions. ${ }^{25}$ For Yamamoto specifically, Alicia Volk writes that the "woodcut's populist origins made it the perfect vehicle for a sociopolitical vision of a 'people's art' promoted through art programs aimed at farmers and peasants. ${ }^{, 26}$ I would clarify this statement with the counter suggestion that, while sōsaku hanga gradually evolved into such a vehicle for Yamamoto in the years that followed, he had not yet articulated these motivations when creating Fisherman, and that the movement's very stirrings thus began

\footnotetext{
${ }^{23}$ Ajioka, "Introduction: Hanga: Japanese Creative Prints," 9.

${ }^{24}$ Yamamoto and his colleagues co-founded the publication Hōsun in 1907 to promote the appreciation of art as a creative discipline that could, among other things, be consumed in tandem with prose and poetry. The project disbanded fairly quickly in favor of another periodical, Shirakaba, and later Tsukuhae, which emphasized the emerging identity of the woodblock print as a work "both designed and cut by the artist," a tenet that would become the backbone of sōsaku hanga in the years that ensued. Noriko Kuwahara, "Onchi Koshiro's Pursuit of Modernity in Paris, 1910s-1930s," in Hanga: Japanese Creative Prints, 24, 40, 50.

${ }^{25}$ Art Gallery NSW, Hanga: Japanese Creative Prints, 9, 11.

${ }^{26}$ Alicia Volk, Made in Japan: The Postwar Creative Print Movement, 23.
} 
as a roughly conceived, spontaneous amalgamation of his two disparate artistic backgrounds. Yamamoto himself later expressed a desire to merge the woodblock medium with the so-called Western style that he had been studying, the latter influence being the primary reason that, when hanga prints were introduced to the Teiten in the decades that followed, they were included in the $y \overline{o g} a$ category. ${ }^{27}$ A keep departure from ukiyo-e that resulted from this objective was a shift in woodblock carving methods. In Fisherman and later examples of sōsaku hanga, the artist cut lines into the woodblock, rather than leaving them in relief as was previously typical of ukiyo-e. The result was a print that consisted primarily of pigment and/or color, with mostly white outlines, thus emphasizing color over line. ${ }^{28}$

In the following several years, Yamamoto continued to simultaneously produce woodblock prints and oil paintings, perhaps most notably The Mosquito Net in 1905 (fig. 2). This work features a young woman gazing wistfully to the right of the viewer in a presumably sunlit room. She sits on a tatami floor, with the features of the room behind her separated and obscured by the titular mosquito net, which encircles a large space in the room containing presumably the figure's futon and a case of books, but nothing else. The sitter's removal from this space renders her exposed and vulnerable, in both a literal and metaphorical sense. Like the fledgling artistic movement that the painter and printmaker was developing at the time, the subject's removal from the safe haven of the mosquito net highlights her individuality, her independence, and, more grimly, her isolation. This early work marked the beginning of a trend in Yamamoto's oeuvre that was at times contradictory with his inclinations toward collectivism; the vast majority of

${ }^{27}$ Art Gallery NSW, Hanga: Japanese Creative Prints, 58.

${ }^{28}$ Lawrence Smith, The Japanese Print Since 1900: Old Dreams and New Visions (London: British Museum Publications, 1983): 1314. 
his paintings and prints that contained human figures placed emphasis on the individual and appear to represent their very singular loneliness and individual contemplation, as evidenced by some of his most well-known works: Hagaki (Postcard) (1917), Dekki no ichigû (A Corner of the Deck) (1912), Shina Fujin (Chinese Woman) (1917), Burutānyu no Irie (Shore of Britannia) (1917), the latter of which will be discussed in more detail later in this chapter (figs. 3 - 6).

At the time of producing of The Mosquito Net and during the remaining course of his tenure as a university student, Yamamoto professed admiration for Gustave Courbet and downright idolatry of Pierre Puvis de Chavannes, whose work he had first encountered during his education at the Tokyo School of Fine Arts. ${ }^{29}$ Puvis continued to be highly influential to Yamamoto's oeuvre throughout his career. This preference is at first glance (and even second glance) a bit incongruous with Yamamoto's personal artistic narrative, considering Puvis' painterly reputation as a kind of anti-revolutionary, whose work was widely well-regarded in France in the nineteenth century during an otherwise politically divisive and tumultuous time, perhaps due to the artists' willingness to pacify the various ideologies of many parties simultaneously. ${ }^{30}$ Yamamoto's own admiration for Puvis' work stemmed from its allusions to Classical Antiquity. In describing Puvis' murals, Yamamoto drew comparisons to the interplay between Christian tradition and Greek and Roman mythology in the works, noting that, although he himself was not a Christian, Yamamoto could recognize and appreciate the symbolic importance of labor as frequently represented in Puvis' paintings. In a particularly

\footnotetext{
${ }^{29}$ Kosaki, Yamamoto Kanae hyōden, 52.

${ }^{30}$ C.B. Little, "The Extent of Puvis de Chavannes' Stately Influence," The Japan Times, January 15, 2014, https:/www.japantimes.co.jp/culture/2014/01/15/arts/the-extent-ofpuvis-de-chavannes-stately-influence/\#.XozCtZNKiCQ (accessed April 7, 2020).
} 
adulatory passage in his diaries, he writes of the figures in Puvis' murals, "Touching the high people's minds, I held back tears in the midst of my own lowness and thought that this artful sky was infinite." 31

Yamamoto's unconditional affection for the work of Puvis — and later Cézanneand unequivocal condemnation of most other European painters of the nineteenth century, after much study, defies logic. While Yamamoto praised the former at length and cited him as one of the key influencers of his own oeuvre, there is in fact little to connect the work of the two artists from a formalist or philosophical standpoint. Similarly, his admiration of Cézanne, whom Yamamoto described as "simple and solid," "the landlord of still life," and a man who "absolutely rejected the imaginary subject and always found his subjects in the realm of reality," stands in stark contrast to his observations on the work of Puvis, a painter known for, as previously mentioned, his penchant for mythological subject matter and allegory. ${ }^{32}$

In many respects, however, it seems that even Yamamoto acknowledged that there was not a clear explanation for his preference for the work of Puvis; the attraction was ineffable, and the allure was perhaps in part so strong because of the pair's inherent artistic disparities. In a particularly telling passage of his diaries, Yamamoto wrote of Puvis:

Chavannes's subjects are found in the Christian spirit. K [here seen to signify Yamamoto] is not a Christian...K and Chavannes don't live in the same manner...K is different from Chavannes's tendency in terms of themes, philosophy, and faith. That said, what impressed $\mathrm{K}$ [about Chavannes] is his fundamental wisdom in creating art with what I call the "pictorial spirit." 33

\footnotetext{
${ }^{31}$ Kanae Yamamoto Memorial Museum, Yamamoto no furansu, 39.

${ }^{32}$ Ibid, 40.

${ }^{33}$ Ibid.
} 
Here, we can interpret Yamamoto's attraction to Puvis' "pictorial spirit" as compatible with his own lifelong quest to render the world with a kind of intrinsic realism, even if his own definition of realism did not conform with that of the rest of the art world.

\section{Paris}

In 1912, with visions of Puvis and Courbet in his imagination and woodblock/oil painting training in hand, Yamamoto traveled to Paris to study art as an international student, having received an invitation through a special nomination program for foreign nationals to study at the École des Beaux-Arts. ${ }^{34}$ While there, he studied printmaking, with an emphasis on 'Western' printmaking styles, which in itself constituted a highly transculturally entangled dynamic. This was due to the fact that, by the early twentieth century, printmaking in Western Europe had already been deeply impacted by ukiyo-e prints and the subsequent phenomenon known as Japonisme that had begun sweeping through Europe, in particular France, throughout the latter half of the nineteenth century. While the elements of Japonisme were most evident in the motifs that Impressionist and Post-Impressionist painters appropriated, this strand of Orientalism also manifested itself in stylistic changes in Western art, including the flattening of perspective, the darkening of contour lines, and the use of a more vibrant color palette in the medium of oil painting.

\footnotetext{
${ }^{34}$ Su describes the moment of Yamamoto's trip to Paris as having occurred during the "height of his reputation," an arguable point that points to continued Westerncentric notions in Yamamoto's work and the sōsaku hanga movement in general, particularly in English language scholarship. While Yamamoto's time in Europe may have garnered him the most fame in the West, within Japan he is much better remembered for the work he did in the later years of his life, in particular with the Children's Free Drawing Movement and the Farmer's Art Movement. Su, "Classicizing the Creative Print: Yamamoto Kanae in France," 161.
} 
Japonisme also marked an increased interest in woodblock printing generally in France, with artists such as Paul Gauguin adopting the medium in their own work. ${ }^{35}$ As such, there was a very clear irony in Yamamoto traveling to Paris to study printmaking techniques under the tutelage of a man referred to as Professor Wartner. ${ }^{36}$

Prior to his arrival in France, Yamamoto had already developed a strong interest in Western art during his training as a yōga painter. He was particularly interested in works from Greek and Roman Classical Antiquity, as he viewed this time period as forming the "foundation from which all other Western art was derived." ${ }^{37}$ Naturally, his admiration for Puvis would have also stemmed in part from this fascination, as the subject and composition of many of Puvis' works derived from Greek and Roman mythology. ${ }^{38}$ However, when it came to recent and contemporary European painters, Yamamoto had compliments only for Cézanne, and derided the vast majority of all European paintings produced after the year 1900 as "confused." ${ }^{39}$ He found the work of painters like Matisse far too abstract, believing that the purpose of a painting was to ultimately stay true, in some intrinsic (and unarticulated) sense to the original subject. It was for this reason that he similarly held the work of most Impressionist painters in contempt; he was unimpressed by Monet and Pissarro's dogged efforts to capture the effect of light and movement over form, preferring instead Cezanne's ultimate devotion to the curve of the mountain and the silhouette of the trees. ${ }^{40}$ His critique of Renoir was, frankly, scathing, as he found his impressions split by a schism between extremes,

${ }^{35}$ Colin Rhodes, Primitivism and Modern Art (London: Thames \& Hudson, 1994), 7, 24.

${ }^{36}$ Kanae Yamamoto Memorial Museum, Yamamoto no furansu, 33.

37 Ibid.

${ }^{38} \mathrm{Su}$, "Classicizing the Creative Japanese Print," Awash in Color, 162.

${ }^{39}$ Yamamoto Museum, Yamamoto's France, 39.

${ }^{40}$ Ibid. 
simultaneously "tempted and terrified." ${ }^{41}$ His pejorative feelings ultimately won out, as he simply could not abide Renoir's vivacious figures. Likewise, while he found Van Gogh's pieces more visually captivating, he dismissed them as too rough, a reflection of a life that was too intense, too raw. ${ }^{42}$ Yamamoto was a proponent of capturing the immediate reality of the subject, as long as that reality was not drowning in too much emotion. In an unexpected turn, he had far more measured analysis of Rodin's work, impressed by his detached devotion to representative realism. ${ }^{43}$

Like his idolatry of Puvis, Yamamoto's criticism of the avant-garde read as haphazardly selective at times, though it is perhaps pertinent to note here that the most scorned object of his criticism was perhaps the Futurist movement, a view consistent with his implied resistance to the conflation of industry with modernity. Futurism emphasized the agency of youth and technological advancement, and while the former would later become integral to Yamamoto’s own Children's Free Drawing Movement, he preferred naturalistic subjects. ${ }^{44}$ He dismissed the works of Vassily Kandinsky and his contemporaries as something of a "crowded dance" and went so far as to describe them as "disgusting." 45 In his correspondence with colleagues, Yamamoto wrote:

There is a group of Futurists who despised the idea of universal form, and sought instead to create a form that appealed to the senses, emotions, nerves, etcetera, which was a wholly original concept, but they produced all of these expressions in the form of theory. It does not make sense to anyone who isn't familiar with its formal elements, and they are instead just amazed by its strangeness and freedom. Their art has, in short, a very

\footnotetext{
${ }^{41}$ Ibid, 40.

42 Ibid.

${ }^{43}$ Ibid.

${ }^{44}$ Marilyn Stokstad and Michael W. Cothren, Art History, 4th edition (Upper Saddle River, NJ: Prentice Hall, 2006), 1033.

${ }^{45}$ Ibid.
} 
interesting "design": but it is nothing more than "poetry" without words and "music" without music. ${ }^{46}$

Similarly, he wrote that he could not fathom that "a new truth has been revealed in the creation of the Futurists. I think that it is just a new hobby. It is just simple and fashionable...It is nothing more than an intense, sunny day. ${ }^{, 47}$ Intriguingly, Yamamoto's view of the Futurists and Kandinsky was not shared by many of his colleagues. In fact, Onchi Koshiro had a great fondness for Kandinsky's work and views on art, admiring that the Russian painter imbued art with an intrinsic sense of spirituality (as illustrated in his treatise Concerning the Spiritual in Art), and additionally appreciating that abstract art afforded the artist the additional ability of expressing his inner, less effable feelings onto the canvas. ${ }^{48}$

While, from a technical standpoint, Yamamoto's command of three-dimensional modelling and color theory improved dramatically during the course of his time in Paris, he would later claim that he felt creatively stifled during his time in France, particularly while in its major urban centers. While living in Paris, he went on several expeditions to London, Lyon, Norway, and Italy, and felt similarly uninspired there. His only moment of creative clarity occurred during a six-week sojourn in the rural area of Brittany on the West coast of France, which proved to be his most productive period during the course of his five years in Europe.

In art historical scholarship, there are conflicting characterizations of Yamamoto's time in Paris prior to his trip to Brittany. While Helen Merritt describes Yamamoto's dissatisfaction with the environment of the city, as well as the domination of the avant-

\footnotetext{
${ }^{46}$ Ibid.

${ }^{47}$ Ibid.

${ }^{48}$ Kuwahara, "Onchi Koshiro's Pursuit of Modernity in Prints 1910s-1930," Hanga: Japanese Creative Prints, 26-29.
} 
garde in France during that period, Stephanie Su argues that Yamamoto took great inspiration from the artistic atmosphere of Paris, and traveled to Brittany not due to urban ennui and the persuasion of Kuroda Seiki, but rather veneration for the French painters who had traveled there before him, such as Paul Gauguin, Emile Bernard, and Maurice Denis. ${ }^{49}$ However, considering Yamamoto's unequivocal dismissal of the oeuvres of both Gauguin, Bernard, and their similarly styled contemporary, Van Gogh, in his correspondence, it seems highly unlikely that this painterly precedent would have been the primary reason for Yamamoto's brief relocation to the West of France. That said, as an artist whose self-image was strongly entangled in the European mythos of the artist as a member of a temporally independent community, it is probable that the island's reputation as a creative haven amongst Western artists did play at least a small role in Yamamoto's selection of destination.

It is more likely, however, that he and his friends traveled there mainly at the urging of Yamamoto's colleague and mentor, Kuroda Seiki, who had traveled to Brittany in 1891 and extolled the virtues of its gorgeous rugged coastline and sweeping sea views, as well as its reputation as a popular destination for artists around Europe, rendering it a hub for creative and professional collaboration. The inspiration that Kuroda found in Brittany was evident from the resulting paintings he produced there, in which the brushwork alone appears to have been far more rapid and expressive. Prior to this moment, Yamamoto had spent most of his time in France dabbling with uninspired sketches of strangers in parks. His time there, rather than selling him on the virtues of Western methods, instead reinforced Yamamoto's belief in the many strengths of the

\footnotetext{
${ }^{49}$ Helen Merritt, Modern Japanese Woodblock Prints: The Early Years (Honolulu: University of Hawai'i Press, 1990), 158-160.
} 
Japanese woodblock style. ${ }^{50}$ Hoping that a brief voyage to the coast might rekindle within him the same creative fire that it had in Kuroda and others, he headed off to Brittany.

There, he shifted his focus back to woodblock prints, creating the work Bay of Breton in 1913 (fig. 6). This work depicts a holstein calf grazing atop a grassy cliff overlooking the ocean. Below, boats with vivid red sails meander along the coast, with two on either side of the cow, and another pair dotting the distant horizon line. In this work, moving stylistically towards an aesthetic that would come to characterize sōsaku hanga, Yamamoto has abandoned the dark contour lines characteristic of his early works like Fisherman, a carryover trait from ukiyo-e, as well as many works produced in France during the vogue of Japonisme. However, despite this rejection of past trends, true to the form of the Creative Prints movement, Yamamoto far from abandons the ukiyo-e precedent entirely, particularly in the manner with which he has "cropped" the composition of the work by showing two sailboats in the close background as drifting off either side of the page. This approach results in an almost snapshot-like effect that was typical of works of the Edo period, and a technique adopted during the heyday of Japonisme as well. ${ }^{51}$ These metacultural layers of influence and appropriation in works like Bay of Breton speak to the complex experiences of Yamamoto and his peers during their artistic travels to Europe in the early twentieth century, a sedimentary network of artistic sources in which nineteenth-century orientalism, Western cultural colonialism, and Meiji-period imperial development were entangled to produce seemingly innocuous pastoral landscapes that belied their sharply political historical context.

\footnotetext{
${ }^{50}$ Wall Text, 100 Years of Farmers' Art in Japan, Ueda City Museum of Art, Ueda, Nagano, November 30, 2019.

${ }^{51}$ Klaus Berger, Japonisme in Western Painting from Whistler to Matisse, trans. David Britt (Cambridge: Cambridge University Press, 1992).
} 
Yamamoto was likely fond of this print and found it representative of the narrative he was trying to convey with his art, as it continued to appear in four subsequent exhibitions in the ensuing decades, including three in Japan and one in Paris in the 1930s. ${ }^{52}$ The original print was originally part of the collection of the Yamamoto Kanae Memorial Museum, and is now housed at the Ueda City Museum. A handwritten description on the back of the work, dated 1946, roughly translates to read:

This print of a bay in Brittany is a woodblock print that I created myself. It was made in the summer of 1913 during my time as an international student when I was traveling with friends in Brittany. This commemorative work shows a cheerful, isolated sea village, replete with apple fields, wheat fields, and a bay. Later, during the Second World War, the region was overtaken by Nazi forces, and both this small village and country where I lived became a half-lost nation of defeat. ${ }^{53}$

While in Brittany, Yamamoto also created Bathers in Brittany (fig. 7). While this work is also a woodblock print, the subject matter, composition, and style is far more reminiscent of the works that his contemporaries and predecessors had painted during their own sojourns on the French island. The method that Yamamoto used to create Bathers is the same that he utilized in his earlier works that had come to characterize the early years of sōsaku hanga. As in the case of Bay of Breton, rather than utilizing bold, black contour lines to denote form, Yamamoto instead relies on the backdrop of the blue ocean to create contrast and distinguish the shapes in the foreground. While this result has, in some scholarship, been labeled a side effect of Yamamoto's adaptation of European printmaking techniques to create his works, other analyses attribute this technique to old painting manuals from China and Japan that the artist would have had

${ }^{52}$ Kanae Memorial Museum, Yamamoto Kanae Seikatsu 120 Nenten (Ueda: Yamamoto City Museum of Art, 2002): 7.

${ }^{53}$ Exhibition Label, "Farmers' Art and the Children's Free Drawing Movement: 100 Years," Ueda City Museum of Art, Ueda, Nagano, November 30, 2019. 
access to as a student. ${ }^{54}$ These conflicting reports serve as further elements of the amorphous realities of concepts like 'influence' and 'inspiration' during this time period, and Bathers in Brittany could very well have been the result of an unconscious amalgamation of influences that even the artist would have had difficulty distinguishing. Here, Su also notes an aspect of Yamamoto's oeuvre that indicates his reverence of Puvis in the color palette that the artist used in his seascapes from Brittany. In "diluting his pigments," she writes, Yamamoto was "rejecting clear seasonality and opting for a more temporally ambiguous feel. ${ }^{, 55}$ This telling observation sheds some light onto the difference in philosophy between the Impressionist painters and Yamamoto during his sōsaku hanga years, and may further indicate why he held most of these artists in such disdain. While both Yamamoto and the Impressionists sought to capture a kind of intrinsic reality within their subject, one that conveyed not only form, but feeling, the Impressionists achievement of this goal was predicated on capturing a fleeting momenttheir work did not just acknowledge, but was dependent on, the ephemerality of an object and its ultimately fleeting nature. In contrast, as can be seen in Bathers and his others works leading up to 1913, Yamamoto's objective was to render a more temporally stable subject, a creative interpretation that was not built on instantaneous impression but on the crafting of his own reality that could serve as a stand-in for a collection of moments. In this way, his singular appreciation for an artist like Puvis, whose work similarly did not focus on an instantaneous moment but a carefully constructed (if contrived) scene, begins to make far more sense.

\footnotetext{
${ }^{54} \mathrm{Su}$, "Classicizing the Creative Japanese Print," Awash in Color, 161.
}

${ }^{55} \mathrm{Su}$, "Classicizing the Creative Japanese Print," Awash in Color, 162. 
Brittany's fate during World War II as "a half-lost nation of defeat," caught in the liminal space between bittersweet constancy and loss, wrapped up a narrative that fit squarely within Yamamoto's own framings of the rural village, in Japan and beyond, as both a synecdochal arm of the nation and a self-contained capsule of nostalgia. It is worth noting that this narrative, which will be further explored in the second and third chapters of this thesis, continues to crop up in other genres of modern and contemporary Japanese folk art as well. ${ }^{56}$ The memory of Yamamoto's time in Brittany stayed with him well after his return to Paris, where he experienced a renewed relative surge in creativity, creating a series of watercolor sketches that included both a series of portraits and studies after the landscapes and figure paintings of Cézanne. In 1920, having returned to Japan, he created his seminal woodblock print, Breton Woman, a relatively large scale portrait of a traditional garbed figure, the study for which he had created during his time in Brittany in 1913 (fig. 8). The original watercolor sketch featured a petite, off scale male figure in plain gray clothing in the background, hoisting what is presumably a massive red sail. It is also possible that it is actually a depiction of a flag, but since the color and shape is reminiscent of the sails seen on the boats in the earlier Bay in Brittany the former hypothesis is more likely.

In a subsequent watercolor sketch produced during the same year, the man and the sail are gone, and a small pencil sketch on the left side of the page of a churchlike structure on a small hill takes its place as a means of connoting distance and denoting the

\footnotetext{
${ }^{56}$ In his analysis of the folk performing art form Kurokawa nō, viewed by the communities as an arm of the farmer's art movement, Eike Grossman writes that, within Kurokawa nō, "all protagonists apply concepts of authenticity and commoditization, tradition and modernity, affiliation and nostalgic longing, change and preservation." Eike Grossman, Kurokawa Nō: Shaping the Image and Perception of Japan's Folk Traditions, Performing Arts, and Rural Tourism (Leiden: Brill, 2013), 2.
} 
ocean as background. In the final woodblock print, all identifying features of the landscape have disappeared; what is presumably the ocean is now simply a uniform block of blue, with subtle carving marks above curving up on either side of the subject's head to create the effect of a mottled gray sky.

There was a seven-year lapse in between the production of the first two studies and the final large scale woodblock print in 1920, the latter of which was created after Yamamoto's return to Japan, which may account for the omission of location-signifying landmarks and other elements from the final work. While the woman's dress very clearly conveys her identity as a native of Brittany, her displacement from a recognizable physical space shifts the focus from her regional identity to her individual one. This shift marks the birth of a theme that Yamamoto later applied to his work in Nagano Prefecture, a frame for conceptualizing pictorial spaces that denotes a kind of universal locality. In both studies and the final piece, the subject's gaze is downcast, the tone contemplative. Voyeurism and male gaze aside, within the picture plane, both subject and artist are gazing inward, and the resulting portrait is an expression of both individual humanity and a metonymic representation of a more collective identity.

This work is singular in Yamamoto's work of this period in that it is a brief return to portraiture during a sojourn marked mainly by landscapes. While the artist's subject matter and mediums used varied greatly as a student in Japan, upon arriving in Paris he focused largely on portraits of women, a trend that changed after about one year, when even his works that include human figures placed them in smaller scale to the increasingly detailed landscape behind them. This gradual transformation demonstrates Yamamoto's changing approach to art as well, and his increased interest in human 
entanglements with the land they occupied. This interest could be viewed as an early precursor to a more comprehensive vision of art as a tool of the people, and in turn its intrinsic connection to rural spaces. During this time Yamamoto's preferred color palette softened as well, drifting away from the warm tones featured in his earlier works to a cooler blue and green color palette. While this shift may certainly have been in part inspired by the similar techniques of Puvis and Cézanne, it also reflected Yamamoto's increased interest in more naturalistic representation, a departure from his fellow hanga artists in Japan who were in turn placing increased emphasis on the importance of imagination in printmaking.

Unexpectedly caught in the outbreak of World War I, Yamamoto fled to London, which, like Paris, he found to be a rather cold, impersonal, and uninspiring city, once again in a departure from his contemporaries. ${ }^{57}$ He stayed there for four months, before returning to Paris for two more years. During this time period he also briefly sojourned in Lyon, where he worked to raise money for a 1916 trip to Italy to see the Renaissance masterpieces. ${ }^{58}$ Like the oil painter Fujishima, Yamamoto had some choice words to describe the country itself, but was quite complimentary of the art he saw there, viewing it as the "source of modern art." ${ }^{, 59}$ Upon returning to France, Yamamoto learned of the death of a former friend and mentor, and, having already spent far longer in Europe than originally intended, began making preparations to return to Japan. Little did he know at the time that the journey home would be pivotal to his evolution as an artist, educator, and philosopher.

\footnotetext{
${ }^{57}$ Yamamoto and Yamagoshi, Yamamoto Kanae no tegami, 37.

${ }^{58}$ Ibid, 129.

${ }^{59}$ Kanae Yamamoto Memorial Museum, Yamamoto no furansu, 39.
} 


\section{Chapter Two:}

\section{The Voyage Home: Finding Purpose in Moscow}

Every pupil is so long an anomaly at school as he has not fallen into the rut of this semi-animal condition. The moment the child has reached that state and has lost all his independence and originality...he no longer is an anomaly: he has fallen into the rut, and the teacher begins to be satisfied with him...This injury is especially important on account of the scholastic education, even if it were good. For the agriculturalist it is impossible to substitute anything for those conditions of labour, life in the field, conversation of elders, and so forth, which surround him; even so it is with the artisan and, in general, with the inhabitant of the city. Not by accident, but designedly, has Nature surrounded the agriculturalist with rustic conditions, and the city dweller with urban conditions. These conditions are most highly instructive, and only in them can each develop. And yet, school lays down as the first condition of education the alienation from these conditions. ${ }^{60}$

\section{Leo Tolstoy, On Education}

The least expensive route home would take Yamamoto through Russia over the course of several months along the Trans-Siberian railway. In the summer of 1916, he began his odyssey across Eurasia, stopping in London once more, and then cutting through Norway and Sweden, before making what was intended to be a brief stop in Moscow. At the time of Yamamoto's arrival, Russia was on the eve of revolt. In fact, upon arriving, Yamamoto remarked in his correspondence with his friends and family that the "state of peasant life in Russia is quite terrible, and it seems like they might want to consider having a revolution of some kind. ${ }^{, 61}$ How timely these words were.

\footnotetext{
${ }^{60}$ Leo Tolstoy, "On Popular Education," On Education, 17-18.

${ }^{61}$ Yamamoto and Yamagoshi, Yamamoto Kanae no tegami, 131. Translated by author.
} 


\section{Russian Folk Art: A Mirror of the Revolution}

In the years prior to Yamamoto's words, the Russian art scene was also in a state of massive overhaul, particularly with regards to folk art. Sarah Warren writes that the tension of this moment can be traced back to the Second All-Russian Exhibition of 1913, a missed attempt to appease the increasingly restless populace with a show that emphasized the importance of traditional craft and Russian nationalism. While the exhibition was well-received by the political elite, another exhibition on Russian folk art put on by avant-garde artist Larionov, The Exhibition of Icon Patterns and Lubki, opening just two days later, highlighted the hypocrisy of the exhibition organized by the tsar. In the latter exhibition, Larionov chose to display traditional folk arts in juxtaposition with an avant-garde show, tracking an aesthetic and cultural link between the art of the past and present. In Warren's words, "the contrast between the imperial and avant-garde displays of folk art indicated that modernity and the primitive were not simple terms with stable associations. ${ }^{, 62}$ It is important to note that that ideological approach would later be echoed in Yamamoto's efforts as characterized by Yuko Kikuchi, who writes that he "represented a departure from the anthropologists' primitivism in that his esthetic interest was combined with the idea of socioeconomic and educational reform." ${ }^{, 63}$

Following Larionov's efforts, two competing forms of contemporary folk art emerged, one as a desperate agent of the dying empire to maintain a foothold on a sense

\footnotetext{
${ }^{62}$ Sarah Warren, "Crafting Nation: The Challenge to Russian Folk Art in 1913," Modernism / Modernity 16, no. 4 (Baltimore: The Johns Hopkins University Press, 2009): 746.

${ }^{63}$ Yuko Kikuchi, "Refracted Colonial Modernity," in Refracted Modernity: Visual Culture and Identity in Colonial Taiwan, ed. Yuko Kikuchi (Honolulu: University of Hawai'i Press, 2007), 219.
} 
of national identity, and another that would come to symbolize the emerging collective identity of the revolution. The subsequent position of folk art as a concept with temporal and ideological fluidity not only allowed it to be co-opted by multiple political factions leading up to the Russian revolution, but also resulted in its appropriation and reconceptualization by myriad other thinkers of the day, within Russia and beyond.

\section{Leo Tolstoy, Anarcho-Pacifism, and Peasant Arts Education}

Prior to Yamamoto's arrival in Russia, Leo Tolstoy's philosophies were already popular within various camps of Japanese intellectuals. His work has been cited as a primary source of Japanese socialism, particularly within the Christian and Buddhist sects of this movement. In addition, his work had already had an impact on agricultural reform and approaches to the peasantry in the 1890s, impact that was in turn infused with elements of Zen Buddhist philosophy by the pioneers of these reforms to create a movement specific to Japan. Most importantly, perhaps, James Mark Shields writes that Tolstoy's contrasting of "the 'countryside' as the locus for true humanity and the 'city' as an emblem of strife, unease, and suffering, was new to Japan, though it grafted readily onto nineteenth century nativist appeals to agricultural productivity and peasant life as a solution to Japan's problems. ${ }^{, 64}$

However, Shields also argues that the popular labelling of Tolstoy as "antimodern," both within and beyond Russia at the time, was inaccurate, and "based on a simple conflation of modernity and urban culture." In fact, he adds, Tolstoy's preference for the rural often appeared in his writing in tandem with a "rationalist interpretation of

\footnotetext{
${ }^{64}$ James Mark Shields, "Future Perfect: Tolstoy and the Structure of Agrarian-Buddhist Utopianism in Taisho Japan," Religions 9, no. 5 (2018): 1-2.
} 
religion" and "proto-existentialist focus on the individual," both synonymous with the intellectual notion of 'modernity' as put forth by the philosophers of the period. ${ }^{65}$ In addition to Tolstoy's focus on the art and education of the peasantry, it was this same "proto-existentialist focus on the individual" that also drew Yamamoto to the late writer's philosophies on art, which he would later interweave to create a heuristic for his own cultural projects.

Sho Konishi’s brilliant book Anarchist Modernism: Cooperatism and JapaneseRussian Intellectual Relations in Modern Japan, takes an even more expansive and ambitious approach to these sentiments, through an investigation of "Japanese-Russian non-state intellectual relations since kaikoku," shedding light on a phenomenon that he dubs "cooperatist anarchist modernity. ${ }^{66}$ Konishi's thesis argues that the development of modern political thought in Russia and Japan from the late nineteenth to mid-twentieth century was a fluid transnational event in which both regions informed one another simultaneously. This contention and its framing pushes back against the grain of much previous historiographical research, as "the idea of Western modernity," Konishi writes, "has been the starting point for much historical scholarship on modern Japan in any field — cultural, intellectual, social, political, diplomatic, scientific, medical, environmental, or religious."

Konishi's study of this cooperatist anarchism as a key centerpoint for conceptions of 'modernity' in Russia and Japan also challenges preceding characterizations of

${ }^{65}$ Shields, "Future Perfect," 2.

${ }^{66}$ Kaikoku refers to the (coerced) opening of Japan to trade and political relations by American naval forces in 1854 following a prolonged period of isolation. Conrad Totman, "From Sakoku to Kaikoku: The Transformation of Foreign-Policy Attitudes, 1853 - 1868," Monumenta Nipponica 35, no. 1 (Spring 1998): 1.

${ }^{67}$ Sho Konishi, Anarchist Modernity: Cooperatism and Japanese-Russian Intellectual Relations in Modern Japan (Cambridge, MA: Harvard University Press, 2013), 3. 
anarchism as counter to it. ${ }^{68}$ In contrast, Konishi proposes an interpretation of anarchist history in Japan that contextualizes it within a nuanced reading of the nation's many temporalities during this time period. He writes:

The phrase "anarchist history" here does not mean simply a history about anarchists. Rather, it expresses a view of modern global history as simultaneously existing, multiple imagined and lived ideas of progress, or "modernities," absent teleological and hierarchical ordering. This book suggests that the concerted attempt to synchronize global time in Meiji Japan failed to permeate the everyday life and historical consciousness of the majority of people, including many of Japan's leading intellectuals and cultural figures. Abandoning the understanding that temporalities in Japan and elsewhere were being synchronized into a single global time, this intellectual history examines the rise of a distinct temporality that developed throughout the second half of the nineteenth and the early twentieth century in Japan, which was structured by the terms of anarchist progress and civilization. This temporality, based on a concept of progress towards an imagined future, coexisted with and simultaneously countered the temporality of Western modernity. ${ }^{69}$

Echoes of this understanding of Japan's twentieth-century temporality can also be found in previous discourse on modern Japanese art, which often characterized painting of the period as negotiating tensions between Japanese 'tradition' and Western 'modernity,' a binary that late twentieth century scholarship often conceptualized in terms of competing movements like nihonga and yōga or sōsaku hanga and shin hanga.

Bert Winther-Tamaki describes these conflations as a perpetuation of historiographical

East-West bifurcation in his book, Maximum Embodiment. Winther-Tamaki writes:

The East/West binary has also impacted Yōga historiography by promoting attention to the relationship between Yōga and Nihonga. Indeed, the parallel development of these two movements of painting is surely one of the most striking features of modern Japanese painting, and theorizing this relationship has been a particularly productive concern of

${ }^{68}$ Konishi writes, "The convenient positioning of anarchism and anarchy in opposition to civilizational progress toward legal, political, and institutional order is itself a product of the ideology of Western modernity. Indeed, anarchy has helped define the Western modern as its antithesis." Ibid, 10.

${ }^{69}$ Ibid, 6. 
Yōga studies...Despite the interconnectedness of Nihonga and Yōga in these models, however, this manner of pairing them in a binary tends to situate Yōga on the periphery of the nation and Nihonga at the core of the nation. ${ }^{70}$

Konishi's fluid understanding of transnational temporalities serves to complicate and nuance these binaries that reinforce a center-periphery model, an approach instrumental to delineating the cultural-political relationship between Japan and Russia at the turn of the century. His observations are also applicable within the context of shared Russian and Japanese humanist entanglements with Ruskinian and Morrissian philosophy. This in turn strongly informed Yamamoto's own conception of modernity, which I will explore later in this chapter. In order to remark upon this engagement, however, it is necessary to provide some background on where it began: Moscow.

Upon arriving in Russia, Yamamoto stayed with the Japanese Consul General Noboru Katagami, who was a prominent figure in Japanese humanist literary circles, who one day on a walk took him by Leo Tolstoy's former home at Yasnaya Polyana. Tolstoy had already passed away at this point, but his wife welcomed them into her home and they ate lunch with her. ${ }^{71}$ At this point, Yamamoto was already aware of the Russian writer's literary works, as they had gained vogue in Japan in the late nineteenth century, with excerpts from War and Peace in particular being translated into a number of Japanese journals. $^{72}$

However, he had been unaware of Tolstoy's extensive social enterprises, particularly in the field of education. Around the same time that he was gaining popularity in Japan, Tolstoy had founded thirteen peasant schools to educate the children

\footnotetext{
${ }^{70}$ Winther-Tamaki, Maximum Embodiment, 10.

${ }^{71}$ Kanda, Yamamoto no monogatari, 62.

${ }^{72}$ Ibid, 63.
} 
of families recently released from the oppressive relegation of serfdom. These schools operated on the basis of both student and teacher autonomy, in which the curriculum and teaching/learning methods would evolve based on the direct experience of the teachers and the students. In these experimental spaces, students were not required to attend school, nor to listen to their instructors once they arrived there. Within the communities, children were also in the majority, and as such played an integral role in designing their own education. This experiment as a widespread movement was short lived, as Tolstoy's efforts were frequently interrupted by Tsarist investigations, inconsistent levels of public interest, and his own writing projects. The initiative finally sputtered to a stop in the late 1860s when Tolstoy was in poor health, though experimental education continued to remain close to his heart until his death. ${ }^{73}$

In the 1850 s and '60s however, the property at Yasnaya Polyana had regularly served as the primary campus for Tolstoy's twenty or so schools, and he outlined the objectives and pedagogical approaches of these schools in the fall of 1862, which he later published in his treatise On Education. In it, he presents an educational format that is structured by subject, but flexible in terms of the day-to-day content of the curriculum. The school did not practice corporal punishment or other forms of traditional discipline for offenses like tardiness, as Tolstoy believed that this enforced the concept of the school as a kind of prison. ${ }^{74}$ While the school did comply with some traditional aspects of

\footnotetext{
${ }^{73}$ Encyclopaedia Britannica, 10th ed. s.v. "Leo Tolstoy" (New York: The Encyclopaedia Britannica Company, 1902), From The Ohio State University https://books.google.com/books?id=cNdEAQAAMAAJ\&q=tolstoy\#v=snippet\&q=tolsto $\mathrm{y} \& \mathrm{f}=$ false (accessed April 6, 2020).

${ }_{74}$ Tolstoy writes: "If you follow out the course of the history of the philosophy of pedagogics, you will find in it, not a criterion of education, but, on the contrary, one common idea, which unconsciously lies at the foundation of all the pedagogues, in spite of their frequent divergence of opinion... all of them tend to this one thing, to the
} 
educational culture from that epoch; for example, girls and boys were not permitted to intermingle during school hours, and there was a designated time set aside for religion studies, in other aspects Tolstoy's implementation of his ideology was rather revolutionary for the time.

In On Education, for example, he devotes a significant passage to the subject of the arts, which he acknowledges that, even at the time, were being widely dismissed from the curricula at public schools in Russia, with educators citing a lack of applicability in the future, particularly in rural, working class communities. Indeed, Tolstoy even pushed back against the condoned format of children's art education of the period, a format that was even facilitated for a time by the teacher who taught mechanical drawing at the Yasnaya Polyana school. This pedagogical approach dictated that art, and specifically drawing, was only necessary in the school system if one was drawing directly from life and learning the technical aspects of the practice. Recounting a moment of sudden clarity, Tolstoy writes:

But it was the very experiment with teaching drawing in this manner which convinced us of the falseness and injustice of this technical programme. The majority of the pupils, after four months of careful, exclusively technical drawing, from which was excluded all drawing of men, animals, and landscapes, ended by cooling off considerably in respect to the drawing of technical objects and by developing to such an extent the feeling and need of drawing as an art that they provided themselves with their secret copy-books, in which they drew men, and horses with all four legs coming out of one spot. ${ }^{75}$

liberation of the school from the historical fetters which weigh heavily upon it." Tolstoy, On Education, 10.

Foucault would later make a more direct comparison of the school with the prison and other state-run institutions: "Is it surprising that prisons resemble factories, schools, barracks, hospitals, which all resemble prisons?" Michel Foucault, Discipline and Punish, trans. Alan Sheridan (New York: Pantheon Books, 1977), 228.

${ }^{75}$ Tolstoy, On Education, 340-341. 
Tolstoy goes on in this manifesto-like essay to argue that the same is true of music in contemporary culture, declaring the right to the arts for the masses, particularly to the children of the nation, as innate and inalienable as a "right to eat beef." He derides the current state of the art world for the value that the bourgeoisie has placed in connoisseurship, believing that students should have the right to explore the world and all the creativity that comes with it on their own terms, free from the dictation of taste. "Introduce a child from the people into this world;" he writes, "you can do that and are doing that all the time by means of the hierarchy of the educational institutions, academies, and art classes....But, upon entering into this world, he will no longer be breathing with full lungs,- - the fresh air, whenever he has to go into it, will affect him painfully and inimically.,76

\section{Yamamoto's Encounter}

Following their visit with Tolstoy's widow, Katagami took Yamamoto to a rural crafts exhibition, displaying furniture and other pieces made by farmers during the offseason when they could not harvest. The practice had been initiated to provide the laborers with a source of income during the less prolific seasons, as the long winters and short summers in Russia meant that the peasantry were often short on funds for food. In addition to having this craft hall, the peasants also made use of the village office in the winter, when it was converted to a practice space to educate farmers on the industrial arts. $^{77}$

\footnotetext{
${ }^{76} \mathrm{Ibid}, 344$.

${ }^{77}$ Kanda, Yamamoto Kanae monogatari, 63-64.
} 
Yamamoto's experience with farmers' art in this area outside of Moscow sparked a sense of inspiration in him that he had heavily sought — and failed to find — in Paris for the nearly half decade that he was there. Spending about four months in the area of Moscow, he delighted in the blending of community collectivism and personal creative autonomy that he saw at farmers' craft exhibitions and children's art shows alike, the principles behind which he would later combine to form the Japan Peasant Art Institute (Nihon Nōmin Bijutsu Kenkyüjo) in 1923. The Institute would be predicated on a combination of working class economic interests, crafting out a sense of local/national identity, and individual creative potential. ${ }^{78}$ Prior to his visit to Moscow, Yamamoto had previously been ruminating on the concurrent state of children's art in Japan. At that time, the Japanese arts education system consisted mainly of drawing classes, and these drawing classes in turn comprised giving pupils examples from which they were expected to copy directly. ${ }^{79}$ The result was considerable uniformity and lack of creativity in children's art produced in a school setting, the same artistic monotony that Tolstoy had lamented in his schools before he decided to change the curriculum. Yamamoto found that the resulting art at these exhibitions was free and more expressive, and that the system effectively cultivated children's creative power. ${ }^{80}$

Yamamoto was also inspired by the format of the exhibition itself. He had never before seen an exhibition that displayed children's work as artistic masterpieces in their own right; children's art was usually presented as inferior to that of adults, hung haphazardly, without proper frames or a respectable exhibition space, and without

\footnotetext{
${ }^{78}$ Kikuchi, Japanese Modernisation and Mingei Theory, 32-33.

${ }^{79}$ Takuya Kaneda, "The Concept of Freedom in Art Education in Japan," The Journal of Aesthetic Education 37, no. 4 (Winter 2003): 12-13.

${ }^{80}$ Kanda, Yamamoto Kanae no monogatari, 64-65.
} 
thorough labeling offering thematic and logistical context. He was impressed by the importance that this exhibition in Moscow placed on children's work.

Following this experience, Yamamoto's correspondence with friends and family quickly began to reflect the impact it had on him, and he began articulating a strong desire to realize two projects: 1) a farmers' art movement in rural Japan, and 2) a Free Drawing movement in schools and programs across the country, in which children would be given free rein to express themselves artistically, particularly in a natural, outdoor environment, as opposed to being shackled to what he saw as the limitations of formal instruction. ${ }^{81}$

Despite Yamamoto's deep reverence for the folk arts of Russia and the impact that this experience had on him, his correspondence during that time period retained an implicit, and occasionally explicit, suggestion of overall Japanese cultural and societal superiority, a theme that recurs several times in his observations on Europe and Italy as well. In a letter to his parents sent shortly after his arrival in Moscow, he complained about the high prices of low quality items at the shops in the city, how goods imported from Japan were advertised falsely as being British goods due to their higher quality and cheaper availability. He also remarked on the strong grip that the Church seemed to have on Russian everyday life. "The power of the church is strong here," he wrote. "I think that it is the most important artery in this country. ${ }^{, 82}$

Yamamoto himself advocated for a more secularized society, implying that the Farmers' Art Movement could come even further if it removed itself from the shackles of religion. Throughout his career, Yamamoto's vacillation between nationalist and

\footnotetext{
${ }^{81}$ Yamamoto and Yamagoshi, Yamamoto Kanae no tegami, 139-156.

82 Ibid, 136-137.
} 
transnationalist sentiments had several recurrences, particularly when he traveled to Taiwan (then under Japanese rule), at the urging of the Imperial government in 1924. As a resident "expert" on world folk crafts, Yamamoto was instructed to observe the Taiwanese craft movement and advise on how it could improve its efforts from a commercial standpoint. Kikuchi notes that he "found them to be of excellent quality, 'beyond the level of my expectation,' noting that their functional nature was an integral part of the self-sufficient lifestyle of the aboriginal people. ${ }^{" 83} \mathrm{He}$ compared them favorably to northern European folk art, stating that their quality exceeded those produced in Russia, Scandinavia, and Germany. While his Japanese colleagues believed that the optimal potential for the Taiwanese craft market lay in bamboo and rattan products, Yamamoto disagreed, arguing that these pieces could not compete with their counterparts produced in Japan and that the smartest move would be for Taiwanese artists to infuse an element of "local color," into their industrial arts and crafts, which would in turn be marketed to international artists. ${ }^{84}$ This position on the one hand demonstrated admiration for the intrinsic value of this "local color" that aligns neatly with Yamamoto's emphasis on the powerful relationship between individuals, art, and locality; however, on the other hand, that observed value was inextricably entangled with tropes of colonial exoticism and a solution that served a growing international capitalist system.

Only a few decades after the West had introduced a distinction between the fine and decorative arts in Japan, Yamamoto employed these same constructed hierarchies in his assessment of contemporary Russian art, writing that the art world itself "was not

${ }^{83}$ Kikuchi, "Refracted Colonial Modernity," 220.

${ }^{84}$ Ibid. 
much," but that the craft and folk arts of the country were quite wonderful. ${ }^{85}$ Throughout all of his correspondence, however, despite his expression of gratitude for the hospitality he was receiving in Moscow from both Japanese expatriates and Russian colleagues (at one point he referred to his summer in Russia as being akin to staying "between two homes" both figuratively and from a geographic standpoint), Yamamoto continued to express the same sense of overarching homesickness and strong desire to return to Japan that had pervaded his writing of the past four years. In his frequent correspondence with his parents and friends, despite keeping them apprised of his happenings abroad, the bulk of Yamamoto's letters still contained talk of home, even after having been away for such a long time. Still months away from his return to Japan, he laid out his logistical plans of how he would proceed once he arrived at port in Tokyo, and began detailing the projects he would pursue upon returning. ${ }^{86}$

During this time, Yamamoto also continued to work on his own artistic repertoire. As in the case of Paris, however, aside from many city sketches that Yamamoto produced while in Moscow, he was not particularly prolific as an artist during his time in Russia. Arguably his most notable work produced there was a color woodblock print, depicting a low flying bird's-eye-view of the city, with an nearly monochromatic blue and white rendering of what appears to be Saint Basil's Cathedral in the background (fig. 9). As in

${ }^{85}$ Kimi Coaldrake explains the political implications of developing this distinction as follows in a paper on late-nineteenth century international expositions: "The categorization of many of Japan's art forms as 'manufactures' at expositions turned what was an academic distinction into a political and diplomatic issue. Historically there was no distinction between fine arts and decorative arts, with no words in the Japanese language to express such a distinction. However, the categorization raised the fear that Japanese civilization would be considered second rate when compared with the West." Kimi Coaldrake, "Fine Arts Versus Decorative Arts: The Categorization of Japanese Arts at the International Expositions in Vienna (1873), Paris (1878), and Chicago (1893), Japan Forum 25, no. 2 (December 2012): 174.

${ }^{86}$ Yamamoto and Yamagoshi, Yamamoto Kanae no tegami, 137. 
the case of his earlier woodblock prints of this period, the details are soft, with shape connoting form in the absence of bold, black contour lines. The perspective of the scene is slightly tilted, with the forms of highly stylized buildings in the foreground curved to add to an overall unstable depiction of an otherwise serene landscape. The only feature not rendered in the cool color palette is a building in a soft reddish brown accent, though it is difficult to speculate on the significance of the building given the aforementioned heavy stylizing of its architectural features. Despite this being a capital city and an ostensibly heavily populated area, there is not a human figure in sight, and dark, fluffy silhouettes of trees dominate the skyline, appearing to infringe on the manmade structures with which they share space. Clouds roll in over the city, and a blue horizon line belies Moscow's landlocked status. The resulting landscape plays with reality in a way that is surprising for an artist who professes a fidelity to it in his work, and the wobbly effect aptly suggests a nation on the brink of upheaval. It is also pertinent to note the sketchy quality of the line in this print, giving the resulting work the effect of a drawing more than a woodblock print. This is an effect that Yamamoto had been creeping toward in his preceding works produced in France, but this rustic and sketchy quality is fully realized in Moscow.

The lack of works Yamamoto produced during the (admittedly short) stint in Russia may at first consideration seem surprising given the degree of inspiration he claimed to take from it, but it also marked an important shift away from his own creative pursuits, one that would last for several decades while he cultivated his own brand of folk arts in Japan. It represented a transition from practicing painter to practicing community organizer. Though Yamamoto's work, particularly during the formative years of sōsaku 
hanga, had always possessed political undertones, in exploring changes to established Japanese institutions like the education system his critiques became more explicit.

Not all were pleased by this development. Yamamoto's interest in Russian folk arts would later create friction for him with the Japanese government, as he was often accused of being a Communist Socialist. This would have been an easy assumption to make, considering Yamamoto's fascination with Russian arts and culture and the fact that the country was in the midst of a Communist Revolution during the 1920s when these allegations occurred. Marxism was also gaining considerable popularity in Japan during this time period, with Kawakami Hajime (1879 - 1946), a professor of economics at Kyoto University, being one its primary proponents. ${ }^{87}$ Kawakami had a strict, authoritarian reading of Marxism, but was also responsible for introducing Ruskinian social and economic theory to the Japanese intellectual community during this period, which would be highly influential to Yamamoto's own artistic and educational theories in the years to come. ${ }^{88}$ Today, Yamamoto continues to be a bit of an enigma in regards to his political leanings; despite some of his more radical ideas regarding proletarian creative agency and his occasional unpopularity with the government, the artist's ultimate public fidelity seems to have remained firmly in the corner of the Japanese empire, as evidenced by the many government-organized committees and publications

\footnotetext{
${ }^{87}$ While there were certainly other figures integral to the spread of Marxist thought in Japan, Kawakami is credited as the leading catalyst. Interestingly, prior to his appointment at the University of Kyoto and subsequent project translating Das Kapital into Japanese, a young Kawakami was fascinated by religion, with the New Testament and Tolstoy's My Religion being two of his favorite texts. Gino K. Piovesana, Contemporary Japanese Philosophical Thought (Tokyo: Sophia University, 1968), 170-171.

${ }^{88}$ Yuko Kikuchi, "The Myth of 254, "The Myth of Yanagi's Originality: The Formation of 'Mingei' Theory in its Social and Historical Context," Journal of Design History 1, no. 4 (1994): 254.
} 
that he spearheaded upon his return to Japan. In spite of these public affiliations, I propose that he in fact harboured some anarchist leanings, in line with the niche ideological space that Yamamoto's primary model for the Farmers' Art Movement, Leo Tolstoy, occupied within political thought, and which permeated his artistic endeavors throughout the latter half of his career. Subsequently, while the authorities may have confused Yamamoto's educational theories as being founded in Marxist thought, the reality was more complicated.

It is important to note that, though indeed there were some parallels between Marx and Tolstoy's views on education, their pedagogies diverged considerably. ${ }^{89} 90$ Firstly, while Tolstoy rejected the concept of the state as an institution, he remained strongly religious, and his personal interpretations of Christianity guided many of his philosophies regarding the peasantry, education and the arts. He also veered away from nationalist rhetoric, having particularly strong interest in various aspects of Chinese

\footnotetext{
${ }^{89}$ It is worth adding here Robin Small emphasizes that Marx avoided writing explicitly on proposed future educational models without simultaneously considering their feasibility in conjunction with contemporary educational practices. This pragmatism stemmed from a desire to avoid contributing to any future literature on "Utopian socialism," which he found counterproductive, further separating his views from those of Tolstoy. However, Small adds, a close reading of Marx's writings nevertheless sheds valuable insight on the philosopher's views on education.

Small, Marx and Education, vii-ix.

${ }^{90}$ One of the primary links that can be drawn between Tolstoy and Marx's respective educational theories was their focus on the primacy of learning as a creative pursuit, though the proposed implementation of this directive manifested itself in contrasting ways. Marx saw this "creativity" as a representation of individual exploration but one that was really just a mirror of collective human nature, one that could shape a child's future experience in the labor force. Tolstoy, similarly, saw creative learning as a gateway to future appreciation of hard work in (largely proto-industrial) society, but he also viewed education, particularly arts education, as a means of creativity for creativity's sake. Considering this disparity, it is thus perhaps unsurprising that Marx's limiting writings on educational theory failed to address the place of art in any substantial way. Small, Marx and Education, 32. Tolstoy, On Education, 342.
} 
culture and incorporating several elements of Buddhism into his conception of spirituality. He was a leading early figure in anarcho-pacifism, a school of thought usually connected to Christian principles, though favored by Mahatma Gandhi in its secular form, and defined as viewing "the state as immoral and unsupportable because of its connection with military power."91

In addition to his own leanings towards religion and pacifism, Tolstoy also went so far as to directly distance himself from Marxist thought, perhaps articulating these differences best in his 1910 treatise, "On Socialism:"

You want me to write an article for your book on social and economic issues, i.e. about what, in my opinion, the best form from the economic point of view, I would like to have in order or to form a modern society.

I can't fulfill your wishes in the first place, because I don't know, I can't know and I think that no one can know the laws that change the economic life of nations, nor the best form of economic life modern society, as socialists and their teachers know, and secondly, also because if I imagined that I know the laws by which humanity moves in its economic development, as well as that best economic form the device in which it should fold I, as all socialist reformers from Saint-Simon, Fourier, Owen to Marx, Engels, Bernstein and others thought and think, I would not have dared to say that.

I would not dare to say this because having in the future economic forms of life for human societies, in my undoubted conviction, can be as little foreseen and defined as the future position of every single living person, and therefore all these fictional people laws and, on the basis of these laws, the various best devices of societies supposed by different people not only do not contribute to the welfare of people, but constitute one of the main reasons for the disorder of human societies, from which suffering people of our time. ${ }^{92}$

${ }^{91}$ Stanford Encyclopedia of Philosophy, "Anarchism," by Andrew Fiala, last modified November 3, 2017, https://plato.stanford.edu/entries/anarchism/_accessed March 3, 2020).

${ }^{92}$ Leo Tolstoy, “On Socialism,” 1910. Журнал "Толстовский Листок/Запрещенный Толстой", 5th ed., trans. Gabriel Mumzhiev (Moscow: Press Solo Publishing House, 1994), Sobraniye klassiki, http://az.lib.ru/t/tolstoj_lew_nikolaewich/text_0850.shtml (accessed February 27, 2020). 
This rhetoric can also serve to cement Tolstoy's leanings towards anarchism, as his cautioning against predicting the outcome of specific government models is compatible with the same admonishment of later leading anarchist thinkers. In a "tribute" to Tolstoy in 1908, Leon Trotsky went so far as to label Tolstoy a "conservative anarchist," pulling his evidence from the same rhetoric the novelist employed in "On Socialism." ${ }^{93}$ While anarcho-syndicalism, which allows for the possibility of an anarchist system that works in tandem with an industrialist society, has been associated with leftleaning strains of Marxist ideology, Tolstoy strayed from this camp as well in his own projects, opting instead for, as alluded previously, a proto-industrialist, agrarian society. ${ }^{94}$ Yamamoto's close ideological connection to Tolstoy provides compelling evidence that the artist's political views, particularly when it came to art and education, aligned more closely with anarchist rather than socialist thought. However, it remains difficult to specify where Yamamoto would have fallen within anarchism's various

${ }^{93}$ Trotsky's full explanation of this labeling reads: "Along this road he becomes a conservative anarchist, because what he requires, first and foremost, is that the state with its whips of militarism and its scorpions of the federal treasury let live in peace the allsaving Karatayev commune. Tolstoy has no inkling whatsoever of the globeencompassing struggle between the two worlds- that of the bourgeoisie and that of socialism - on the outcome of which hinges on the destiny of mankind. In his eyes socialism always remained a variety of liberalism, of little interest to him. In his eyes Karl Marx as well as Frédéric Bastiat were representatives of one and the same 'false principle' of capitalist culture, of landless workers, of state coercion. In general, once mankind has ventured onto a false road, it really matters little how near or how far this road has been travelled. Salvation can come only by turning back." Interestingly, towards the end of his life Trotsky would stray from Marxism and take on more anarchist leanings. Lenin also staunchly criticized Tolstoy's theories, writing that, while he respected the author's genius, in the case of politics Tolstoy was "writing about things he couldn't understand.” Leon Trotsky, “Tolstoy, Poet and Rebel (Written on Tolstoy's Eightieth Birthday," 1908, trans. John G. Wright in Fourth International 12, no. 13 (May-June 1951): 90.

${ }^{94}$ Chomsky and Jay, "The Relevance of Anarcho-Syndicalism," Chomsky on Anarchism, 136. 
camps ideologically ${ }^{95}$ Yamamoto's close alignment with Tolstoy's philosophical approach could suggest a leaning towards pacifism as well, though his aforementioned continued close ties with the Japanese government during the height of its imperial expansion, coupled with his extensive work in Japan-occupied Taiwan, contradicts this potentiality.

In this light, Yamamoto's interest in Tolstoy becomes further complicated by the latter's own writings, which used Japanese as an unfavorable example of oppressive government rule as far back as 1910 . He writes:

And his action is more significant, richer in the consequences of all possible parliamentary speeches, world congresses, socialism and all these amusements and means of tearing the truth from oneself. Both governments and capitalists know this very well. They know this with a sense of self-preservation and everywhere, in Japan they even prohibit books proclaiming this simple, wellknown truth, and put in jail those people who profess it in their lives. Governments and capitalists know where the danger is. ${ }^{96}$

Despite this intellectual connection to political dissent, and aside from several run-ins with the Japanese government questioning his political leanings, Yamamoto simultaneously remained very much an arm of the imperial establishment until the end of his life, serving as an officer of the Japanese Print Service Society (Nippon hanga hokokai), an association established by the print journal Etchingu to promote the nationalist aspects of the Japanese woodblock print that had many ties to the imperial

\footnotetext{
${ }^{95}$ It is necessary to acknowledge here that the distinction between anarchism and socialism became a bit muddled in twentieth century scholarship on the subject, though I do not have the time or space to devote to this debate here. In his "Notes on Anarchism," for example, Chomsky explores anarchism's characterization as a libertarian wing of socialism in the work of thinkers like Rudolph Rocker and Daniel Guerin, the latter of whom quoted Adoph Fischer's statement that "every anarchist is a socialist, but not every socialist is an anarchist." Noam Chomsky, "Notes on Anarchism," Chomsky On Anarchism, 123. ${ }^{96}$ Tolstoy, "On Socialism."
} 
government. ${ }^{97}$ However, Sho Konishi hints that he may have held these views privately, using the fact that Fisherman, a distinctly "non-war" print, was produced during the height of the Russo-Japanese War, when the artist's contemporaries were producing largely wartime/imperialist imagery, though Kendall Brown notes that the overall volume of production of war prints was markedly reduced from that during the preceding SinoJapanese War. ${ }^{98} 99$

The fact that Fisherman does not contain any explicit wartime or nationalist imagery does not necessarily designate it as "non-war." It still may fall under the category of imagery emblematic of what Asato Ikeda describes as "Japanese Fascism." In The Politics of Painting, Ikeda writes that even "non-battle paintings" could be "profoundly steeped in the state's wartime ideology, whose ultimate aim was to restore Japan's unique cultural sensitivities." ${ }^{100}$ While Ikeda is speaking in regards to paintings produced during World War II, these nationalist artistic patterns were already beginning

${ }^{97}$ Kendall H. Brown outlines some of these ties in her essay "Japanese Woodblock Prints and War," which notes that the inaugural ceremony was held at the Tokyo headquarters of the Imperial Rule Assistance Association (IRAA), and that its advisers included representatives from the War Ministry and the Naval Department. She adds that the "official oath of the Japanese Print Service Society promulgated in Fujikake's address underscores the idea that woodcuts are Japanese in spirit because of their long and glorious history and also because their production requires focused physical and mental energy. Prints symbolized the character of the nation."

Kendall H. Brown, "Japanese Woodblock Prints and War," in Art and War in Japan and its Empire, 1931 - 1960, ed. Asato Ikeda, Aya Louise McDonald, and Ming Tiampo (Leiden: Brill, 2013), 221-222.

${ }^{98}$ Sho Konishi, "The People at Rest: The Anarchist Origins of Ogawa Usen's 'Nihonga,"' World Art 11, no. 2 (December 2011): 256.

In Anarchist Modernity, Konishi also adds that "at the height of the war, the print aesthetically and powerfully represented 'the people' as unconnected to the war and the state's ongoing project to enter Japan into the circle of Western modern nation-states." Konishi, Anarchist Modernity, 171.

${ }^{99}$ Brown, "Japanese Woodblock Prints and War,"Art and War in Japan and its Empire, 211.

${ }^{100}$ Asato Ikeda, The Politics of Painting: Fascism and Japanese Art During the Second World War (Honolulu: University of Hawaii Press, 2018), 8. 
to stir during the Meiji Period as well. In 1904, when Fisherman was created, the article that accompanied its reproduction in Hōsun hinted at the contradictory blending of nationalist tropes and radicalism that would pervade Yamamoto's work in the decades to follow. On the one hand, the text praised the artist as a young revolutionary who sought to eliminate the traditional division of labor in the production of woodblock prints, advocating for works that were completed entirely by the hand of the artist and therefore elevating the medium to the status of fine art. On the other hand, however, Yamamoto was simultaneously advocating for a return to the style of Edo Period ukiyo-e and traditional motifs, in line with the same aims to "restore Japan's unique cultural sensitivities" that Ikeda observed in later Japanese art movements. ${ }^{101}$

Similarly, Yamamoto's later career continued to tiptoe along a fine line between two disparate ideologies, crossing far beyond this line on either side on more than one occasion. While his explicit invocation of Tolstoy as the primary influence towards the development of his Farmers' Art Movement and Children's Free Drawing/Free Education, and his subsequent implementation of many of the same ideals that were rooted in a proto-industrial branch of anarchism, were by nature counter to the concept of modern nationhood and imperial expansion as championed by the Japanese government during that time, at the same time Yamamoto continued to work closely with the imperial government at various intervals throughout the remainder of his life. Whether this contradiction was due to an interest in political/personal self-preservation or another cause is unclear, a thing that remained constant throughout Yamamoto's life was this omnipresent inconsistency, an amalgamation of transcultural influences that weaved

\footnotetext{
101 "Fisherman," The Cleveland Museum of Art, https://www.clevelandart.org/art/1960.122 (accessed April 14, 2020).
} 
competing notions of politics, education, and culture to culminate in his exploration of the potentiality of rural spaces as locales for the confluence of the seemingly conflicting binaries of modernity and tradition, collectivism and individualism, the local and the translocal, and the simultaneous necessity for and superfluity of money.

In the weeks immediately leading up to his return to Japan, Yamamoto's correspondence (again primarily with his parents) appears almost excessively focused on money. Over the course of several letters, he meticulously details the cost of individual products sold in the Russian markets and how they compare to Japanese prices. He consistently remarks on his own financial plans, the debts he needs to pay, and how he is going to go about providing for himself upon his return to Japan. As the collection of correspondence available does not include the letters he was receiving from his family and friends, it is difficult to ascertain whether these comments were in response to questions posed by his pen pals or if this preoccupation with economics was a personal one. Money, from a young age, was never far from the back of the artist's mind growing up, and his perpetual preoccupation with it, which continued well into adulthood, may also in part account for his shift to a more utopian anarchist lifestyle in his later years once he had settled his outstanding debts in Japan. ${ }^{102}$

In either case, by the time he departed from Moscow, despite his enthusiasm for the folk arts movement, children's art and the friendships he had made there, Yamamoto's correspondence also hinted at burnout. He expressed frustration that there were art events he wished to attend in the city, but could not afford, and became increasingly disparaging of the quality of Russian goods and patronizing of the whole that the Russian Orthodox Church seemed to have on the average Russian household.

${ }^{102}$ Yamamoto and Yamagoshi, Yamamoto no tegami, 136. 
However, he still lamented not being able to enjoy the city in all of its winter glory prior to his departure in October, and remarked in a rather bittersweet tone that now, in Moscow, he felt as if he were in a place "in between two hometowns," "after Paris" and "before Japan." ${ }^{103}$ Yamamoto’s meaning is not made exactly explicit here, and it is difficult to say whether this claim indicates that Moscow serves for him as a kind of third space that is an balanced amalgamation of the two, or if it is instead a kind of liminal halfway point, both figuratively and geographically, between two locations where he had established a home for himself. I propose that Yamamoto likely held both sentiments, despite his complicated relationship with Paris, but that the first interpretation is closer to his meaning in this context. The positioning of Moscow as a thematic crossroads between his education in France and Japan serves as a credible, if slightly heavy-handed analogy, for the deeply entangled web of European and Japanese creative influences that Yamamoto had been negotiating throughout his career in a quest to articulate his artistic vision. While the city was by no means the midway point between two creative hometowns, it did serve as a space in which Yamamoto was able to resolve these voices and articulate his vision more clearly. That vision, it turned out, was for contemporary peasant arts.

\section{Yamamoto's Folk Arts and A Brief Discussion of Mingei}

It bears briefly discussing the relationship between mingei, also known as the Japanese Folk Arts Movement or People's Art Movement, and the transnational folk arts discourse thus far. I find it also pertinent here to attempt to clearly situate and articulate Yamamoto's own role in this movement, as his name often appears adjacent to

${ }^{103}$ Ibid, 137. 
scholarship on mingei but rarely as a part of the discussion, though his own enterprises align very closely_ and at times overlap — with it.

Mingei was officially established in the 1920 s by the artist Yanagi Soetsu, following the latter's contact with Korean folk arts and ceramics during a trip to Korea in 1916, around the same time Yamamoto was returning to Japan via Russia. Mingei was predicated on principles of an innate understanding of beauty, aesthetics, and tradition, a formula that Yanagi liked to frame as original to his own thought processes and the inherent superiority of Japanese folk arts, though he did acknowledge his Korean sojourn as the impetus for this project. However, in recent years, scholars-most notably Yuko Kikuchi—have begun to push back strongly against these claims of originality, with Kikuchi arguing that Yanagi plagiarized many of his ideas from preexisting Ruskinian and Morrissian models, as well as existing intellectual writing from additional Western and Japanese sources. ${ }^{104}$ Kikuchi also notes that the late Taisho and early Showa periods were characterized as an epoque of "triangular movement," as proposed by Izuhara Eichi, who organized the contemporary craft movements of the day in the following three categories:

1. The movement centred in the Kokuritsu Kōgei Shidoshō (National Crafts Institute), established by the government in 1928 to improve the design of products for export.

2. The Mukei (No Form) group and the Jitsuzai Kogei Bijutsukai (Existing Crafts Art Society), established in 1926 and 1935 respectively by the 'artist-crafts- men' to create new crafts based on their new craft aesthetics.

\footnotetext{
${ }^{104}$ Yuko Kikuchi, “The Myth of Yanagi's Originality: The Formation of 'Mingei' Theory in its Social and Historical Context," Journal of Design History 7, no. 4 (1994): 247-248.
} 
3. The various peasant and folk crafts movements led by such people as Yamamoto Kanae and the Mingei group led by Yanagi Soetsu. ${ }^{105}$

As we can see here, Yamamoto's Farmer's Art Movement and Free Drawing Movement have been placed within the same category, a narrow designation considering the relatively slim distinctions between each of these three camps. In fact, Konishi goes so far as to not even distinguish between People's Art (as he chooses to stylize mingei) and Yamamoto's artistic projects. ${ }^{106}$ However, Yamamoto rarely, if ever, spoke of his own work as precedent or concurrent to Mingei. Assuming that some kind of key distinction between Yamamoto and Yanagi's respective enterprises existed, the next step is to determine what that distinction was.

Kikuchi argues that the primary difference was "that Yamamoto...had social aims such as the improvement of the standard of life and education for peasants so that they could lead more fruitful and creative lives, while the Mingei movement's aesthetic aim merely idealized the peasants' crafts as having the supreme beauty of craft."107

Yanagi believed that the objectives of Yamamoto's work were far less nuanced. While it seems that Yamamoto did not have much to say about Mingei, Yanagi and his followers were a bit more forthcoming in their criticism of the Farmer's Art Movement, for which the development proceeded that of Mingei by several years. Kim Brandt contends that, in fact, Mingei borrowed considerably from the tenets of Farmers' Art in its early days, but that Yanagi was loath to acknowledge the connection. In a 1935 essay titled "Mingei to nōmin bijutsu" (Mingei and Farmer's Art), Yanagi was quite scathing in his contempt. Brandt notes:

\footnotetext{
${ }^{105}$ Ibid, 257.

${ }^{106}$ Konishi, Anarchist Modernity, 335.

${ }^{107}$ Kikuchi, "The Myth of Yanagi’s Originality," 258.
} 
...he condemned farmers' art roundly as "something that a Western-style artist [yoyaga] fond of foreign countries had Japanese country youth make in imitation of objects he thought beautiful and selected from among foreign farmers' art." Unlike mingei, according to Yanagi and his cohort, farmers' art was nothing more than a Westernized bauble produced at the whim of urban intellectuals; it reflected none of the regional, functional character of "purely Japanese," "purely agrarian" objects "born" rather than "made" in the countryside. ${ }^{108}$

These remarks, while tonally counter to Kikuchi's favorable comparison of Yamamoto with Yanagi, do fit into her key arguments contrasting the two artist's philosophies. She contends that, at the end of the day, while Yanagi advertised mingei as a movement predicated on the aesthetic, it was simultaneously a strongly nationalist enterprise, of which the local elements of rural arts were often lost and/or obfuscated in the interest of a more general national narrative. In the midst of Japanese colonization of Korea, Yanagi employed rhetoric that essentialized and primitivized Korean arts and culture to perpetuate the pervading imperial narrative of Japanese exceptionalism. In addition, he promoted a positivist, yet standardized understanding of Japanese culture through folk arts. Kikuchi writes:

Yanagi also began articulating ethnic characteristics. He grasped ideas from [Émile] Mâle and [O.P. Bede] Jarrett about the nexus between 'religion', 'local', 'national' and 'universal' art as he later developed Mingei theory connecting ethical values with Japanese local folkcrafts, with the idea of national and ethnic art as well as with the idea of universal modern art. ${ }^{109}$

I would add that in contrast, while Yamamoto himself certainly had some political connections that tied him to nationalist interests (he traveled to several separate prefectures preaching the importance of local folk crafts, and at one point even referred to this campaign as its own kind of grassroots "propaganda"), a nationalist approach was not

${ }^{108}$ Kim Brandt, Kingdom of Beauty: Mingei and Politics of Folk Art in Imperial Japan (Durham, N.C.: Duke University Press, 2007), 93-94.

${ }^{109}$ Kikuchi, Japanese Modernisation and Mingei Theory, 48. 
a defining tenet of his peasant art movement. Yamamoto not only freely acknowledged international influence and connections, but simultaneously emphasized an ultimate and intrinsic connection to place through a lens that was primarily localized at the community, and, on occasion, individual, level. In his correspondence regarding the catalogue of one of his first exhibitions of farmers' art in the 1920s, Yamamoto was very intentional in his selection of the images that would be the face of the exhibition. He sought pieces that showed the artists' personal connections to the local landscapes they depicted, often within their hometowns. ${ }^{110}$

If we can take away anything from this chapter, it is that, while Yamamoto had many formative artistic experiences in Japan and Europe prior to this moment, his short sojourn in Russia was the site of confluence for all of the fragments of ideas he had collected over the course of his young career. While the early years of sosaku hanga can certainly be seen as a precursor to the peasant art movements to come, his experience in Russia directly and almost immediately instigated the development of the Farmers' Art Movement and the Children's Free Drawing Movement upon his return to Japan. As I have previously alluded however, I would contend that the general principles for these ideals were already percolating when Yamamoto arrived in Moscow; the latter simply presented him with a way to articulate them.

It is difficult to say what sort of impact Yamamato's work and philosophies in turn had in Russia, a subject which certainly warrants further investigation in another paper. That said, the broader network of anarchist artistic culture in Japan certainly had reciprocal impact on the work of Russian writers and artists, particularly in the vein of introducing the notion of the child as an instrumental figure within this system. This is ${ }^{110}$ Yamamoto and Yamagoshi, Yamamoto Kanae no tegami, 156. 
particularly evident in the work of the writer Vasilii Eroshenko, who traveled to Japan first in 1919 and produced a number of children's stories that, Konishi writes, "seemed to give perfect expression to the peripheral spaces of children's and animals' worlds that were understood to precede the cultural distinction between East and West, subject and object."111

Of course, Yamamoto would play an integral part in constructing this "cultural revolution" that Russian thinkers would begin to themselves emulate, once he returned from his own transformative experience in Moscow. Having spent a fruitful summer and fall in Russia, Yamamoto decided to return to Japan once and for all. A dramatized biography of the artist characterizes Yamamoto's feelings as he made preparations to return to Japan as follows:

In Moscow it was already winter by October. Yamamoto, having seen the winter scenery of Russia, left Moscow just before the Russian Revolution on December 7th, and headed to Japan via the Trans-Siberian railway. Crafts made by the poorest farmers, paintings by small children...Kanae thought while he looked at the pure white view of Siberia from his window. From the people who should be the world's least conspicuous arose these shining works. He could not help but feel it deep within his heart. So, from this voyage, that is how two ideas were borne: Free Drawing, and the Farmer's Art Movement. ${ }^{112}$

It can of course not be confirmed what precisely was running through Yamamoto's head while he was speeding through the snowscapes of Eastern Russia, though his preceding and subsequent correspondence with family members and colleagues certainly suggests that these thoughts were close to his mind. Regardless, the pensive nature of the passage neatly caps the mapping of Yamamoto's artistic and ideological oeuvre that I have charted in these first two chapters. My next discussion

\footnotetext{
${ }^{111}$ Konishi, Anarchist Modernity, 334.

${ }^{112}$ Kanda, Yamamoto no monogatari, 65.
} 
explores how Yamamoto implemented his beliefs and subsequent projects in Japanese communities, in particular Nagano. I argue that, while history has framed the Free Drawing Movement and the Farmer's Art Movement as two distinct phenomena, their greatest divergence is in name only, and they are in fact two components of a single motive: to encourage liberated creative expression within the disenfranchised peasant communities, and to set in place a system within which these communities could subsequently thrive through cooperation amongst creative individuals. I then go on to examine how Yamamoto's resulting legacy has shaped and diverged from aspects of contemporary art and art institutions in Japan that address the complicated interplay between local and translocal concerns. 


\section{Chapter Three:}

\section{Folk Art and New Modernities in Yamamoto's Inaka}

The previous two chapters examined the early stages of Yamamoto's career on both a personal and artistic level, not only in the context of his contemporaries in the art world, but also within concurrent events and frameworks in the realms of politics and philosophy. This third and final chapter incorporates the findings of these preceding investigations into a study of Yamamoto's projects upon his return to Japan, and the legacy that his particular conception of folk art has had on contemporary reconciliation of the global and the local in Japanese art. I conclude with several brief case studies of contemporary art institutions in Japan, using international art festivals and present-day folk arts as examples of how the tenets of Yamamoto's movement have simultaneously persisted and been adapted in present-day understandings of rural transnationalism.

Upon his return to Japan in late 1916, Yamamoto took over a friend's printing company, shifted his focus back to oil painting, and began to brainstorm ideas for the development of a new printmaking association. He officially established the Nihon Sōsaku Hanga Kyokai with several colleagues in the summer of 1918. A year later, he established the Japan Children's Free Drawing Exhibition and organized its inaugural exhibition in Tokyo. This project proposed a liberated approach to arts education that allowed children to exercise their creativity freely, as inspired by the exhibitions Yamamoto had encountered in Moscow. For nearly a decade, the movement was a runaway success, with his practices being implemented in public schools across Japan; as 
previously mentioned, to this day, many schools continue to take their students outside for a designated day during the school year to paint freely from nature. ${ }^{113}$

After having introduced and worked to implement these policies into public school curricula in accordance with the government, Yamamoto finally returned to his hometown of Ueda in the latter part of 1919, ready to put the second phase of his project into effect. Here he sought to use the arts as an alternative form of income for farmers during the winter months. He received financial support from the Ministry of Agriculture, Ministry of Education, and several private donors to realize this project, creating schools, classes, community events, and spaces to promote the didactic learning environment that he so sought. While in Ueda, Yamamoto continued his work on large scale educational policy change and publications. ${ }^{114}$

In 1921, Yamamoto published his book, Free Drawing Education, in which he defined the terms connected to his movement and drew an explicit line between the concepts of 'freedom' and 'creativity.' Building upon this connection, he wrote:

Our education of freedom is not to educate as teachers like. It is not a worship of freedom showing the model of freedom but to teach freedom itself...In my belief, the essence of human beings will never be improved if their freedom is restrained. At least those who don't know freedom will never grow. To enrich individual freedom is our idea of education. ${ }^{115}$

Yamamoto's movement retained popularity nationwide for the better part of a decade; in 1923, he established the Japan Peasant Art Institute, which expanded upon

\footnotetext{
${ }^{113}$ Kanae Yamamoto Memorial Museum, Yamamoto Kanae, An Essay on Kanae Yamamoto (Ueda: Yamamoto City Museum of Art, 2009), 3-4.

114 "Yamamoto Kanae ryaku nenpu" (Kanae Yamamoto in Brief), Ueda City Museum of Art, November 30, 2020.

${ }^{115}$ Takuya Kaneda, "The Concept of Freedom in Art Education in Japan," 13.
} 
receiving a large amount of government funding in $1925 .{ }^{116}$ However, the political climate changed swiftly, and when the Japanese government began moving towards a more militaristic regime in the late 1920s, Yamamoto's interest in "freedom" in education became less and less tenable on a large scale. He lost government funding and struggled to find new patrons. Yamamoto officially declared an end to the movement in 1928, and gradually the programs he had designed began to dissolve. ${ }^{117}$ For the next seven years, he withdrew from the national art scene, though he continued to write fairly prolifically for several publications and assist in the organization of several sōsaku hanga exhibitions. ${ }^{118}$ This period also marked a renewed focus on his own oeuvre. For the first time since studying in Tokyo, he returned to oil painting. This was primarily a result of the early establishment of Shunyokai in 1922, an organization that he co-founded with several colleagues to combat the permeation of the Western avant-garde into contemporary Japanese art. Yamamoto exhibited with the collective until 1935, when he held a solo exhibition in which the organization chose not to participate. ${ }^{119}$

Yamamoto's prominent role in the establishment of Shunyokai demonstrates his continued conflicted attitudes towards the relationship between Western and Japanese art. As in the case of transnational influences behind the development of sōsaku hanga and his peasant art movements, Yamamoto's criticism of art did not fall neatly on the sides of

\footnotetext{
116 "Yamamoto Kanae ryaku nenpu" (Kanae Yamamoto in Brief), Ueda City Museum of Art, November 30, 2020.

${ }^{117}$ Kaneda, "The Concept of Freedom in Art Education in Japan," 15.

${ }^{118}$ Yamamoto Kanae Memorial Museum, Yamamoto Kanae An Essay on Kanae Yamamoto, 8.

119 "Yamamoto Kanaette donna hito?" (What Kind of Person was Kanae Yamamoto?), Nagano kenden tōtekikōgeihin shitei Shinshū Ueda no kibori kōgei nōmin bijutsu (Nagano Prefecture Traditional Craft Designation: Farmers' Art and Woodcrafts of Ueda Shinshu), http://www14.ueda.ne.jp/ kiboriya/yamamoto-kanae.html (accessed April 16, 2020).
} 
binary fault lines between East and West. While he enjoyed the "realism" of several nineteenth-century French painters, he continued to deride the more abstract forms of the European modernists; namely, Picasso and Matisse. ${ }^{120}$ This suggests that Yamamoto's artistic judgements were dictated primarily by personal aesthetics and style rather than geography and culture, though these matters of taste may also have been informed by the increasing prevalence of nationalist rhetoric within art circles.

The advent of the Second World War resulted in further obfuscation of Yamamato's vision. 1937 saw the establishment of a "National Schools" system that standardized primary and secondary education. While the curricula continued to include both drawing and handicrafts, the disciplines became condensed into a single mandated textbook, with emphasis placed on the development of practical skills, such as "building motors or model airplanes." ${ }^{121}$ Though Yamamoto passed away in 1946, his ideological approach to education enjoyed a brief revival in the aftermath of World War II. The Japanese government continued to impose strict restrictions on arts curricula in schools, but a group of teachers that were disillusioned with the state of Japanese education following the war came together to create several non-government organizations, most notably Sozo Biiku Kyokai (The Society for Creative Aesthetic Education). ${ }^{122}$ In addition, a small coalition of volunteers previously involved in the Farmers' Art Movement came together in 1945 to form Nōmin Bijutsu Rengōkai (The Federation of Peasants' Art), and in the decades that followed remnants of Yamamoto's original initiatives were revived in

\footnotetext{
${ }^{120}$ Yamamoto Kanae Memorial Museum, Yamamoto no furansu, 40.

${ }^{121}$ Kingo Masuda, "A Historical Overview of Art Education in Japan," The Journal of Aesthetic Education 37, no. 4 (2003): 8.

${ }^{122}$ Kaneda, "The Concept of Freedom in Art Education in Japan," 14.
} 
Nagano. ${ }^{123}$ It was through these efforts that some of Yamamoto's ideas continue to be implemented in rural communities and in Japanese public schools today. ${ }^{124}$

After his death, Yamamoto's legacy has continued to thrive particularly well in his adopted hometown of Ueda. A now defunct hospital was named after the artist, but there is also an elementary school, and the painter/printer is one of the more notable names buried in the cemetery of the Dairin Temple in the center of the city. ${ }^{125}$ The Yamamoto Kanae Memorial Museum was established in 1962, and its collection comprised the majority of Yamamoto's own body of work, as well as many pieces produced by his pupils in the Children's Art and Free Drawing Movement. ${ }^{126}$ In 2002, the museum organized a massive retrospective exhibition, curated by Maezawa Tomomi and Yamada Toshiyuki, to celebrate its 40th anniversary and 120th anniversary of Yamamoto's birth. In the "Aisatsu" to the exhibition catalogue, the organizers remark on the far-reaching impact of Yamamoto's work despite the fact that he was not particularly prolific as an artist. In fact, they note, Yamamoto produced fewer than thirty woodblock prints over the course of his career (this number did not include designs or small images that he later made for advertisements and book covers, etc.). These prints were all produced over the course of sixteen years during the early part of his career before he returned to Japan from his travels abroad. Though the sōsaku hanga movement did not gain full steam until the years following World War II, as Alicia Volk noted in her book,

123 "Sengo no nōmin bijutsu" (War Farmers' Art), Ueda City Museum of Art, November 30, 2019.

${ }^{124}$ Kaneda, "The Concept of Freedom in Art Education in Japan," 14.

${ }^{125}$ Kanda, Yamamoto Kanae no monogatari, 3.

"Dairinji," Ueda City Website, https://www.city.ueda.nagano.jp/site/kankojoho/6023.html (accessed March 23, 2020).

${ }^{126}$ Kanae Yamamoto Memorial Museum, Yamamoto Kanae Seikatsu 120 Nenten (Ueda: Yamamoto City Museum of Art, 2002): 7. 
Made in Japan: The Postwar Creative Prints Movement, Yamamoto continues to be credited as one of the key catalysts to the movement and the ensuing appearance of emphasis on intrinsic realism and the individual creative process of the artist in modern Japanese art. ${ }^{127}$ In his catalogue essay for the exhibition, Noriyaki Seo acknowledges that Yamamoto's own artistic production stopped abruptly due to his cultural and educational pursuits, remarking that the apparent disjointed nature of the artist's interests has made it difficult at times to neatly wrap up and characterize his legacy. The secret, he argues, still remains with the prints. "The attitude that he carried toward art during the first half of his life while making prints was lifelong," he writes, "When one looks at the development of each of his pursuits that followed, his interest in integrating what was once considered to be prosaic and utilitarian into art remains wonderfully consistent.",128

This sentiment establishes a thematic contiguity with the various stages of Yamamoto's career that does not often arise in other scholarship, as most analysis of his life and work focuses either on the sōsaku hanga movement or his later educational initiatives, with the bridges between the two largely absent. In Ueda, however, this interrelatedness has been demonstrated in comprehensive retrospective exhibitions on the artist's life and work. ${ }^{129}$ The Yamamoto Museum of Art closed in 2011, and the collection was absorbed by the Ueda City Municipal Art Museum in 2014 following renovations. In addition to putting on regular exhibitions that focus on Yamamoto's work, the Ueda Museum also holds a Yamamoto Kanae Triennial, which consists of a

\footnotetext{
${ }^{127}$ Volk, Made in Japan, 5-6.

128 Noriayaki Seo, "Juyoshi ichi Yamamato Kanae no hanga wa dono yo ni miraetekitaka" (Reception History: How Were Yamamamoto Kanae's Prints Received?), Yamamoto Kanae Seikatsu 120 Nenten, 16-17. Translated by Author.

${ }^{129}$ Examples include the Yamamoto Kanae Seikatsu 120 Nenten of 2002 as well as a 2019-2020 exhibition chronicling the last century of farmers' art in Nagano.
} 
competition amongst established and up and coming contemporary printmakers.

According to the Triennial's website, the competition seeks to "highlight works that pursue originality and artistry that will advance the development of print art that Yamamoto was so passionate about. ${ }^{130}$

In the fall of 2019, the Ueda Museum housed an exhibition titled "100 Years of Farmers' Art," focusing primarily on the work of Yamamoto and his legacy. ${ }^{131}$ The exhibition took up the entirety of the museum's gallery space, following a chronological trajectory that began with Yamamoto's work as a student in Japan and then Paris, explored his encounter with the Russian Folk Arts Movement in Moscow and followed with the subsequent Children's Free Drawing and Farmer's Art Movements of the 1920s as well as their revival following the war. These works include both functional lacquerware and decorative wooden relief carvings, upon both of which persimmons were a common subject. Japanese persimmons, or kaki are a fruit found across the country, originally native to China and brought to Japan over a thousand years ago. As a national fruit of Japan, the persimmon holds a special place in Japanese folklore and is a primary symbol of autumn. ${ }^{132}$ In one piece from Yamamoto's Farmers' Art initiative, a cluster of persimmons are carved in relief into a large rectangular block of stained wood. The persimmons are vivid orange, with green leaves providing distinct contrast against the muted background.

\footnotetext{
130 "Yamamoto Print Grand Prix Competition, Triennale," Ueda Santomyuze, https://www.santomyuze.com/museumevent/7th_hangataisho-ten/ (accessed March 20, 2020).

131 "Nōmin bijutsu: jidō jiyu ga 100nenten," Ueda City Museum of Art, November 30, 2019 - February 24, 2020.

${ }^{132}$ Four Seasons in Kyoto: Festivals and Symbols, “Autumn: Season of Flame,” 2002, Kyoto Broadcasting System, https://fod-infobasecom.proxy.library.carleton.ca/p_ViewVideo.aspx?xtid=30318 (accessed April 20, 2020.
} 
The lack of functionality in objects like this is an important item of note here. Yamamoto's interest in folk arts stemmed from the idea of giving peasants without work in the colder months a sense of usefulness, and often in Russian and Japanese folk arts objects produced reflected that incentive with a utilitarian purpose. This also aligned with Yamamoto's position as a scholar of the philosophies of John Ruskin and William Morris. Morris staunchly believed in the importance of bringing elements of beauty to the everyday, and, in accordance with Ruskin, that one should "have nothing in your houses that you do not know to be useful or believe to be beautiful." ${ }^{, 133}$ While the objects produced by Yamamoto's students often had an innate functional purpose due to their use as a potential source of income, they also often existed in the form of some kind of tableaux or sculpture, suggesting that his background in painting and printmaking, as in the case of Morris, allowed for the enhancement of a space's beauty to qualify as functional usefulness. This allowance stands in contrast to aspects of other folk art and handicraft movements; for example, mingei artists largely produced objects with utilitarian function, such as ceramic vessels or clothing. ${ }^{134}$

The exhibition culminated in several galleries showcasing works from the contemporary farmers' art movement in the region. The majority of these pieces consisted of relief wood carvings, with subject matter that ranged from regional motifs to abstract representation. In Japan, regional products and goods continue to be an integral

${ }^{133}$ Mark Bevir, The Making of British Socialism (Princeton: Princeton University Press, 2011), 88.

${ }^{134}$ This was due to Yanagi's belief that folk crafts obtained beauty through use. Brian D. Moeran explains: "If a craft was not used it would lose its raison d'être...The more a thing was used, the more beautiful it became. That was why, in Yanagi's opinion, the act of creation alone was not sufficient to give a thing beauty." Brian D. Moeran, "Yanagi Muneyoshi and the Japanese Folk Craft Movement, Folklore Studies 40, no. 1 (1981): 96-97. 
part of local and national society and culture; goods for which a region is known are dubbed meibutsu, a term imbued with an automatic and specific sense of collective local pride. ${ }^{135}$ While certain regions of Nagano are well-known for things like oyaki (a small dumpling), soba, and yuzu, one of the lesser-known meibutsu of the prefecture are akebi, or "chocolate vine," which produces an oblong fruit with a purple husk containing a sweet tuberlike cluster of seeds within.

Harvested in the autumn months, the consumption of akebi has waned in Japan over the course of the past century. The sweet center was previously served as a delicacy, while the rind is occasionally sliced and fried as a vegetable component in a meat course. In the past, the vine itself of certain varieties was sometimes used to weave baskets. ${ }^{136}$ In the Ueda City Museum exhibition, local artist Yokokawa Yoshimasa's Akebi uses the same wood carving relief technique employed by his predecessors to create a stylized rendering of the fruit (fig. 10). Set within a black frame, three clusters of akebi fruits sit within a backdrop of green leaves. Lacking the same stately level of naturalistic details as the previously described persimmons, the bold contrast of the rich and vivid color palette against a black background and border, as well as the oblique stylization of the fruits themselves evokes an aesthetic stereotypical of modernity that stops just short of whimsy.

This mode of stylization allows for the artist to stay true to the naturalist subject's form yet simultaneously provide a dynamic, emotional dimension to the work, compatible with the type of so-called "realism" that Yamamoto championed during the

${ }^{135}$ Jerry Chi, Foster Chiang, Russell Gottfredson, Neeraj Maathur and Erica Sugai, "Meibutsu: The Economic and Cultural Significance of Traditional Japanese Products, Knowledge@Wharton, The Wharton School of Business, https://knowledge.wharton.upenn.edu/article/meibutsu-the-economic-and-culturalsignificance-of-traditional-japanese-products/ (accessed April 20, 2020).

${ }^{136}$ Dai Nihon Nōkai, Useful Plants of Japan Described and Illustrated (Tokyo: Agricultural Society of Japan, 1895), 58, 76-77, 92. 
Taisho and Showa Periods, yet simultaneously very distinct from it. As in the case of the earlier examples by mid-twentieth century folk artists, akebi depicts a local fruit using local wood to dictate its general form. However, despite the similarities between these works produced over a period of half a century, there are some marked stylistic differences as well.

The similarity in materiality of these pieces also poses a question that explores the ever-confounding nature of contemporaneity, hinted at in a separate argument made by Bert-Winther Tamaki in his essay, “The Ligneous Aesthetic of the Postwar SōsakuHanga Print Movement and American Perspectives on the Japanese Culture of Wood.” Tamaki's observations on the importance of wood as a material in Japanese art from both a historical and contemporary standpoint surfaces as he explores the overseas American interest in Japanese woodblock prints at the time:

Even in recent years, Japan has continued to be regarded as something of a mecca for lovers of fine woodwork, ranging from unpainted timber architecture to a wide variety of utilitarian and aesthetic objects crafted of wood. Perhaps because printmakers' skill with the woodblock induced a sense of attachment to this broader culture of wood, wooden architecture and artifacts such as Buddhist temples and altar sculptures are among the motifs they favor. Moreover, some prints bring the viewer into a more direct confrontation with the physical and aesthetic properties of wood as a material. $^{137}$

This tension becomes more explicit later on in the essay as he describes the motives of American collectors James Michener and Oliver Statler behind their passion for sōsaku hanga. While Tamaki does acknowledge a certain element of exoticism that

${ }^{137}$ Bert Winther-Tamaki, "The Ligneous Aesthetic of the Postwar Sosaku-Hanga Print Movement and American Perspectives on the Japanese Culture of Wood," Archives of Asian Art 66, no. 2 (Durham: Duke University Press, 2016): 216-217. 
lies somewhere near the crux of this interest, he also uses their observations to add to his own point:

The affirmation of a Japanese aesthetic of rustic wood would seem to play into a depreciating contrast with industrial materials associated with modernized or advanced nations. Nevertheless, to their credit, Michener and Statler strongly and repeatedly defended and valued the modernity and cosmopolitanism of this contemporary Japanese art form. Thus, it would be unfair to view their embrace of contemporary Japanese prints as adhering to the Orientalist paradigm that cast modern Asian people and culture into a fossilized past. ${ }^{138}$

While the wood carvings of the Farmers' art movement and sōsaku hanga prints of the postwar years are not the same art forms by any means, there does exist a common theme in both mediums and movements regarding the temporal ambiguity of the wood as medium. On the one hand, it fosters connotations of rusticity and reflects back at traditional Japanese art forms. However, on the other, the similarity of material serves as a pointed reminder of dramatic evolutions in style and form, as we can see in another contemporary work from the recent Ueda exhibition (fig. 11). The work depicts a cluster of Chinese lantern flowers etched in relief from the corner of a wooden cube. Other pieces are far less representational, pieces of curved wood stained in dark and light shades that play with the abstraction of light and form, as seen in another piece from the same exhibition (fig. 12). Considering Yamamoto's abhorrence of the highly stylized forms favored by Picasso and Matisse, the permeation of such abstracted subject matter in contemporary Farmers' Art is distinctly ironic.

That said, this shift is simultaneously demonstrative of the temporal dynamism of the Farmers' Art Movement. Almost in tandem with the ambiguous temporal materiality of its art, contemporary approach to Farmers' Art in Ueda professes a similar reclamation

${ }^{138}$ Winther-Tamaki, "The Ligneous Aesthetic of the Postwar Sōsaku-Hanga Print Movement," 220. 
of a traditionally primitivized medium as modern. A wall text for "100 Years of Farmers' Art" reads: "Efforts for the 'next 100 years' are gradually progressing, but in the future, efforts will be made to develop new peasant art...and to discover and nurture human resources who will lead the next generation." 139 This statement suggests that present-day practitioners of Farmers' Art in Ueda do not view their work as simply a static replication of a traditional art form, but a living and evolving contemporary genre that is constantly subject to change and innovation.

While many museums and events in Ueda commemorate Yamamoto's legacy explicitly, there remain echoes of the work of Yamamoto and his contemporaries in many present-day Japanese art institutions. The latter often seek to transcend, or find themselves at odds with, the tensions between the same socially constructed binaries that the pioneers of movements like sōsaku hanga and the various folk arts movements confronted: tradition and modernity, rural and urban, and the local and the translocal. Due to feasibility constraints, I do not have the time or means to delve into each of these examples here, but I will discuss two case studies that I find to be illuminating in regards to two different manifestations of these conflicts that arise.

\section{The Space Between Time: Echigo Tsumari and Kurokawa nō}

The Echigo Tsumari Art Triennial (ETAT) is a modern art festival held every three years in Niigata Prefecture, located on the Sea of Japan. Nestled between the water and the mountains, the Echigo-Tsumari Art Field opens to the public every spring, and comprises a network of contemporary art museums and open air installations that seek to

139 “"Tsugi no 100nen' ni muketa atarashitanana torigomi” (New Initiatives for the "Next 100 Years"), Ueda City Museum of Art, November 30, 2019. 
propel the Art Field's mission of, in light of global environmental concerns, structuring

new ways of thinking and engaging with the natural landscape through the vehicle of art.

The English version of Echigo-Tsumari's official website reads:

Echigo-Tsumari is known for heavy snowfall in winter. This motivates cultural exchanges based upon the principle captured by the Japanese expression "seikô udoku; kakô tôdoku", which can be rendered in English as "In summer, cultivate the fields; in winter, cultivate the mind." Cultural facilities, created by global artists and run by local people, warmly welcome visitors and travellers. In viewing the artworks, the visitor passes through terraced rice fields and forests of native beech, encountering festivals and traditional customs, thereby experiencing the landscapes and cultures of Echigo-Tsumari through all five senses. Through this experience, we recover the memories of an origin that we had forgotten, and develop new links connecting people to each other and to the land. ${ }^{140}$

The Triennial brings together artists from all over the world, and is organized by the Tokyo gallery Art Front Gallery, but, despite this globally-minded framework, the organizers of the festival maintain a self-professed focus on the connection to the natural landscape and local culture. ETAT may find itself innately tethered to an urban center which complicates its efforts, but Niigata-native Fram Kitagawa, the chairman of Art Front Gallery and overseer of the triennial, argues for the cruciality of the rural landscape as a pillar for a restructuring of what constitutes contemporaneity. In the introduction to the inaugural issue of Art from the Land, a web-based periodical produced by ETAF, he writes:

While some people think that "contemporary art is a way to engage with the problem of a city and therefore the leading edge lies in a metropolis", I would disagree. Over years, I have been made aware of the significance of presenting the Echigo-Tsumari Art Triennale in a place like Echigo-Tsumari.

Artworks are produced and appreciated in a space consisting of multiple layers of a place - nature, history and the life of people bring

\footnotetext{
140 "What is Echigo Tsumari Art Field?", Echigo Tsumari Official Site, www.echigo-tsumari.jp/eng/about (accessed September 23, 2020).
} 
different attractions to people as opposed to viewing artworks in a white cube, as if conducting chemistry experiments. ${ }^{141}$

In writing and interviews, Kitagawa does not appear to ever mention Yamamoto's work by name as a source of inspiration, though he has invoked in interviews the works and projects of the celebrated Japanese novelist and children's author, Miyazawa Kenji, whose name is often cited in tandem with Yamamoto in literature on Japanese education and rural art movements. Miyazawa was born in 1896 in Iwate Prefecture in the northeastern corner of Honshu. While he promoted many of the same ideals as Yamamoto, such as freedom and creativity in children's education (though perhaps not expressly characterized as such) and an interest in a return to an agrarian societal model, the two thinkers' views diverged in several distinct areas. Firstly, Miyazawa was a devout Buddhist, and his religion played a formative role in how he perceived the world and produced his art, a foundational difference that stood in stark contrast to Yamamoto's secular approach. In addition, Miyazawa's educational background was in agricultural science, and he taught this subject for several years before moving on to more expressly literary ventures. Subsequently, whereas Yamamoto's primary focus was art and its compatibility with an agrarian lifestyle, Miyazawa's interest was in agricultural communities and their compatibility with the arts.

Miyazawa's literary works themselves provide an abundance of thematic and structural fodder to inform the reconciliation of the local and the translocal that permeated not only the peasant arts movements in Japan but also the contemporary structures designed by figures such as Kitagawa. Miyazawa began writing at a time when

\footnotetext{
${ }^{141}$ Fram Kitagawa, "On the Inaugural Issue of the Web Magazine, Art from the Land," Art from the Land 1 (September 30, 2019), https://www.echigotsumari.jp/en/media/190930-kitagawafram/ (accessed April 16, 2020).
} 
Tokyo was the center of the Japanese literary world, both in location of production and fictional settings. He felt that there were issues that arose from such a universal creative pursuit finding a fixed nexus in the capital, and in response sought to, as Hoyt Long writes, "develop representational strategies that linked the narrative locus and actual site of writing in Iwate (the where) with attempts to critically reimagine this locus in ways that countered or contradicted the expectations of those at the center (the what)."142 In regards to his own inspiration, Kitagawa has specifically invoked Miyazawa's Rasuchijin Society, which the latter established in 1926 in his home prefecture of Iwate. ${ }^{143}$ Miyazawa never provided any reasoning behind the name "Rasuchijin," though the kanji 池 (chi) and 人 (jin) translate to “earth" and "man” respectively. Miyazawa's Rasuchijin Society focused on improving agricultural practices in the region, and he supplemented the daily labor with musical performances, literary readings, and other cultural events. After a tumultuous two years, the Rasuchijin Society closed, though the location has since been converted into a museum and is open to the public to this day. The ultimate failure in execution of Miyazawa's vision has been attributed to a number of factors, including resistance by many of the locals to Miyazawa coming into the region after spending much of his career in major city centers to teach them how to farm their own land. ${ }^{144}$ However, despite its untimely end, Long also remarks on the broader historically instructive purpose that projects like Rasuchijin can serve in his prologue to

\footnotetext{
${ }^{142}$ Hoyt Long, On Uneven Ground: Miyazawa Kenji and the Making of Place in Modern Japan (Stanford: Stanford University Press, 2011): 10.

${ }^{143}$ Editorial Department, "Intabyū: Kitagawa Furamu (Kōhen)" (Interview: Fram Kitagawa, Part 2), Art iT Magazine, https://www.artit.asia/u/admin_interviews/TcQwSJKyouAFlOng4MUL (accessed February 4, 2020). ${ }^{144}$ Donald Keene, Dawn to the West: Japanese Literature of the Modern Era, vol. 4 (New York: Columbia University Press, 1999), 288-289.
} 
The Making of Place. The system of contemporary rural locality that Miyazawa, and, I would note, his contemporaries, put in place operate within a nuanced algorithm of potential and limitations, with Long expounds upon below:

...These activities, when set against parallel efforts by Tokyo-based intellectuals and the backdrop of a rapidly transitioning rural society, have to tell us about the institutional pathways (cooperatives, schools, political groups, artist coteries) and many discursive channels (public lectures, regional newspapers, foreign translations, mimeographed pamphlets) available in the interwar period for reinventing rural locality in real time. I am interested in how Miyazawa used these to translate thought into action and to make the local feel socially and culturally relevant, but also in how these same pathways and channels circumscribed what was possible for him to achieve. ${ }^{145}$

Long expands upon this rumination on the symbiotic nature of the relationship between cultural understanding of rural and urban spaces in the following pages as well:

For not only does it underscore the radical multiplicity of "the local" as a site of identification, suggesting that this multiplicity is partly generated by the uneven ways that discourse about a place, and the actions taken there, enter wider networks of cultural production, it also raises important questions about how this unevenness impacts the potential of things said and done locally to work back upon the physical and cultural character of a place. ${ }^{146}$

With this passage, Long endows Miyazawa with an understanding of spatial complexity that creatives have struggled to negotiate to this day. In a rural, peripheral space like Iwate or Nagano, artistic production entered into this complex network of center and periphery and the liminal space between and found its meaning and reception morphed by a reciprocal cultural relationship. For example, the Farmers' Art Movement may have begun in Ueda as a means for peasants to regain their agency as producers but

${ }^{145}$ Long, On Uneven Ground, 12.

${ }^{146}$ Ibid, 13. 
also to gain a foothold on the present-day art scene in early to mid-twentieth century Japan. The creation of this movement simultaneously informed and fed into a larger narrative of rurality produced by the so-called 'center;' in this case, the imperial capital.

In the case of Yamamoto, the prevailing conflation of the rural with the primitive, as James Mark Shields pointed out in regards to Russian folk art, often undercut and morphed the perception of what he was trying to achieve in the art world, and continues to encounter primitivist rhetoric to this day. While his legacy remains powerful within Japan, that legacy remains, more often than not, firmly shackled to its engagement with the reductive binary of tradition and modernity, two terms that, as the ambiguity and nuance of artistic production in these rural spaces prove, are nothing more than culturally constructed fictions.

In many ways, Yamamoto and Miyazawa's difficulty in finding a footing for a sense of rural modernity in an industrialist world foreshadowed the parallel struggles of the contemporary rural art institutions of the present-namely, those that attempt to bridge the gap between the local and the global.

For example, ETAT has encountered its fair share of debate regarding its own degree of success in these efforts. On the one hand, scholar Brad Monsma has remarked on the uniquely rural positioning of the Triennial, and how the location yields a thematic departure from the "festivals in Japan and elsewhere that are urban and centralized, linking art with international commercial development." In contrast, he writes, "EchigoTsumari is rural, scattered throughout 750 square kilometres, and insistent upon the local and what cannot be commodified." 147 However, this rather utopian framing of the space

\footnotetext{
${ }^{147}$ Brad Monsma, "The Distributive Agency of the Echigo-Tsumari Triennale," Journal of Contemporary Chinese Art 3, no. 3 (September 2016).
} 
and its festival contrasts with the arguments of several other scholars, who contend that ETAT's good efforts remain muddled by its intrinsic link to some of the more nefarious side effects of the consumerist global art scene, and that this foray into necessary commodification has come at the expense of the preservation of local culture and ways of life.

Ewa Machotka explores the dynamic between ETAT's mission and the results through one of the foundational principles of its approach to eco-art, satoyama, "which evokes a harmonious coexistence between humans and nature." ${ }^{\prime 48}$ The term has become popular not only in Japan but as a worldwide "buzzword" for compatible environmental efforts across the globe. However, as Machotka points out, often ETAT's exhibitions and projects expand to themes beyond eco-art that broach a far broader scope of both local and global social and cultural issues, a diversity of narratives that may be diluted by its efforts to brand itself for a specific global marketing narrative. "Is satoyama," she writes, “simply 'co-opted' or 'consumed' by ETAT as a component of the marketing industry that has been engineered to revitalize the region?"149

To answer this question, Machotka explores the broader impact that contemporary art festivals have on the local regions in which they are held:

Today festivals are no longer ritualistic, recurrent short-term events affirming social, religious, ethnic, national, or historical bonds, but also function as sites for the consumption of experiences that involve capitalist markets, sets of social relations, and flows of commodities...There is little doubt that biennales are entangled in the festivalization of art. They also play a vital role in the process of enhancing the cultural capital and economic value of the locations in which they take place. ${ }^{150}$

${ }^{148}$ Ewa Matchotski, "Consuming Eco-Art Satoyama at the Echigo-Tsumari Art Triennial," in Katarzyna J. Cwiertka, Ew Machotka, eds., Consuming Life in Post-Bubble Japan (Amsterdam: Amsterdam University Press, 2018), 217.

${ }^{149}$ Ibid, 226.

${ }^{150}$ Ibid, 227. 
She goes on to contend that what sets ETAT apart from other biennials and triennials of its kind is that it is not a temporary fixture in the community, but one that has entrenched itself deeply within the fabric of the local culture and economy. Works by celebrity artists around the world remain in the Art Field as permanent fixtures, while the town also has a permanent art museum, the Echigo-Tsumari Satoyama Museum of Contemporary Art. While Machotka acknowledges that ETAT's presence has certainly commodified and promoted the "sentimentality" of concepts like satoya, she pushes back against the idea that the institution should be perceived as a "large satoyama Disneyland. ${ }^{, 151}$ She writes:

...It is not surprising that, although it is often overlooked or looked down upon, ecological art is closely entwined with exchange and consumption. This is grounded in the nature of art itself and its relationships with reality. Culture and art are inseparable from their production context and they are not autonomous but an integral part of society. If capitalism structures certain societies, in a society where 'commodification is dominant, everything that is external to this commodification becomes marginal, liable to be socially irrelevant or merely yet-to-be-commodified.' Thus, consumption cannot tarnish 'pure ecological art,' as both are products of the same socio-cultural, political, and economic conditions. ${ }^{152}$

Machotka makes a valid and compelling point in the context of eco-art specifically, considering the conditions of its development as summarized above; however, I would argue that her claims regarding capitalist structures are less convincing when we apply them to her previous discussion regarding the festivalization of local culture. While "production context" is certainly an intrinsic element of art within a capitalist society, at the same time, small scale consumerism cannot be conflated with its

${ }^{151}$ Ibid, 231.

${ }^{152}$ Ibid, 231-232. 
large scale counterpart, and these differences of context and conditions must be

reconciled when introducing local, rural arts contexts to translocal ones.

The introduction of a paper by Thekla Boven demonstrates just how complicated

the quest for achieving a successful dialogue between the local and the translocal can be.

Speaking of criticisms of Echigo Tsumari within academia, Boven writes:

For instance, after conducting a social study on the different actors involved in the process of installation art, Suzane Klien criticized the festival's framework as having "merely achieved a nostalgic romanticization of regional values and lifestyle," and thus failing to engage the locals in a self-sufficient cultural, socio-economic nexus." In other words, to put it harshly, short-term economic profit has managed to divert the attention from actual local revitalization. But as Gibson states, practices of cultural revitalization were inherited from urban contexts and capitalist customs, which can at times mislead similar practices to address the specificity and key issues of the rural setting - whether it is in the process of making artworks, reviewing them or assessing their meaning in regards to a rural environment in decline. ${ }^{153}$

Large international festivals and contemporary art institutions like Echigo

Tsumari and Naoshima are not the only present-day rural art establishments that face challenges and scrutiny. Japanese folk arts also struggle to reconcile their conflicted relationship with tradition and modernity. Kurokawa nō, for example, is a traditional Japanese performing art that originates in the rural town of Kurokawa, a small village located in the outskirts of the city of Tsuruoka in Yamagata Prefecture. Nestled within the Shonai Plain and tucked between several mountains, Kurokawa is a prolific producer of rice and, as I will discuss below, a celebrated branch of Japanese theater. ${ }^{154}$

\footnotetext{
${ }^{153}$ Thekla Boven, “Assessment of Echigo Tsumari's Repurposing of Schools: For a Locally Designed Culture-Led Revitalization of Assets in Declining Rural Areas," AIJ vol., 81, no. 730 (December 2016): 2693.

154 Grossman, Kurokawa nō: Shaping the Image and Perception of Japan's Folk traditions, Performing Arts and Rural Tourism, 9.
} 
Eike Grossman notes the paradoxical situation that Kurokawa nō finds itself in. On the one hand, it is a traditional performance art that is an integral arm of the community. However, since the government designated it within a group of folk traditions that were regarded as "national important, intangible folk cultural properties in 1976," there is also a kind of national responsibility that Kurokawa nō is expected to uphold. The town receives public funding to support the art, and, as many tourists flock to the region every year as a result, this integral aspect of the local culture takes on an internationally commodified form. This newfound identity of Kurokawa nō places it into another ironic situation: the necessity to treat Kurokawa nō as a relic of the past and perform that past as a means of collective survival in the present. "In order to obtain government funding for community development projects," Grossman writes, "communities promote their local traditions as important cultural properties. With this recognition traditions have been increasingly regarded as a device to attract visitors to remote areas and communities are urged to adapt to new audiences and performance contexts."155

It is also interesting to examine the manifestations and predicaments of presentday folk art in parallel with Yamamoto’s folk arts movements nearly a century prior. Where Yamamoto sought to use art as a means of providing income and value to farmers' time during the off-season, today the offseason becomes a hindrance rather than a help through a phenomenon known as dekasegi, which results in an absence of work opportunities in small farming communities, particularly during the offseason. In the case of Kurokawa, Grossman explains, farmers are forced to travel to find work elsewhere,

155 Ibid, 15. 
which disrupts the staging of events integral to kurokawa $n \bar{o} .{ }^{156}$ As in the case of ETAT, wide scale tourism and consumerist culture becomes a necessary arm of rural contemporary art. However, I contend that this intrinsic bind to spectacle has the potential to dilute the message behind these artistic projects, and perpetuate the longstanding narrative of the rural as an archaic, and even primitive, periphery to the urban center.

${ }^{156}$ Ibid, 16. 


\section{Conclusion}

This thesis has explored the life and work of Yamamoto Kanae, focusing primarily on three specific periods in his life: his time spent in Paris, Moscow, and Ueda. In my analysis of his activities within the context of his contemporaries and concurrent political and cultural events, I have sought to synthesize his disparate, yet interconnected work with sōsaku hanga, the Children's Free Drawing Movement, and the Farmers’ Art Movement to articulate a congruent narrative of Yamamoto's approach to art.

My original objective with this analysis, aside from providing a comprehensive English-language monograph to a body of literature in which Yamamoto has previously been largely a supporting actor for broader narratives on Japanese Creative Prints, folk arts, and education, was to use Yamamoto as a case study to reassess understandings of modernity in rural spaces - particularly in the context of folk art — and point to paths of reconciliation of pre-existing urban-rural and local-translocal binaries. While this objective remained an integral component of my argument, as I researched and wrote over the course of the past year, the stakes evolved to create a far more multivalent enterprise. The contextualization of Yamamoto within and broader assessment of these binaries raises existential questions about notions of contemporaneity in rural art that moves beyond form and prompts spatial and temporal considerations, which in turn connect to the role that present-day structures, such as the contemporary manifestation of capitalism, play within these frameworks.

In capitalist societies, for example, consumerism is obviously a necessary aspect of societal structure. However, as I noted in Chapter Three, small-scale free market economies are not easily translated to these practices on an international scale. This 
becomes an obstacle as rural spaces are introduced within a global context; in many aspects of society, including facets of the art world, commodification has become a dominant part of a collective understanding of transnational modernity that, if not carefully negotiated, has the potential to dilute defining aspects of local culture. Subsequently, rural arts face a conundrum in finding a way to situate themselves within a contemporary transnational context, one that does not require either falling into the pitfall of primitivist kitsch and commodification or sacrificing identity to fit within a narrow prevailing model of modernity.

This economic aspect is one of several areas in which the narrative relationship between the local and the translocal and the rural and urban requires nuancing, including existing rhetorical frameworks and vocabulary. This nuancing in turn requires a reframing of the rural within art historical discourse, one that allows for contemporaneity without a necessary link to urbanity. I propose that this restructuring begins with a reexamination of, not only existing spatial frameworks, but temporal ones as well. Eliminating the longstanding center-peripheral construct of the urban and the rural in this way can facilitate further deconstruction of additional social, cultural and geographical binaries in our current discourse that have historically perpetuated power imbalances.

In order to create these spaces, constant examination and reimagining of these relationships is also necessary. Excellent work has been done in these arenas already; the ever-evolving discourse on transcultural theory, as well as issues of comparison, is paving the way and providing a nascent vocabulary for these conversations to take place. ${ }^{157}$ Comprehensive case studies that conceive of new relationships between

${ }^{157}$ Several examples include Monica Juneja's work with transcultural theory and Jaś Elsner's Comparativism in Art History. 
modernity and rurality or locality provide working models for the type of nuanced engagement with these topics that is possible, from Partha Mitter's The Triumph of Modernism to Reiko Tomii's aforementioned Radicalism in the Wilderness. ${ }^{158}$ However, there is still an abundance of material left to be explored, and new ways of framing and articulating this discourse in institutional settings.

The cultural and political relationship between Russia and Japan as viewed through the lens of Yamamoto's experience became an unexpected focal point of my thesis. Originally, the Russia connection was intended to be a passing anecdote, an observation of a seemingly one-directional transmission of influence that served as a mere catalyst for the work that Yamamoto later did in Japan, as well as a tangential path to unpacking the socioeconomic debates that have persisted in local and translocal arts since that time. Yamamoto only spent a few short months in Moscow, and, as a result, both the literature and available correspondence directly germane to this sojourn is limited. I quickly realized, however, that the artistic and political dynamic between Japan and Russia during this time period contains a rich trove of potential scholarship far beyond the link between Yamamoto and Tolstoy. Both figures, in their respective

Monica Juneja, “'A Very Civil Idea...' Art History, Transculturation, and World-Making - with and Beyond the Nation," Zeitschrift für Kunstgeschichte (Journal for Art History) 81, no. 4 (December 2018): 461-485.

Jaś Elsner, Comparativism in Art History (London: Routledge, 2017).

${ }^{158}$ The Triumph of Modernism examines "the intricate interplay of Western modernism and Indian nationalism in the evolution of colonial-era Indian art." However, it also analyzes this relationship within the context of local arts and community in colonial India.

"The Triumph of Modernism," University of Chicago Press Books, https://press.uchicago.edu/ucp/books/book/distributed/T/bo5456457.html (accessed April 30, 2020).

Partha Mitter, The Triumph of Modernism (Chicago: University of Chicago PressReaktion, 2007).

Reiko Tomii, Radicalism in the Wilderness (Cambridge, MA: The MIT Press, 2016). 
navigation of complicated relationships with the establishment, and specifically their national governments, harbor seemingly contradictory and uneven ideological narratives that, when examined holistically, actually provide a cogent vision of the distinct moment of ideological flux emblematic of the turn of the twentieth century. These narratives are particularly striking and rich in nations whose positions as international powers were uncertain during that time.

The resulting dynamic between Japan and Russia, as Konishi alludes, demonstrates a situation of transnational fluidity that subverts, not only archaic binaries of East and West, but also subsequently many of the pitfalls of comparison subject to cultural and political power imbalances. ${ }^{159}$ Russia, as a power located at the geographical center between Europe and Japan, also has a muddled identity during this epoch. Both nations find their political identities compromised by their own struggles with their national and international ones and the narratives that they were seeking to construct both internally and externally. The niche space where Russian and Japanese art history meets provides a fascinating working ground for transnational interaction during the early twentieth century, as well as transcultural diffusion. This understudied field has the potential to yield fascinating insights on the nature and manifestations of influence, as a point of comparison for a more comprehensive debate about modernity in rural folk arts that I was only able to explore thoroughly from the standpoint of Yamamoto in this project.

With so many rich potential avenues left unexplored, this thesis can serve as a springboard to a variety of further research. Moving forward, it would be interesting to ${ }^{159}$ Konishi, Anarchist Modernity. Rita Felski and Susan Stanford Friedman, Comparison: Theories, Approaches, Uses (Baltimore: Johns Hopkins University Press, 2013). 
pursue a more comprehensive integrated analysis of notions of modernity and contemporaneity in Russian and Japanese folk arts. From an educational perspective, with arts education dwindling worldwide, it would be useful to further study the legacy of Yamamoto's Free Drawing Movement and other educational efforts in modern pedagogies, in Nagano and beyond, and potentially use these findings to propose effective developments in both school arts curricula and public arts education internationally. Lastly, I would be interested in exploring a more comprehensive study of the relationship between anarchism and art in Japan in the twentieth century, as I believe that there is much more to be unpacked that I was only able to briefly touch upon here. Yamamoto Kanae's complex approach to art and life may be challenging to unravel, particularly considering the ways in which his public ideologies and inspiration often contradicted his professional associations. Simultaneously, however, he was constantly blurring, if not obliterating, the lines between established demarcated understandings of time, place, and politics, and he therefore serves as an ideal case study for a contemporary approach to art history that seeks to break down binary frameworks and replace them with more nuanced models. 


\section{Appendix I: Images}

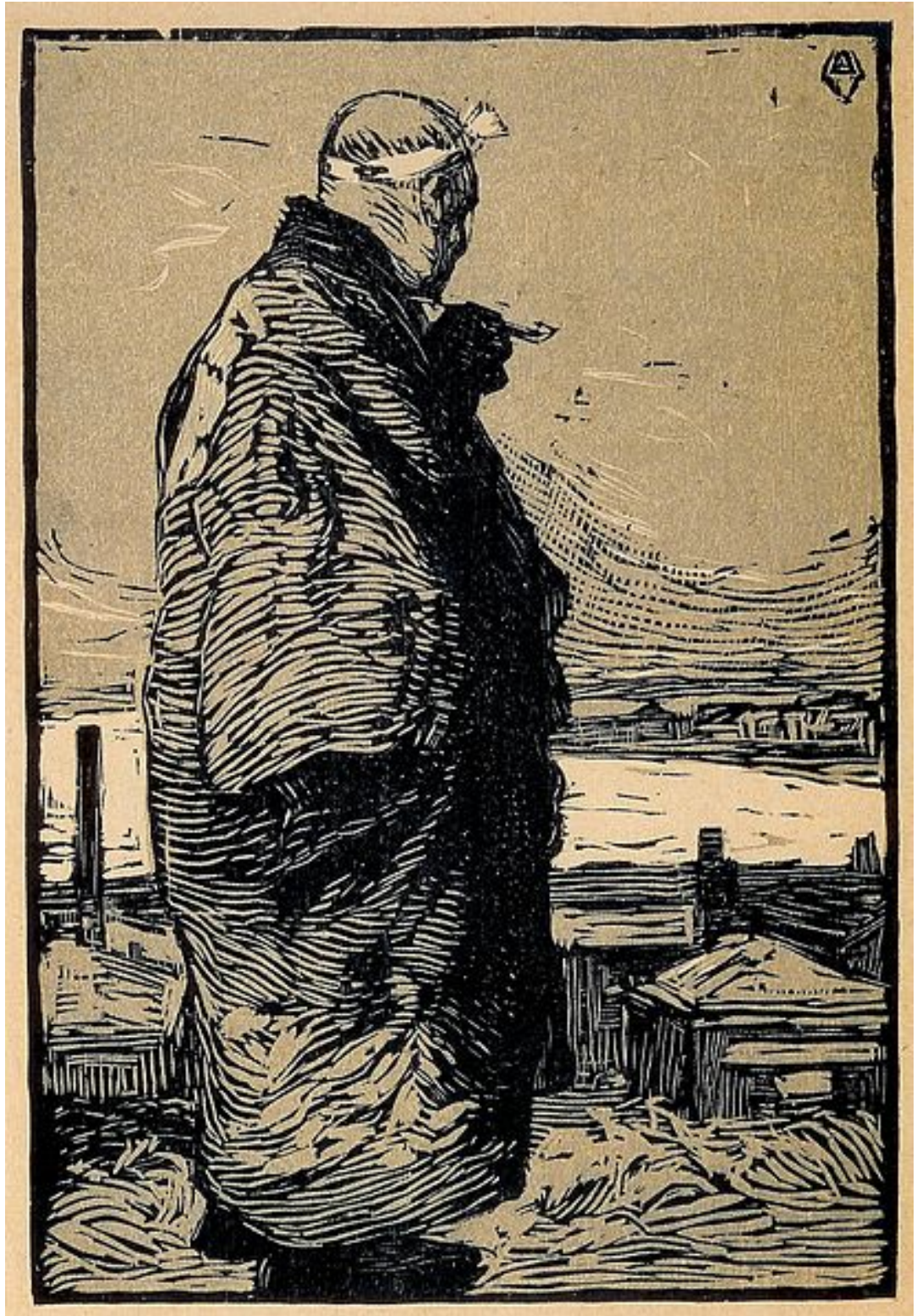

Fig. 1 Kanae Yamamoto, Gyofu (Fisherman), 1904, woodcut, 26.0 x 18.7 cm, Ueda City Museum of Art, Ueda. 


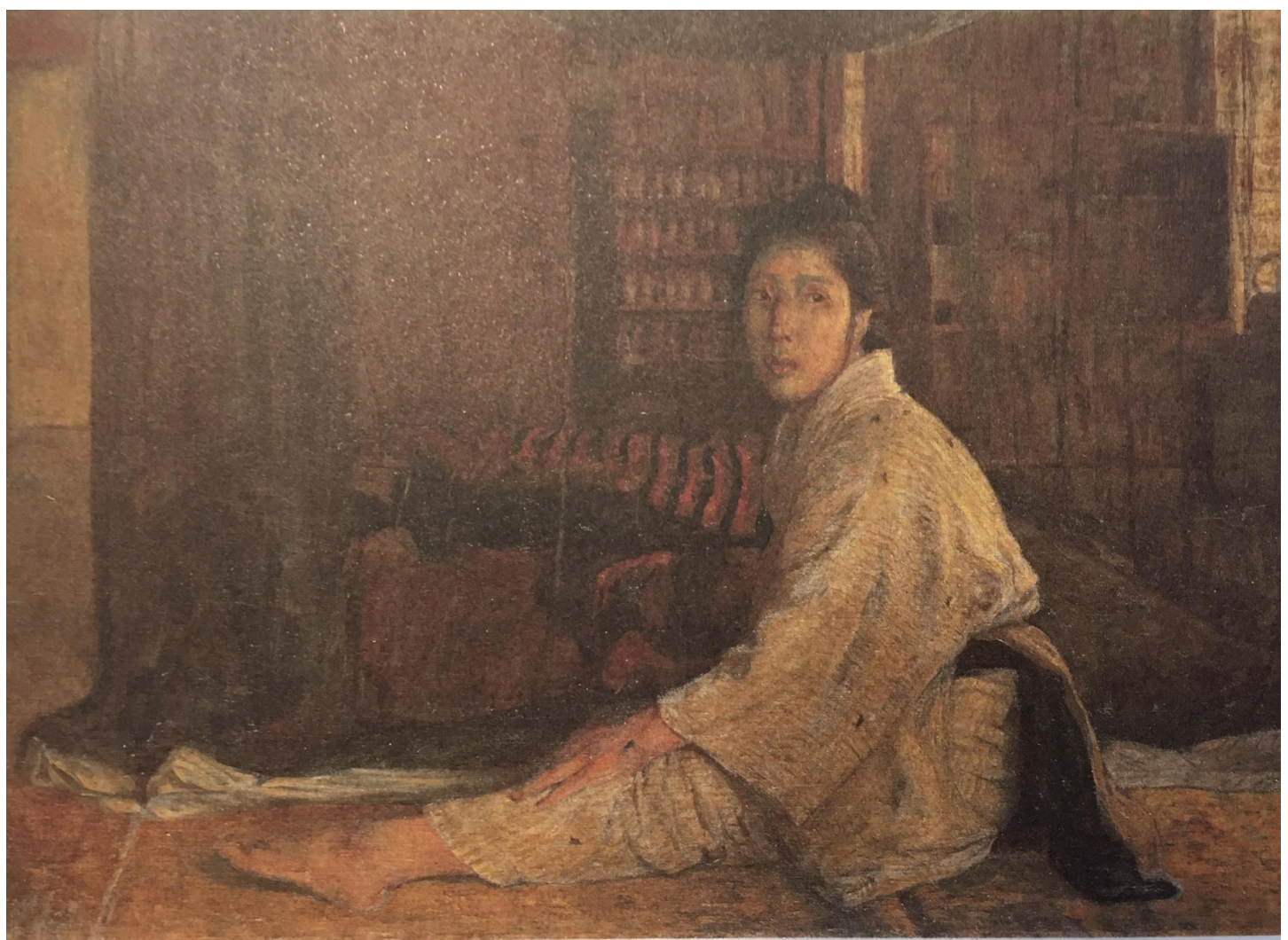

Fig. 2 Yamamoto, Kaya (The Mosquito Net), 1906, oil on canvas, 72.7 x $100 \mathrm{~cm}$, , Ueda City Museum of Art, Ueda. 


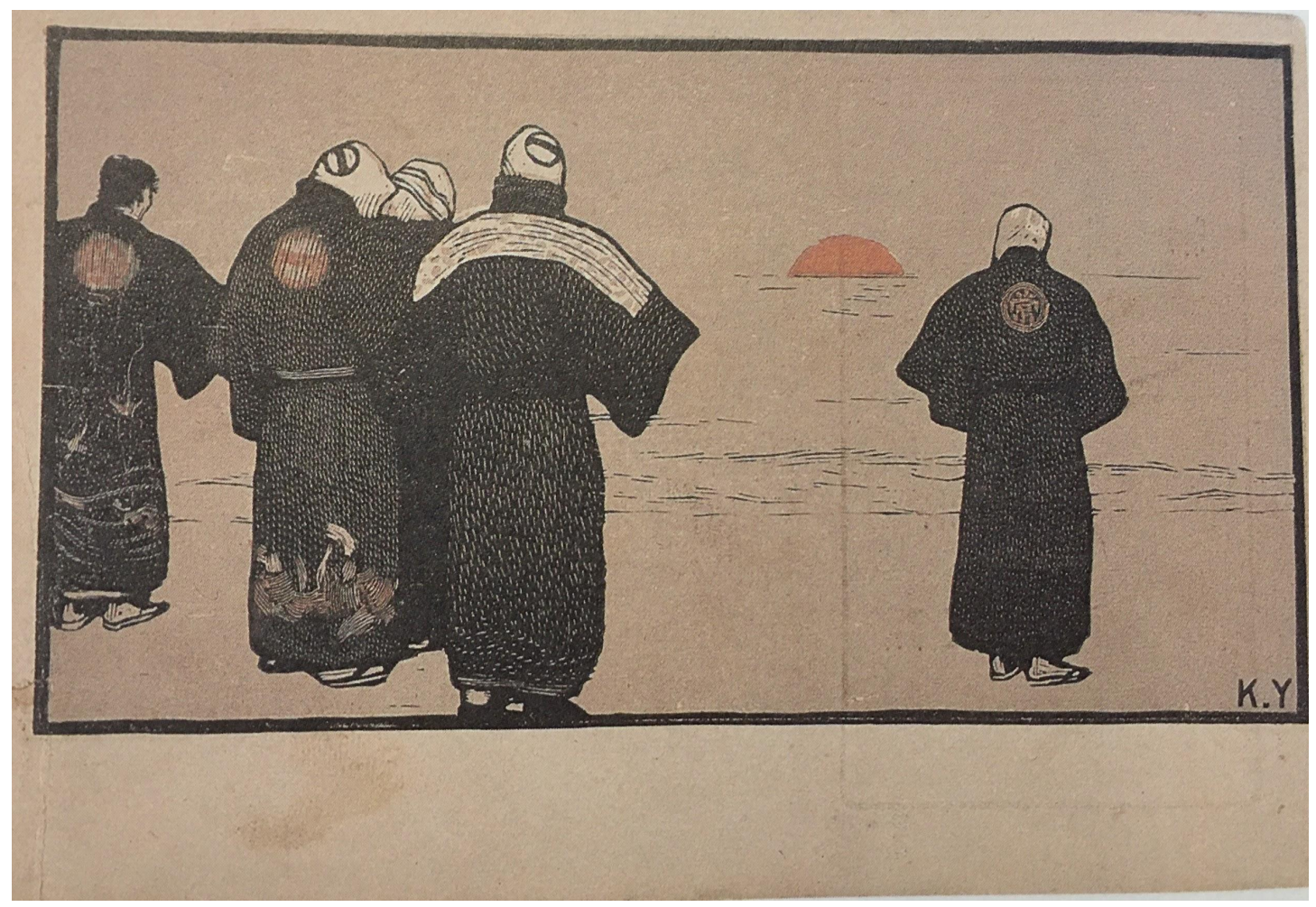

Fig. 3 Yamamoto, Hagaki (Postcard), 1917, woodcut, Ueda City Museum of Art, Ueda. 


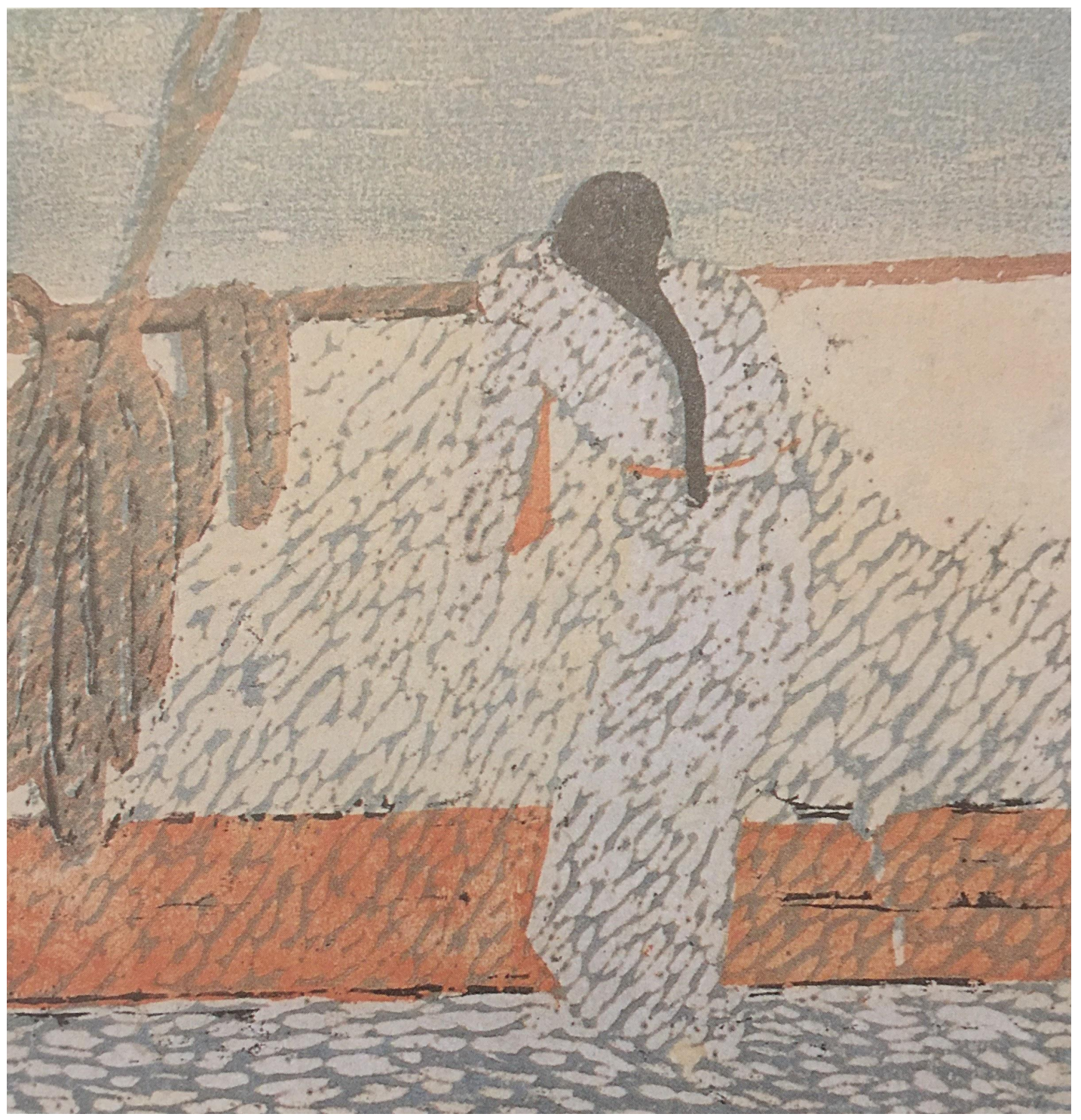

Fig. 4 Yamamoto, Dekki no ichigu (A Corner of the Deck), 1912, woodcut, 17.7 x 17.0 $\mathrm{cm}$, Ueda City Museum of Art, Ueda. 


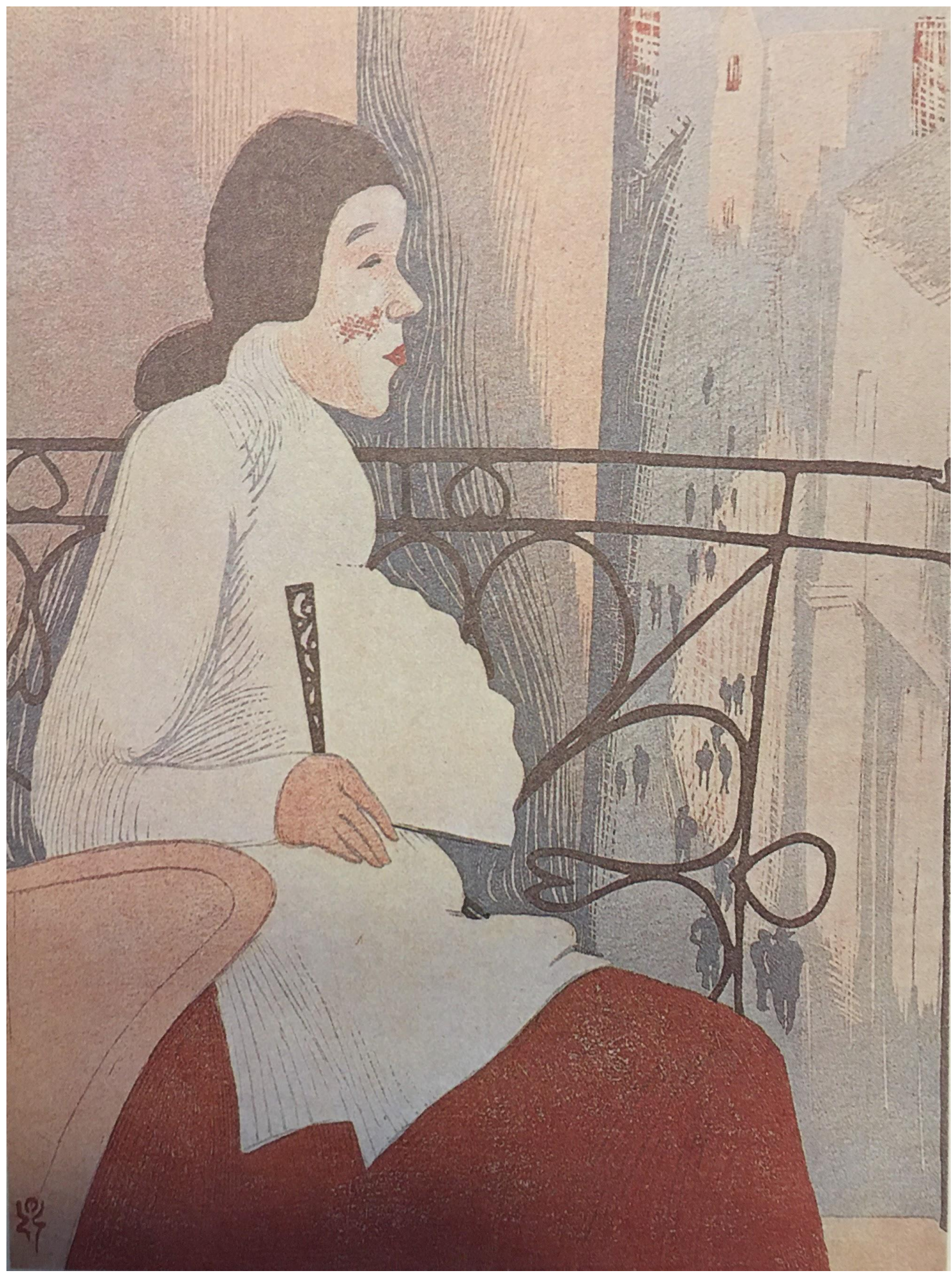

Fig. 5 Yamamoto, Shina Fujin (Chinese Woman), 1917, woodcut, 30 x $23.5 \mathrm{~cm}$, Ueda City Museum of Art, Ueda. 


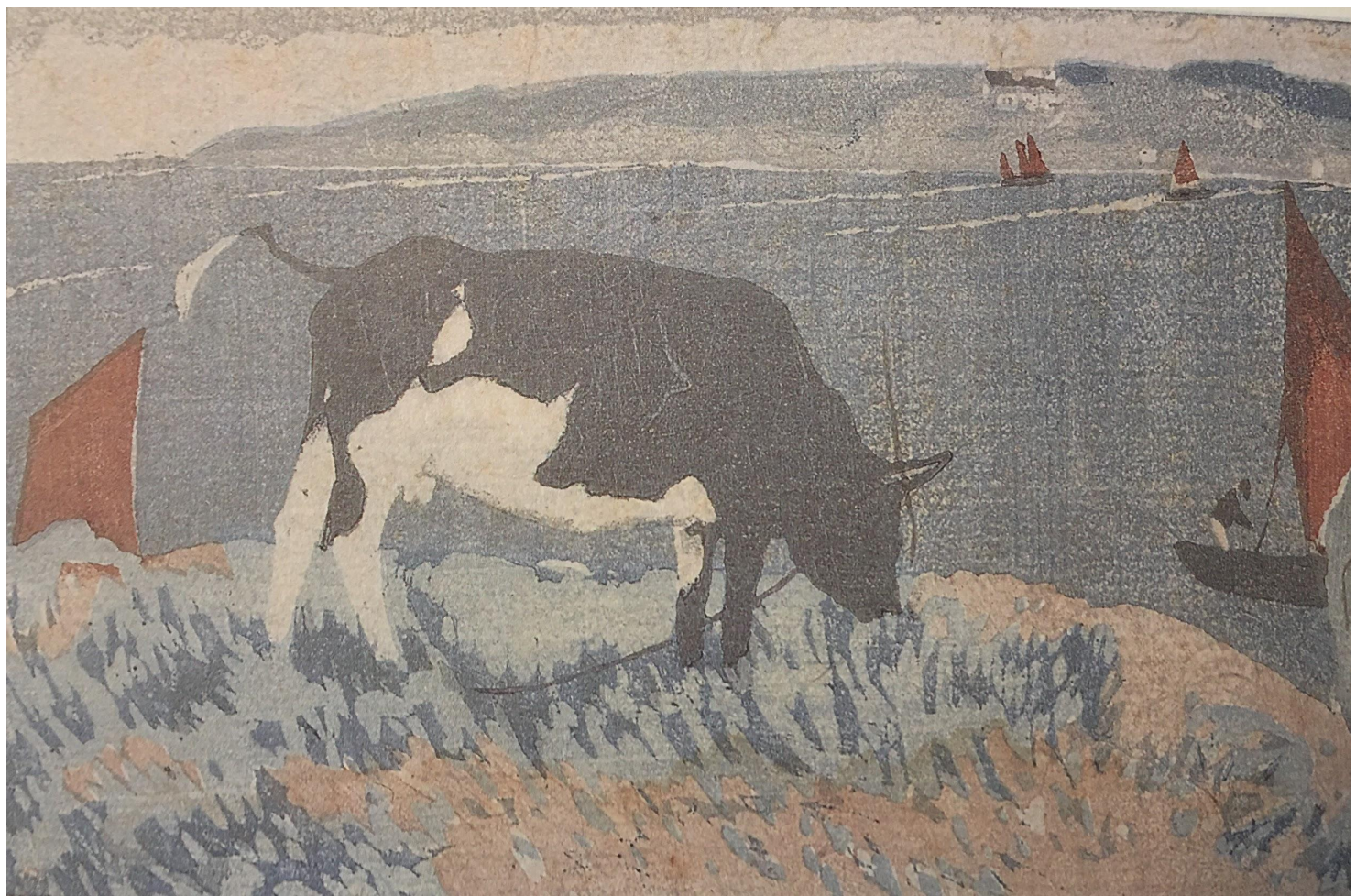

Fig. 6 Yamamoto, Burutaanyo Irie (Bay in Breton), 1913, woodcut, 14.0 x $21.3 \mathrm{~cm}$, Ueda City Museum of Art, Ueda. 


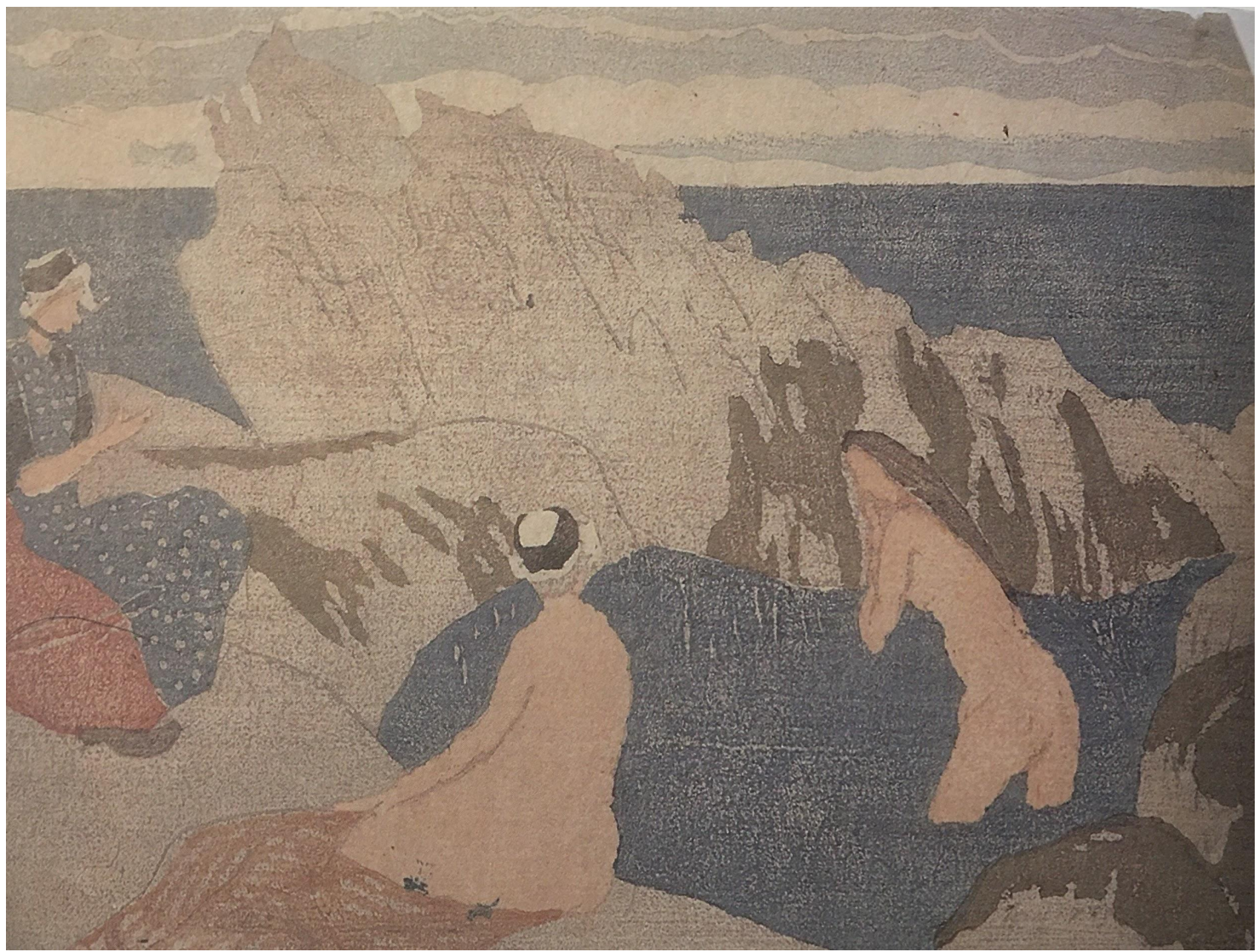

Fig. 7 Yamamoto, Buratonnu no suiyoku (Bathing in Brittany), 1913, woodcut, $14.5 \mathrm{x}$ $20.7 \mathrm{~cm}$, Ueda City Museum of Art, Ueda. 


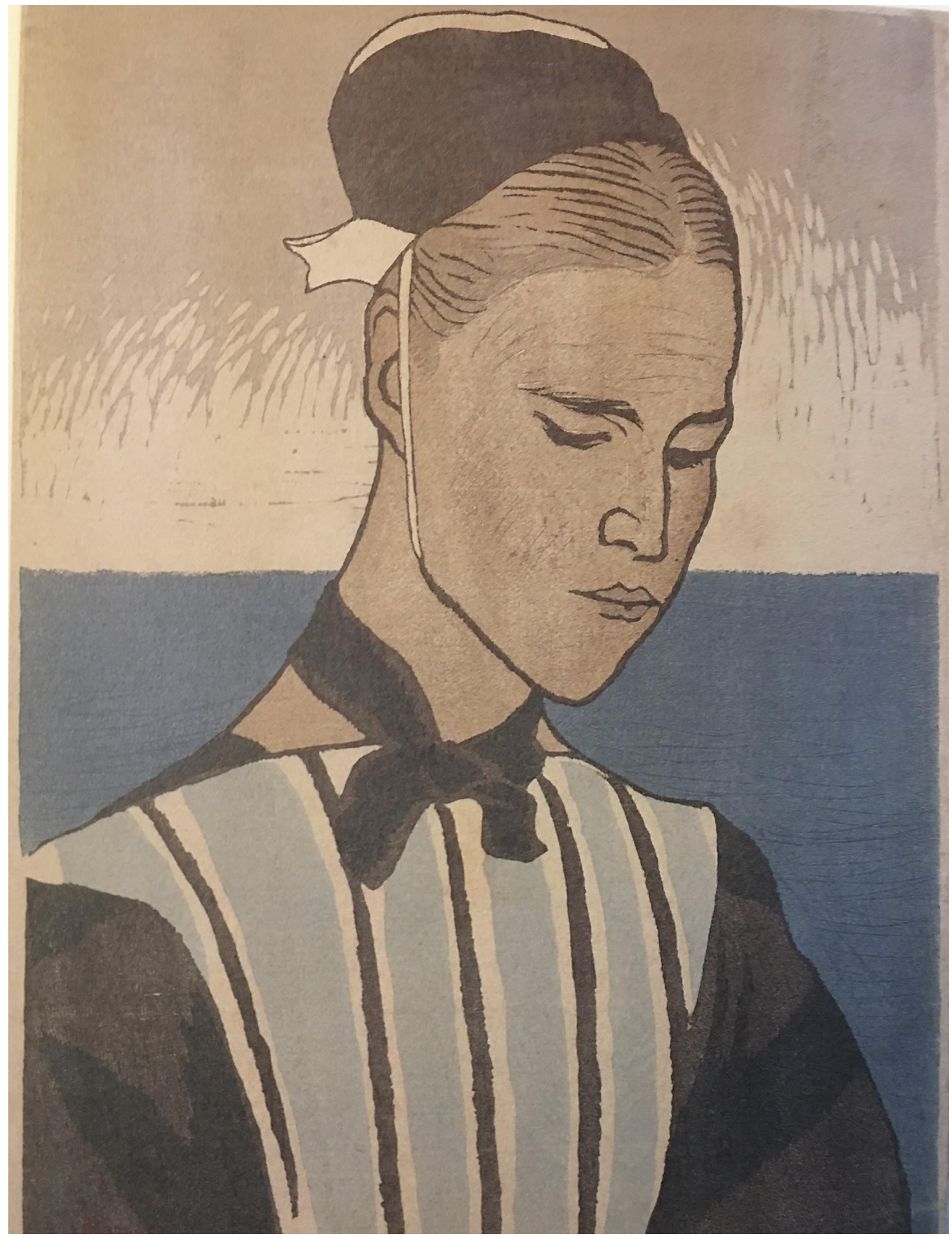

Fig. 8 Yamamoto, Burutonnu (Breton Woman), 1920, woodcut, 36.8 x 28.4 cm, Ueda City Museum of Art, Ueda. 


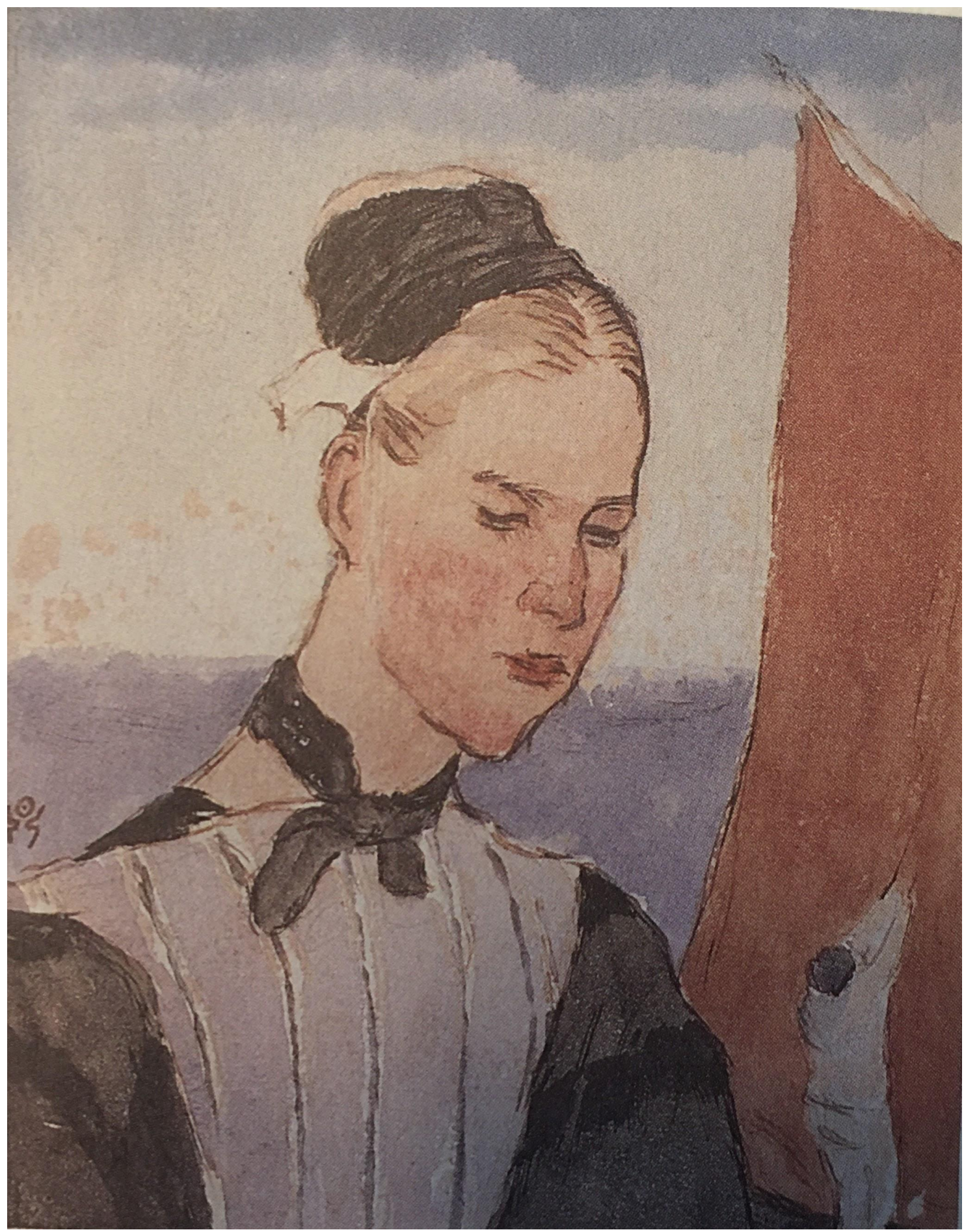

Fig. 8a Yamamoto, Burutonnu (Breton Woman-Study), 1913, watercolor on paper, $13.8 \mathrm{x}$ $10.8 \mathrm{~cm}$, Ueda City Museum of Art, Ueda. 


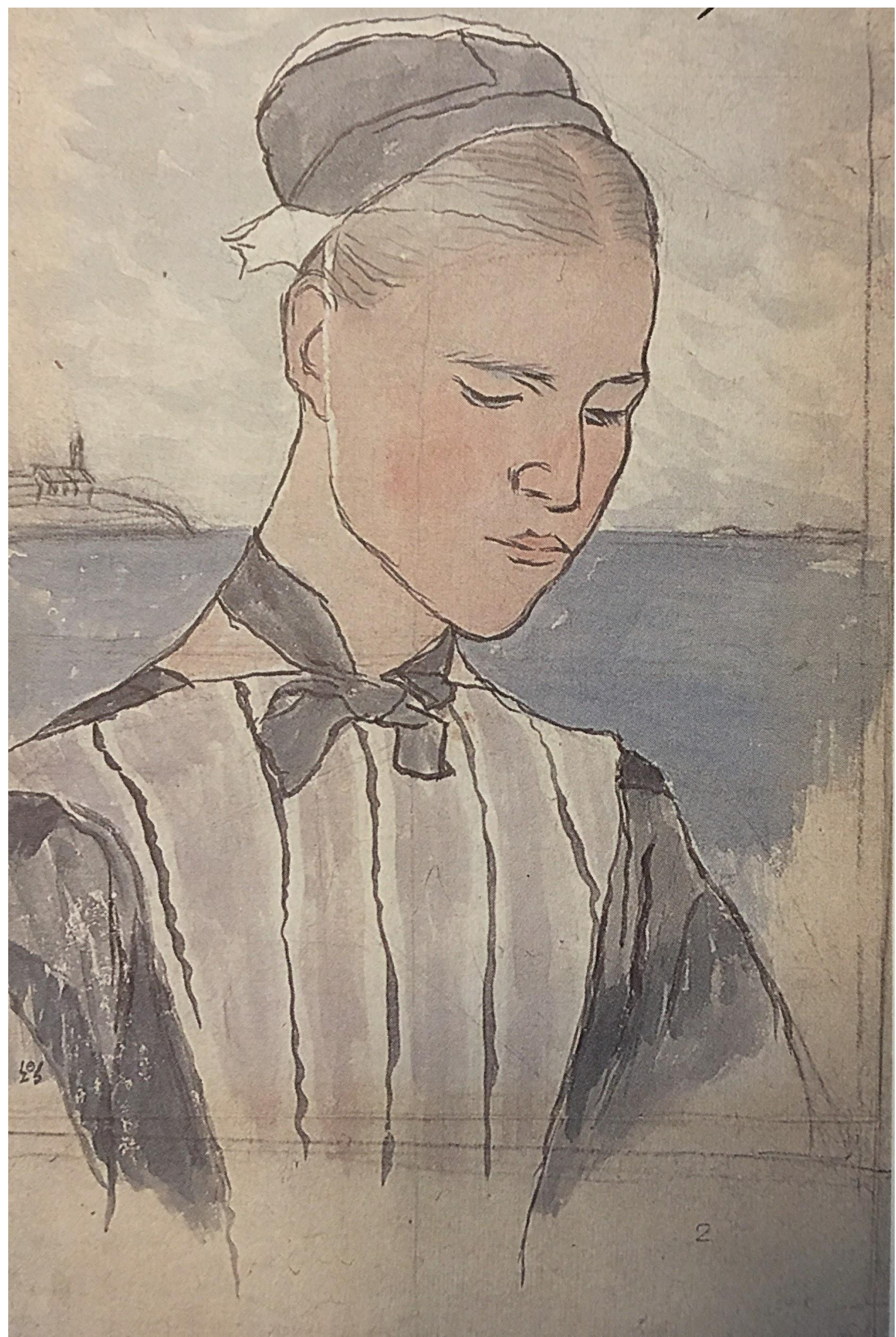

Fig. 8b Yamamoto, Burutonnu (Breton Woman-Study), 1913, watercolor on paper, 48.2 x $38.1 \mathrm{~cm}$, Ueda City Museum of Art, Ueda. 


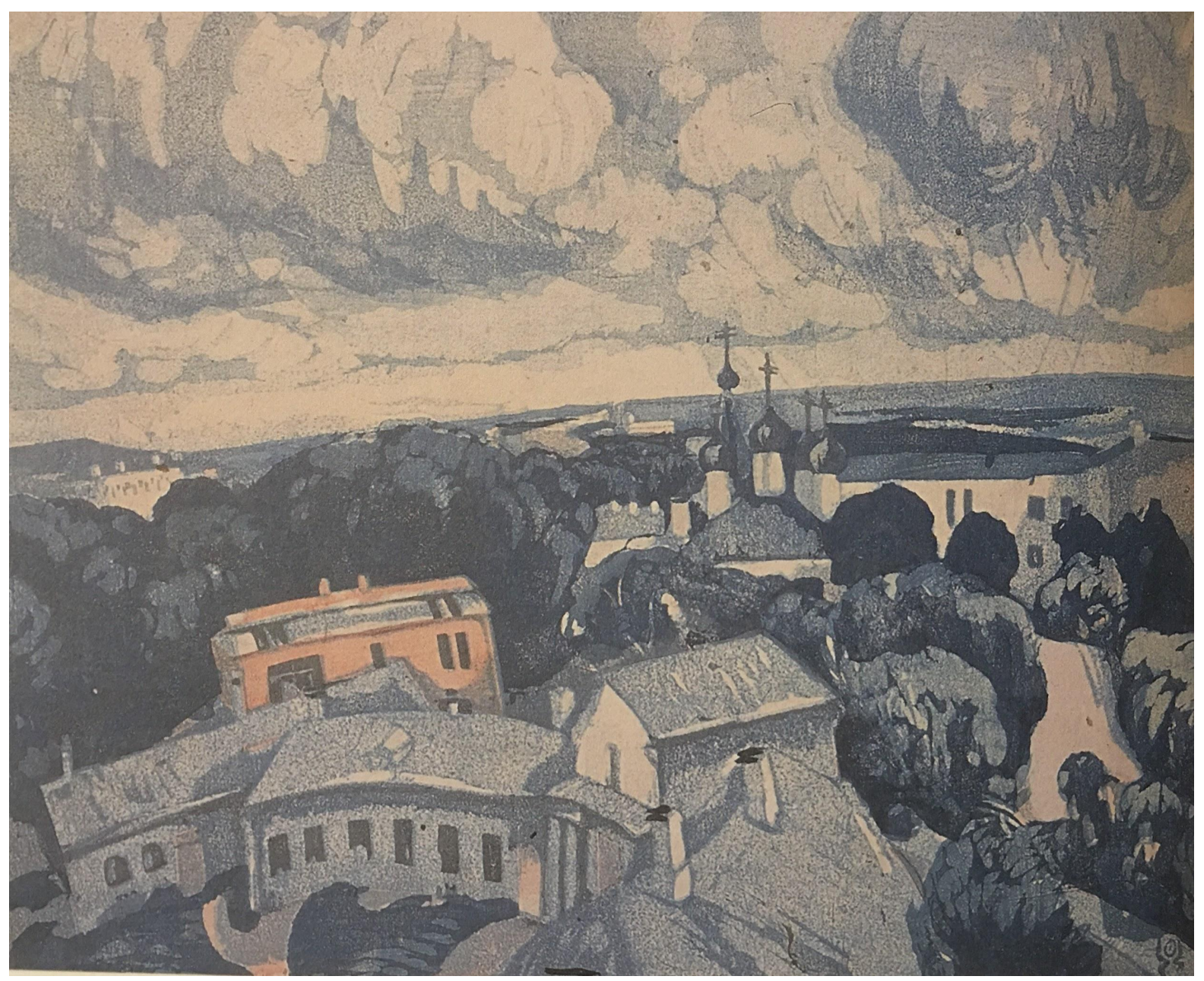

Fig. 9 Yamamoto, Mosukuwo (Moscow), 1916, woodcut, 34.7 x $42.6 \mathrm{~cm}$, Ueda City Museum of Art, Ueda. 


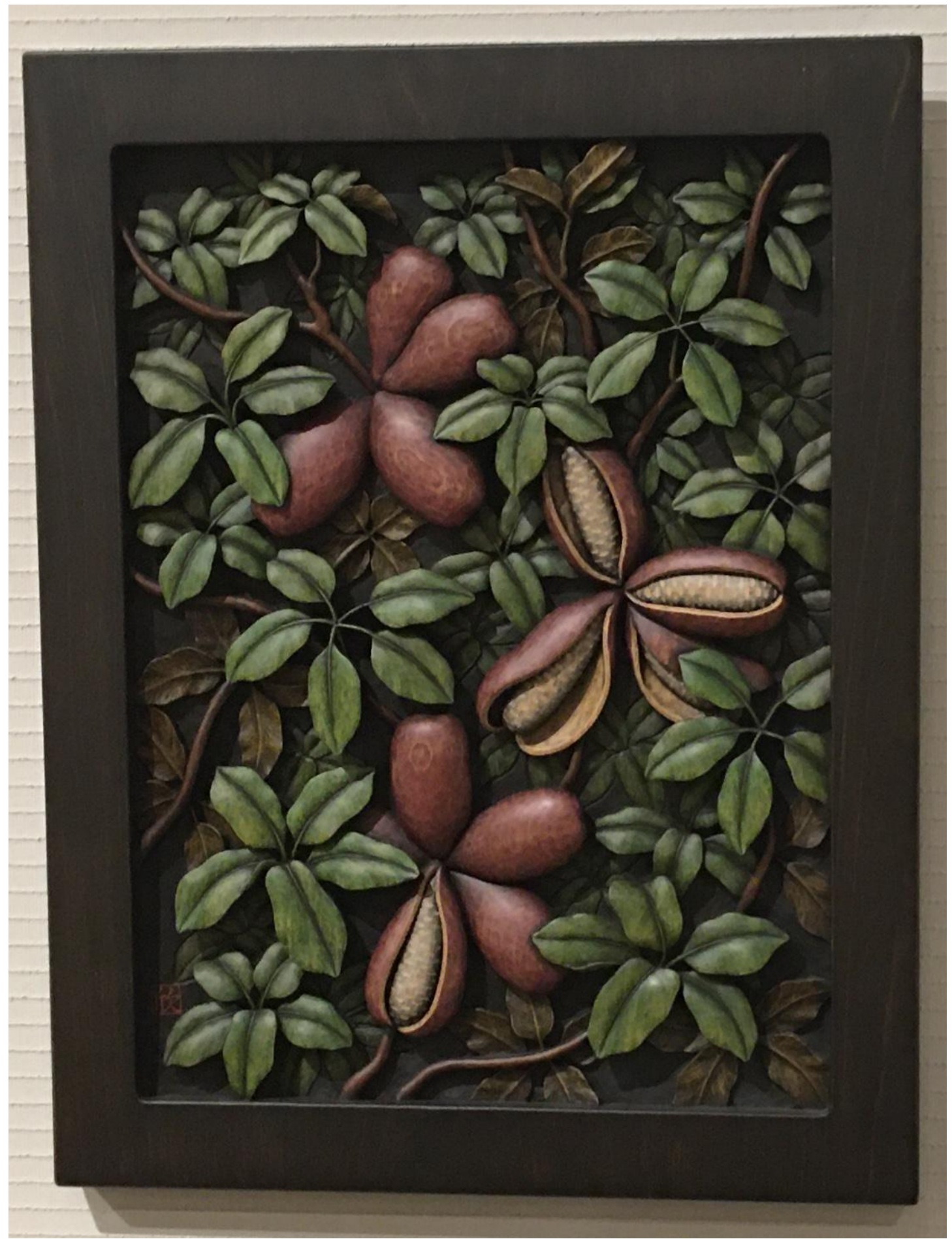

Fig. 10 Yokokawa Yoshimasa, Akebi, relief carving, date unknown, Ueda City Museum of Art, Ueda. 


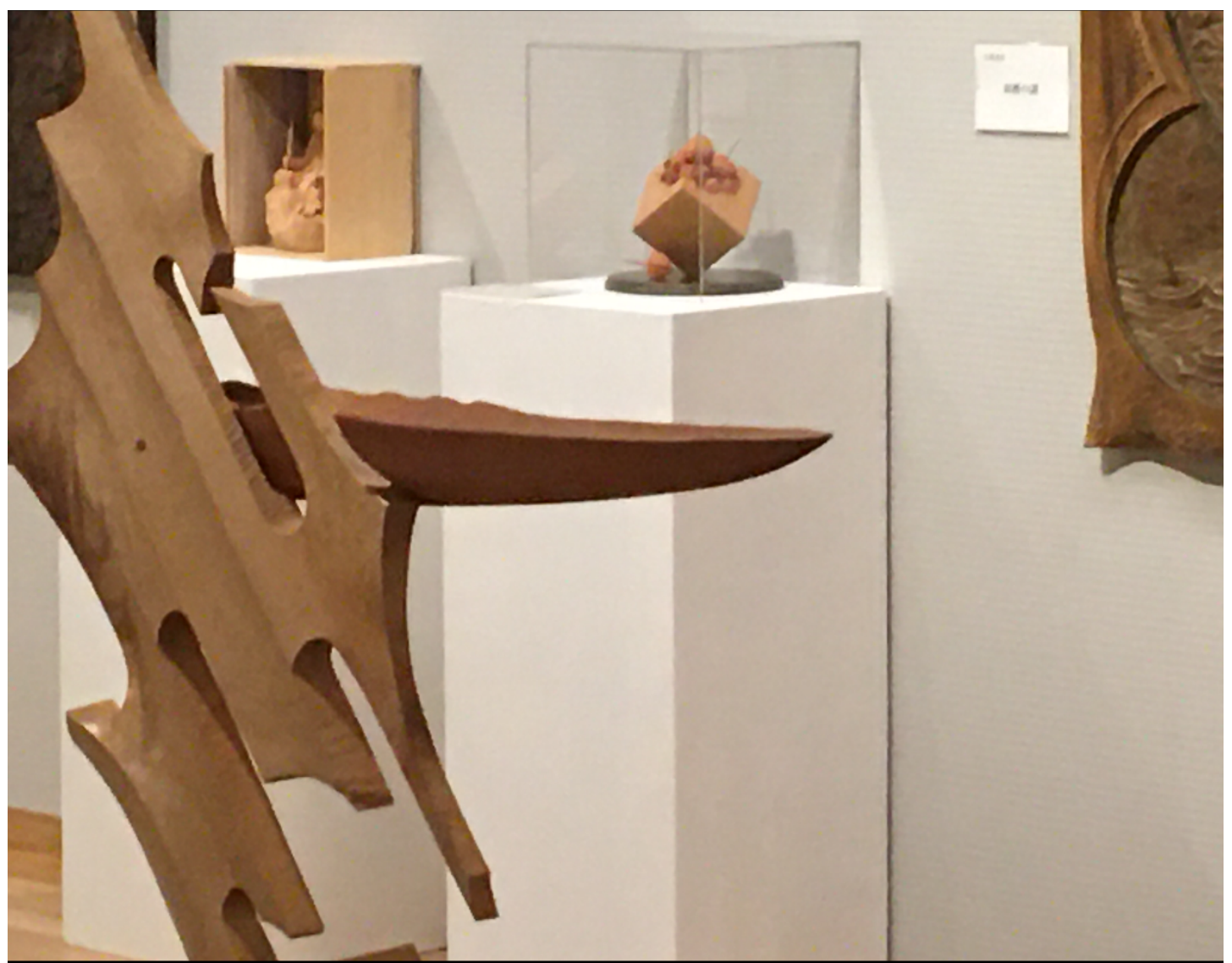

Fig. 11 Artist unknown, Hōzuki, wood sculpture, date unknown, Ueda City Museum of Art, Ueda. 


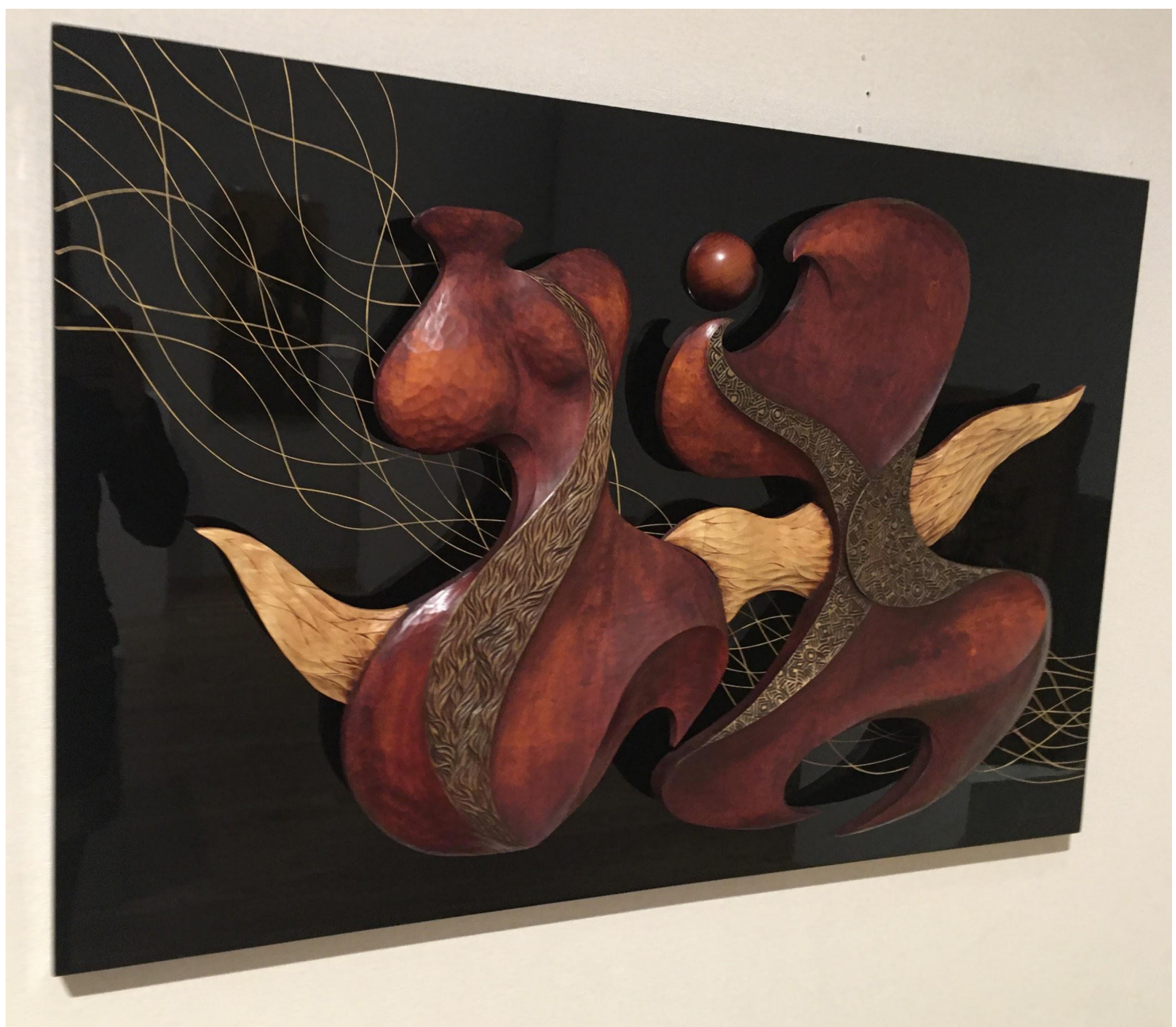

Fig. 12 Artist Unknown, 25, relief carving, date unknown, Ueda City Museum of Art. Ueda. 


\section{Bibliography}

Ajioka, Chiaki. Hanga: Creative Japanese Prints. Sydney: Art Gallery NSW, 2000.

"Autumn: Season of Flame." Four Seasons in Kyoto: Festivals and Symbols. Kyoto Broadcasting System, 2002.https://fod-infobasecom.proxy.library.carleton.ca/p_ViewVideo.aspx?xtid=30318.

Berger, Klaus. Japonisme in Western Painting from Whistler to Matisse. Translated by David Britt. Cambridge: Cambridge University Press, 1992.

Bevir, Mark. The Making of British Socialism. Princeton: Princeton University Press, 2011.

Boven, Thekla. “Assessment of Echigo-Tsumari Art Triennial's Repurposing of Schools: For a Locally Designed Culture-Led Revitalization of Assets in Declining Rural Areas." Journal of Architecture Planning AIJ 81, no. 730 (December 2016): 2693-2700.

Brandt, Kim. Kingdom of Beauty: Mingei and Politics of Folk Art in Imperial Japan. Durham, N.C.: Duke University Press, 2007.

Chi, Jerry, Foster Chiang, Russell Gottfredson, Neeraj Maathur and Erica Sugai/ "Meibutsu: The Economic and Cultural Significance of Traditional Japanese Products.”Knowledge@Wharton, The Wharton School of Business. https://knowledge.wharton.upenn.edu/article/meibutsu-the-economic-andcultural-significance-of-traditional-japanese-products/.

Coaldrake, Kimi. "Fine Arts Versus Decorative Arts: The Categorization of Japanese Arts at the International Expositions in Vienna (1873), Paris (1878), and Chicago (1893)." Japan Forum 25, no. 2 (December 2012): 174-190.

Cwiertka, Katarzyna J. and Ewa Machotka. Consuming Life in Post-Bubble Japan. Amsterdam: Amsterdam University Press, 2018.

Dai Nihon Nōkai. Useful Plants of Japan Described and Illustrated. Tokyo: Agricultural Society of Japan, 1895.

"Dairinji." Ueda City Website.

https://www.city.ueda.nagano.jp/site/kankojoho/6023.html.

Echigo Tsumari Art Field. "About.” Echigo Tsumari Art Field. Accessed May 18. 2019. http://www.echigo-tsumari.jp/eng/about/.

Elsner, Jaś. Comparativism in Art History. London: Routledge, 2017. 
Fiala, Andrew. “Anarchism.” In Stanford Encyclopedia of Philosophy. Stanford University, November 3, 2017. https://plato.stanford.edu/entries/anarchism/.

"Fisherman." The Cleveland Museum of Art. https://www.clevelandart.org/art/1960.122.

Foucault, Michel. Discipline and Punish. Translated by Alan Sheridan. New York: Pantheon Books, 1977.

Foxwell, Chelsea, and Anne Leonard. Awash in Color: French and Japanese Prints. Chicago: University of Chicago Press, 2012.

Grossman, Eike. Kurokawa No: Shaping the Image and Perception of Japan's Folk Traditions, Performing Arts and Rural Tourism. Leiden: Brill, 2013.

Ikeda, Asato. The Politics of Painting: Fascism and Japanese Art During the Second World War. Honolulu: University of Hawaii Press, 2018.

Ikeda, Asato, Aya Louise McDonald, and Ming Tiampo. Art and War in Japan and its Empire, 1931 - 1960. Leiden: Brill, 2013.

Juneja, Monica. ““A Very Civil Idea...' Art History, Transculturation, and WorldMaking - with and Beyond the Nation." Zeitschrift für Kunstgeschichte (Journal for Art History) 81, no. 4 (December 2018): 461-485.

Kanae Yamamoto Memorial Museum. Yamamoto Kanae, An Essay on Kanae Yamamoto. Ueda: Yamamoto City Museum of Art, 2009.

Kanae Yamamoto Memorial Museum. Yamamoto Kanae no furansu (Yamamoto Kanae's France). Ueda: Kanae Yamamoto Memorial Museum, 2007.

Kanae Yamamoto Memorial Museum. Yamamoto Kanae Seikatsu 120 Nenten (120 Years of Yamamoto Kanae). Ueda: Yamamoto City Museum of Art, 2002.

Kanda, Aiko. Yamamoto Kanae Monogatari (The Story of Yamamoto Kanae). Ueda: Kanae Yamamoto Memorial Museum, 2009.

Kaneda, Takuya. "The Concept of Freedom in Art Education in Japan." The Journal of Aesthetic Education 37, no. 4 (Winter 2003): 12-19

Keene, Donald. Dawn to the West: Japanese Literature of the Modern Era, vol. 4. New York: Columbia University Press, 1999.

Kikuchi, Yuko. Japanese Modernisation and Cultural Theory: Cultural Nationalism and Oriental Orientalism. London: Routledge, 2004.

Kikuchi, Yoko. Refracted Modernity: Visual Culture and Identity in Colonial Taiwan. Honolulu: University of Hawai'i Press, 2007. 
Kikuchi, Yuko. "The Myth of Yanagi's Originality: The Formation of 'Mingei' Theory in its Social and Historical Context." Journal of Design History 1, no. 4 (1994): 247266.

Kitagawa, Fram. "On the Inaugural Issue of the Web Magazine, Art from the Land." Art from the Land 1, September 30, 2019. https://www.echigotsumari.jp/en/media/190930-kitagawafram/.

Komatsu, Kayoko. "Genealogy of Self-Expression: A Reappraisal of the History of Art Education in England and Japan.” Paedagogica Historica 53, no. 3 (2017): 214227.

Konishi, Sho. Anarchist Modernity: Cooperatism and Japanese-Russian Intellectual Relations in Modern Japan. Cambridge, Mass.: Harvard University Press, 2013.

Konishi, Sho. "The People at Rest: The Anarchist Origins of Ogawa Usen's 'Nihonga."' World Art 11, no. 2 (December 2011): 235-256.

Kosaki, Gunji. Yamamoto Kanae hyōden: Yume ōki senkaku no gaka [Kanae Yamamoto critical biography: Pioneer artist of many dreams]. Tokyo: Shinanoji, 1979.

Little, C.B. "The Extent of Puvis de Chavannes' Stately Influence.” The Japan Times, January 15, 2014. Accessed April 7. 2020. https://www.japantimes.co.jp/culture/2014/01/15/arts/the-extent-of-puvis-dechavannes-stately-influence/\#.XozCtZNKiCQ.

Long, Hoyt. On Uneven Ground: Miyazawa Kenji and the Making of Place in Modern Japan. Stanford: Stanford University Press, 2011.

Masuda, Kingo. "A Historical Overview of Art Education in Japan.” The Journal of Aesthetic Education 37, no. 4 (2003): 3-11.

Mehl, Margaret. 'N.F.S. Grundtvig, Niels Bukh and Other 'Japanese' Heroes: The Educators Obara Kuniyoshi and Matsumae Shigeyoshi and Their Lessons from the Past of a Foreign Country." European Journal of East Asian Studies 6, no. 2 (January 2007): 155-184.

Merritt, Helen. Modern Japanese Woodblock Prints: The Early Years. Honolulu: University of Hawai'i Press, 1990.

Miller, Alison. "Exhibition Essay: Sosaku Hanga: Twentieth-Century Japanese Creative Prints." The Bowdoin College Museum of Art. Accessed January 20, 2020. https://courses.bowdoin.edu/sosaku-hanga-2016/exhibition-essay/. 
Mitter, Partha. "Decentering Modernism: Art History and Avant-Garde Art from the Periphery." The Art Bulletin 90, no. 8 (December 2008): 531-548.

Mitter, Partha. The Triumph of Modernism. Chicago: University of Chicago PressReaktion, 2007.

Moeran, Brian D. "Yanagi Muneyoshi and the Japanese Folk Craft Movement." Folklore Studies 40, no. 1 (1981): 87-99.

"Nōmin bijutsu: jidō jiyu ga 100nenten." Ueda City Museum of Art, November 30, 2019 - February 24, 2020.

Noriyaki, Seo. "Juyoshi ichi Yamamato Kanae no hanga wa dono yo ni miraetekitaka" (Reception History: How Were Yamamamoto Kanae's Prints Received?), Yamamoto Kanae Seikatsu 120 Nenten, 16-17. Translated from the Japanese by Author.

Pateman, Barry and Noam Chomsky. Chomsky on Anarchism. Edinburgh, Oakland and West Virginia: AK Press, 2005.

Piovesana, Gino K. Contemporary Japanese Philosophical Thought. Tokyo: Sophia University, 1968.

Rapley, Ian. "When Global and Local Culture Meet: Esperanto in 1920s Rural Japan." Language Problems and Language Planning 37, no. 2 (2013): 179-196.

Rhodes, Colin. Primitivism and Modern Art. London: Thames \& Hudson, 1994.

“Sengo no nōmin bijutsu” (War Farmers' Art). Ueda City Museum of Art, November 30, 2019.

Shields, James Mark. "Future Perfect: Tolstoy and the Structure of Agrarian-Buddhist Utopianism in Taisho Japan.” Religions 9, no. 5 (2018): 1-12.

Small, Robin. Marx and Education. Hampshire, UK: Ashgate, 2005.

Smith, Lawrence. The Japanese Print Since 1900: Old Dreams and New Visions. London: British Museum Publications, 1983.

Stokstad, Marilyn and Michael W. Cothren. Art History. 4th edition. Upper Saddle River, NJ: Prentice Hall, 2006.

"The Triumph of Modernism." University of Chicago Press Books. Accessed April 30, 2020. https://press.uchicago.edu/ucp/books/book/distributed/T/bo5456457.html.. 
Tolstoy, Leo. On Education. Translated by Leo Weiner. Chicago: University of Chicago Press, 1967.

Tolstoy, Leo. “On Socialism,” 1910. Журнал "Толстовский Листок/Запрещенный Толстой", 5th ed. Translated by Gabriel Mumzhiev. Moscow: Press Solo Publishing House, 1994. Reprinted in Sobraniye klassiki. Accessed February 27, 2020. http://az.lib.ru/t/tolstoj_lew_nikolaewich/text_0850.shtml/

Tomii, Reiko. Radicalism in the Wilderness: International Contemporaneity and 1960s Art in Japan. Cambridge, Ma.: MIT Press, 2016.

Totman, Conrad. "From Sakoku to Kaikoku: The Transformation of Foreign-Policy Attitudes, 1853 - 1868.” Monumenta Nipponica 35, no. 1 (Spring 198): 1-19.

Trotsky, Leon. "Tolstoy, Poet and Rebel (Written on Tolstoy's Eightieth Birthday.” 1908. Translated by John G. Wright in Fourth International 12, no. 13 (May-June 1951): 90 .

“"Tsugi no 100nen' ni muketa atarashitanana torigomi" (New Initiatives for the "Next 100 Years"). Ueda City Museum of Art, November 30, 2019.

Ueda City Museum. “Farmers' Art and the Children's Free Drawing Movement: 100 Years.” Exhibition Label.

Volk, Alicia. Made in Japan: The Postwar Creative Print Movement. Seattle: University of Washington Press, 2005.

Wall Text. 100 Years of Farmers' Art in Japan. Ueda City Museum of Art, Ueda, Nagano.

Warren, Sarah. "Crafting Nation: The Challenge to Russian Folk Art in 1913." Modernism / Modernity 16, no. 4 (Baltimore: The Johns Hopkins University Press, 2009): 743-765.

Winther-Tamaki, Bert. Maximum Embodiment: Yōga, the Western Painting of Japan, 1912 - 1955. Honolulu: University of Hawaii Press, 2012.

Winther-Tamaki, Bert. "The Ligneous Aesthetic of the Postwar Sōsaku-Hanga Print Movement and American Perspectives on the Japanese Culture of Wood." Archives of Asian Art 66, no. 2 (Durham: Duke University Press, 2016): 213-238.

Yamamoto, Kanae and Yamagoshi Shuzo. Yamamoto no Tegami. Ueda: Yamamoto Kanae Memorial Museum of Art, 1971.

"Yamamoto Kanaette donna hito?" (What Kind of Person was Kanae Yamamoto?), Nagano kenden tōtekikōgeihin shitei Shinshū Ueda no kibori kōgei nōmin bijutsu 
(Nagano Prefecture Traditional Craft Designation: Farmers' Art and Woodcrafts of Ueda Shinshu)/ http://www14.ueda.ne.jp/ kiboriya/yamamoto-kanae.html.

"Yamamoto Kanae ryaku nenpu" (Kanae Yamamoto in Brief). Ueda City Museum of Art, November 30, 2020.

"Yamamoto Print Grand Prix Competition, Triennale." Ueda Santomyuze, https://www.santomyuze.com/museumevent/7th_hangataisho-ten/.

Yamasaki, Yoko and Masashi Tsujimoto. The History of Education in Japan (1600 2000). London: Routledge, 2017. 